Portland State University

PDXScholar

1991

\title{
Effects of setting on Japanese ESL students' interaction patterns
}

Noriko Yamamoto

Portland State University

Follow this and additional works at: https://pdxscholar.library.pdx.edu/open_access_etds

Part of the Applied Linguistics Commons, and the Bilingual, Multilingual, and Multicultural Education Commons

Let us know how access to this document benefits you.

\section{Recommended Citation}

Yamamoto, Noriko, "Effects of setting on Japanese ESL students' interaction patterns" (1991). Dissertations and Theses. Paper 4272.

https://doi.org/10.15760/etd.6156

This Thesis is brought to you for free and open access. It has been accepted for inclusion in Dissertations and Theses by an authorized administrator of PDXScholar. Please contact us if we can make this document more accessible: pdxscholar@pdx.edu. 
AN ABSTRACT OF THE THESIS OF Noriko Yamamoto for the Master

of Arts in TESOL presented June 5, 1991.

Title: Effects of setting on Japanese ESL Students'

Interaction Patterns.

APPROVED BY THE HEMBERS OF THE THESIS COMMITTEE:
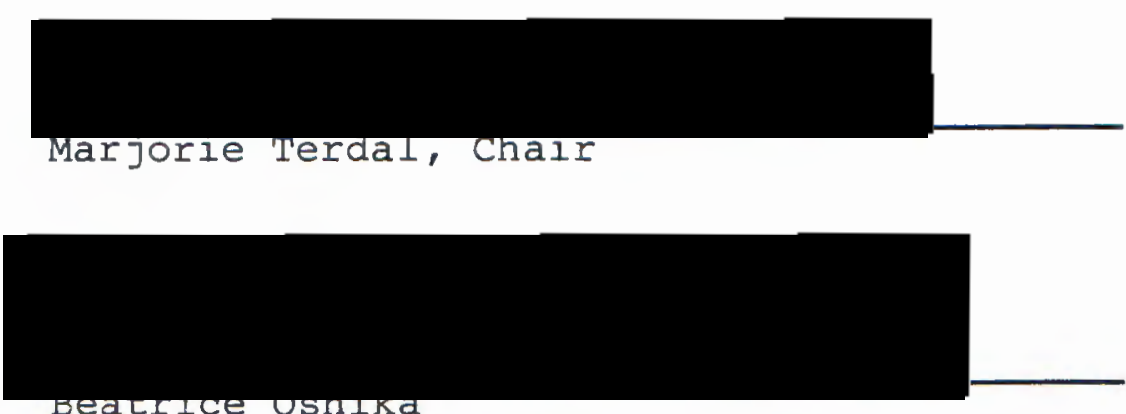

bealince Usinka
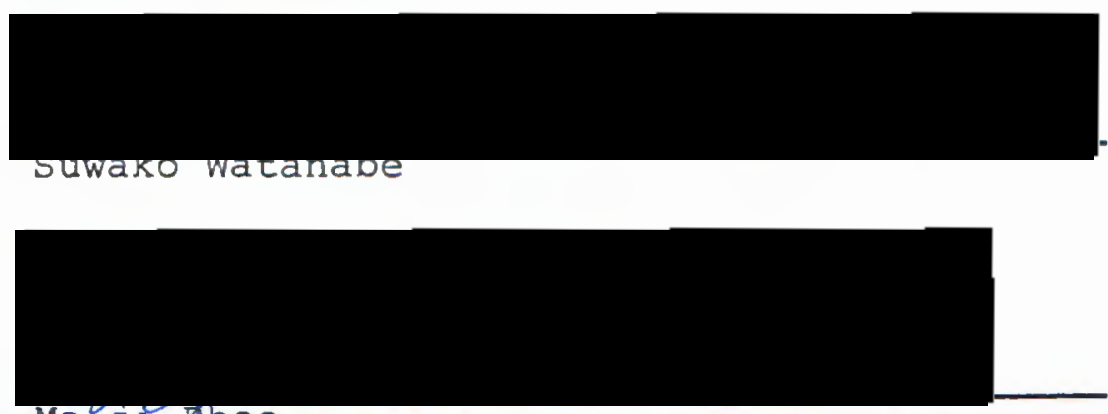

Ma-ji ghee

Japanese ESL students are often evaluated negatively by their teachers because of their quiet verbal behavior in the classroom; yet, this study suggests that such silence 
may be situation specific. The purpose of this study is to describe characteristics of eight Japanese ESL students' production and interaction by comparing with those of four non-Japanese students, across three settings: teacher-fronted, group work, and NS-NNS conversation. This study was aimed at answering three major questions about Japanese learners' oral behavior:

1. How do Japanese learners talk compared with non-Japanese learners in each of the three settings, and what kinds of utterances do they produce?

2. What interaction strategies do Japanese learners use in each of the three settings?

3. Why do Japanese learners speak less and take fewer turns in the classroom?

Interactions in the three settings were audio and videotaped, transcribed, and coded using categories adapted from Long and Tarone. To determine amount and complexity of production, ten syntactic measures were calculated, including number of turns, words, s-nodes, and fragments. To examine interaction, eleven strategies were coded, including comprehension checks, clarification requests, confirmation checks, repetitions/rephrases, avoidance, and long initial pauses. Also, to investigate why Japanese students were silent in the classroom, they were interviewed in Japanese.

Results of syntactic analysis indicate that the Japanese students took significantly fewer turns than the non-Japanese students only in the teacher-fronted 
setting. In the group work setting, the students in both groups took a more nearly equal number of turns, and in the one-to-one setting, the Japanese students took significantly more turns than the non-Japanese students. These findings suggest that although it was noted that the Japanese students' oral proficiency may be lower than that of the non-Japanese students, the stereotype of Japanese students as silent is only a reflection of their behavior in the teacher-fronted classroom.

Results of interaction analysis indicate that the teacher-fronted setting contained the fewest negotiated interactions, compared to other settings. It was found that the Japanese students preferred avoidance and long initial pauses, whereas the non-Japanese students preferred repetitions/rephrases.

Reasons given for their silence in the classroom were categorized as psychological (e.g., fear of losing face), linguistic (e.g., fewer parallels between Japanese and English), and sociocultural (e.g., different participation patterns).

These findings suggest that a small-group setting (including pair-work) is more beneficial for Japanese students. In order to help quiet Japanese students develop their proficiency in communication, teachers need to provide a less threatening situation in which each student has opportunities to experience negotiated interactions. 
EFFECTS OF SETTING ON

JAPANESE ESL STUDENTS' INTERACTION PATTERNS

$$
\text { by }
$$

NORIKO YAMAMOTO

A thesis submitted in partial fulfillment of the requirements for the degree of

MASTERS OF ARTS

in

TESOL 
TO THE OFFICE OF GRADUATE STUDIES:

The members of the committee approve the thesis of Noriko Yamamoto presented June 5, 1991.

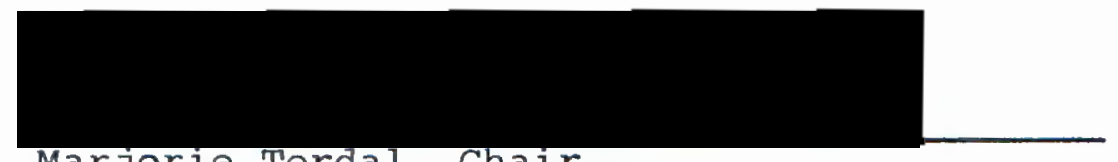

Marjorie Terdal, Chair

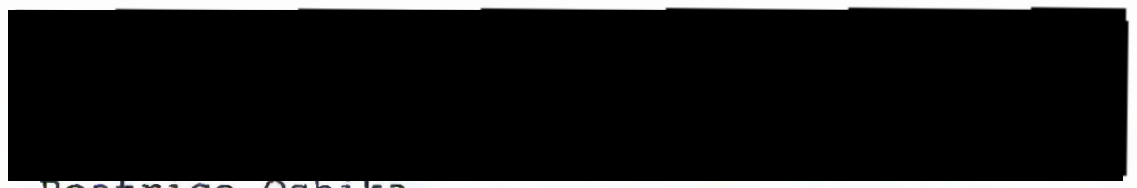

Beatrice oshika

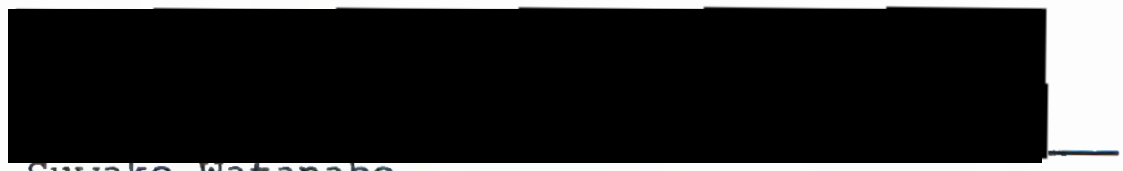

suwako watanabe

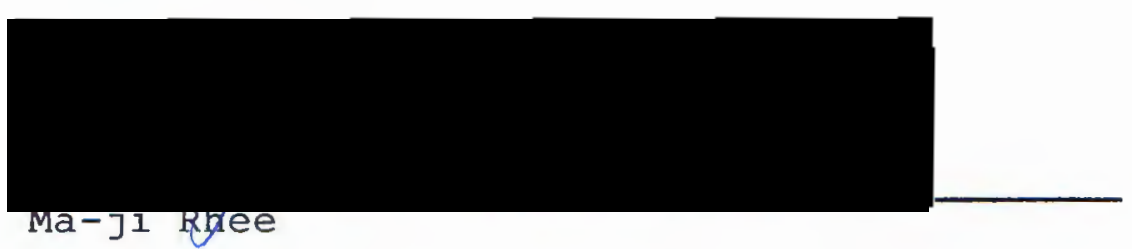

\section{APPROVED :}
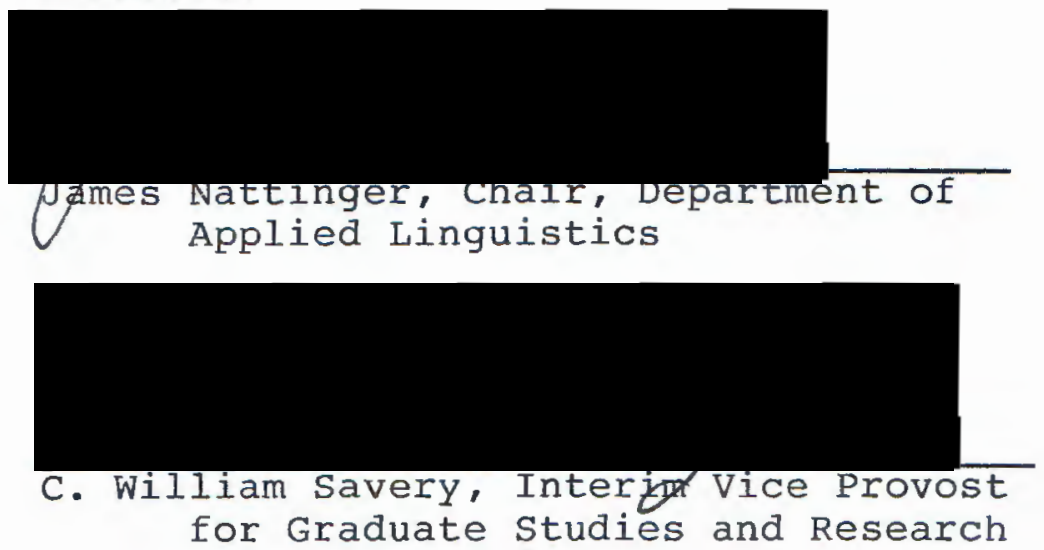


\section{ACKNOWLEDGMENTS}

Many people helped me complete this study. I would like to express my deepest gratitude to my advisor, Dr. Marjorie Terdal. Since I started the TESOL M.A. program, she has continuously offered me encouragement and guidance and trained me as a researcher of language acquisition and teaching. I am also grateful to Dr. Beatrice Oshika. She provided continuous support throughout the entire research process and offered insightful suggestions and comments which helped me develop this study. I would also like to express sincere gratitude to Dr. Suwako Watanabe, who deepened my understanding of sociolinguistics and cultural perspectives in discourse study. Throughout my writing process, these three members of my committee helped me refine this thesis. I wish to thank them for their patience and forthright advice. Dr. Ma-ji Rhee also provided helpful ideas and support in completing this study. I feel very fortunate to have had these experts on my committee.

I would also like to thank all the ESL teachers and students who participated in this study, especially Jane Dresser, who was once my ESL teacher. She helped 
me at every stage of the research process and offered valuable advice.

I would like to extend my thanks to my friends, in Japan and in the United States, who have been supportive of me throughout my graduate study. Yoko Tsuchitori and Yasuko Takarada, as well as my former students in Japan, were a source of support and strength. Especially, I wish to thank Michitsugu Yoshida and Akihito Hashizume, for their continuous encouragement. My special thanks go out to Suzanne Raschke, Diane Gregg, Maureen Sprague, Carolyn Hainline, and Nobuko Murakami. In particular, I want to thank my best friend, Christopher Jones, for his tremendous support and assistance.

Finally, I would like to express my thanks to my mother, Takako Yamamoto, and my late father, Yukio Yamamoto, who taught me the importance of desires and endeavors to achieve goals in life. I wish to thank them.

To these and all those I cannot name here, I give my heartfelt thanks. 
TABLE OF CONTENTS

ACKNOWLEDGMENTS $\ldots \ldots \ldots \ldots \ldots \ldots \ldots \ldots \ldots \ldots \ldots \ldots \ldots \ldots \ldots \ldots$

LIST OF TABLES $\ldots \ldots \ldots \ldots \ldots \ldots \ldots \ldots \ldots \ldots \ldots \ldots \ldots \ldots \ldots$

CHAPTER

I INTRODUCTION $\ldots \ldots \ldots \ldots \ldots \ldots \ldots \ldots \ldots \ldots$

Statement of the Problem ........... I

Purpose of the Study ............ 4

Research Questions............... 7

Summary $\ldots \ldots \ldots \ldots \ldots \ldots \ldots \ldots \ldots$

I I LITERATURE REVIEW $\ldots \ldots \ldots \ldots \ldots \ldots \ldots \ldots$

Notion of Communicative Competence ....99

SLA Studies of Negotiation .......... 13

Empirical Studies of Interaction in

L2 Discourse ................ 29

summary $\ldots \ldots \ldots \ldots \ldots \ldots \ldots \ldots \ldots \ldots$

III METHOD ...................... 39

Participants .......................... 39

Data Collection .................43

Data for Analysis .............. 48

Analysis ......................49

summary $\ldots \ldots \ldots \ldots \ldots \ldots \ldots \ldots \ldots$

IV RESULTS AND DISCUSSION OF SYNTACTIC ANALYSIS 60

Comparison of JP Vs. NJP in Each setting 61 
Syntactic Features of JP across Three Settings .............66 68

Overall Effect of Ethnicity and setting on syntactic Features ..........6 69

Summary $\ldots \ldots \ldots \ldots \ldots \ldots \ldots \ldots \ldots$

$V$ RESULTS AND DISCUSSION OF INTERACTION ANALYSIS 75 Comparison of JP vs. NJP in Each setting 75 Interaction Strategies of JP across Three settings ............. 82

Overall Effect of Ethnicity and setting on Interaction Strategies ...... 86

Summary $\ldots \ldots \ldots \ldots \ldots \ldots \ldots \ldots$

VI RESULTS AND DISCUSSION OF INTERVIEWS ....... 91

Psychological Factors ............. 91

Linguistic Factors .............. 95

Sociocultural Factors ............... 103

Summary ................... 108

VII CONCLUSIONS $\ldots \ldots \ldots \ldots \ldots \ldots \ldots \ldots \ldots \ldots$

Summary of the study ............ 110

Limitations ................... 112

Suggestions for Future Research ...... 112

Implications for Teaching ......... 115

Conclusions $\ldots \ldots \ldots \ldots \ldots \ldots \ldots \ldots \ldots \ldots \ldots \ldots$

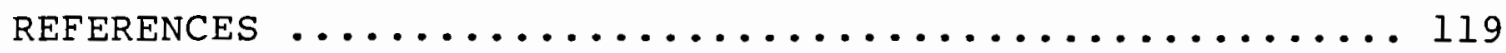

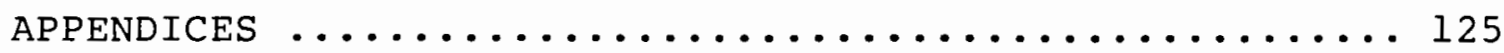

A ESL TEACHERS' COMMENTS ON JAPANESE STUDENTS 125

B PARTICIPATION FREQUENCIES IN
THE TEACHER-FRONTED CLASSES $\ldots \ldots \ldots \ldots \ldots 130$

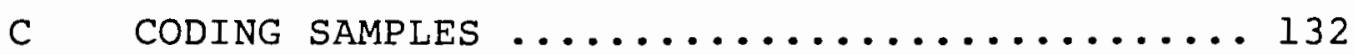


D TRANSCRIPTION SAMPLES ................. 135

E RAW FREQUENCIES OF SYNTACTIC AND

INTERACTIONAL FEATURES ............ 139 


\section{LIST OF TABLES}

TABLE

PAGE

I Profiles of Japanese subjects ........ 41

I Profiles of Selected Non-Japanese subjects ................... 42

III JP vs. NJP: Amount of Talk in TF ..... 62

IV JP vs. NJP: Complexity of Talk in TF ... 63

$\mathrm{V}$ JP vs. NJP in TF: Proportion of Words in $\mathrm{S}$-nodes and Fragments .......663

VI JP vs. NJP: Amount of Talk in GW ..... 64

VII JP vs. NJP: Complexity of Talk in GW ... 65

VIII JP vs. NJP in GW: Proportion of words in S-nodes and Fragments ...... 65

IX JP vs. NJP: Amount of Talk in NS .... 66

$X$ JP Vs. NJP: Complexity of Talk in NS ... 67

XI JP vs. NJP in NS: Proportion of Words in s-nodes and Fragments ......667

XII Summary of Means of JP's syntactic Features across Three Settings .. 68

XIII ANOVA Dependent Measure: Total Turns ... 69

XIV ANOVA Dependent Measure: Total Words ... 70

XV ANOVA Dependent Measure: Total S-nodes 71

XVI ANOVA Dependent Measure: Words in s-nodes ......................... 71

XVII ANOVA Dependent Measure: Fragments ..... 71 XVIII Summary of syntactic features ........ 72 
XIX JP vs. NJP: Repetitions/Rephrases in TF 76

XX Summary of Mean Frequencies of Interaction Strategies in GW ....77

XXI Summary of Mean Frequencies of Interaction Strategies in NS ....8 81

XXII Summary of Means of JP's Comprehension Strategies across Three settings 83

XXIII Summary of Means of JP's production Strategies across Three Settings 84

XXIV Summary of Three Interaction Strategies 87

XXV ANOVA Dependent Measure: Repetitions/

Rephrases ............... 87

XXVI ANOVA Dependent Measure: Long Initial

Pauses .................. 88

XXVII ANOVA Dependent Measure: Avoidance ....8 89 
CHAPTER I

\section{INTRODUCTION}

In communicative language classrooms, Japanese learners, as well as other Asian learners, are often characterized as being less interactive, 'quiet' students, whose 'silence' is considered a problem (Sato, 1981). Despite the general awareness of Japanese learners' problem in speaking, few attempts have been made to provide empirical studies of Japanese learners' speech inside and outside of the language classroom. The purpose of this study is to describe and analyze Japanese ESL learners' oral behavior in various contexts and to present possible explanations for their less interactive behavior in the classroom.

\section{STATEMENT OF THE PROBLEM}

My initial interest in this issue arose from personal observations made when I taught conversational English to a group of adult learners in Japan. I found that, contrary to my expectations, not all of my students participated equally in classroom activities. Only a few aggressive learners, who were not necessarily 
linguistically advanced, consistently took advantage of the opportunity to use English in the classroom.

I have also observed quiet Japanese students in ESL classes in the United States and have asked myself why, if Japanese students are motivated enough to come to the U.S. to study EngIish or other subjects in English, they remain quiet in class.

Through observations and informal discussions with ESL teachers and their Japanese students, I found that the participation pattern is significantly different between active learners and passive learners, and that this unbalanced interaction structure was perceived as a problem by both the teachers and students in the ESL classroom. Why is 'silence' problematic in the language classroom? In classes on other topics, the behavior of those quiet learners is seldom regarded as being 'inappropriate', but 'silence' in the language classroom is perceived negatively. In a language classroom based on a communicative approach, learners are expected to participate and interact actively in the classroom. Tannen (1985) explains that "a silence is negatively valued, when it is too long or appears at what seems like the wrong time and the wrong place" (p. 109). If Japanese learners remain quiet, it seems that two major problems may arise: one is theoretical/ pedagogical, and the other is sociological.

From a theoretical/pedagogical perspective, 'silence' 
does not appear to help in the development of second language acquisition (SLA). In current SLA studies, the critical role of interaction in the development of communicative competence of the second language (L2) has been examined and supported with strong evidence from various perspectives (e.g., Long, 1981; Ellis, 1984a; Hatch et al., 1986). Although more theoretical issues will be discussed in the following chapter, it is believed that a certain amount of interaction is optimal for learners to develop their communicative competence. Thus, when Japanese learners do not participate much in classroom interaction, their rate of SLA, especially that of oral competence, may be slower than that of more interactive learners.

The other problem for Japanese learners arises from a sociological perspective; that is, quiet learners are often negatively evaluated in the classroom. As suggested by Mehan (1982), if we look at an ESL classroom as a school setting in which learners are evaluated/graded on the basis of their participation, less active learners in the language classroom may often be regarded as less competent or deficient learners. Also, negative evaluation of their performance in class causes quiet learners to have a negative self-image as speakers of English both in and out of the language classroom.

Despite the likely importance of oral behavior of quiet learners in the language classroom, there have been 
few SLA studies in this area (Sato, 1981; Duff, 1986). Instead, some scholars have minimized learners' 'silence' as merely a reflection of a 'silent period' in which learners primarily wait and prepare for the natural growth of L2 (Krashen, 1982). However, many teachers know that learners need to engage in communicative exchange in order to develop their communicative competence. Concerned about those quiet learners who are left out in the classroom, Brown (1987) asks "what about the other half of our foreign language students for whom speech does not 'emerge' and for whom the 'silent period' might last forever" (p. 189). I believe that a language classroom needs to be a place where learners, both active and passive, are able to explore their second language.

PURPOSE OF THIS STUDY

The purpose of this study is to examine selected aspects of both syntactic features and interactional features that appear to characterize Japanese learners' production and interaction in second language (L2) discourse. As reported in the 1985 studies by Long and Porter, and by Pica and Doughty; it has been suggested that learners' talk varies in different settings. With an assumption that learners' competence is variable depending on the type of context, it has been predicted that Japanese learners' $\mathrm{L} 2$ and their interaction would vary in different 
settings and that their oral performance in whole class situations may not adequately indicate Japanese learners' communicative competence. Therefore, partially as a means of confirming the findings made in the classroom, a setting outside the class is also included in this study. In other words, this study primarily examines effects of setting on Japanese learners' production and interaction. First, the study describes the extent to which Japanese learners talk or do not talk (i.e., amount of talk) and the types of language they use (i.e., syntactic complexity). It has been commonly agreed that SLA requires "a certain amount of production, practice, or other mental operation" (Chaudron, 1988, p. 7). Although there seems to be a stereotype of Japanese learners as silent, which is often regarded to be problematic in the language classroom, their speech has not been previously investigated yet. Thus, it is important to document quantity and quality of Japanese learners' production. The methodological frame for this analysis of syntactic features was guided by Porter (1986) and by Rulon and McCreary (1986).

secondly, the study reports on 'interaction strategies' used by Japanese learners. I use the term 'interaction strategy' to capture the aspect of the learner's role in negotiation. 'Negotiation' is explained by Ellis (1985) as follows: 
A major feature of conversations involving L2 learners is that the learner and native speaker together strive to overcome the communicative difficulties which are always likely to arise as a result of the learner's limited L2 resources. This has become known as the 'negotiation of meaning'. (p. 14l)

Although features of negotiation are found in both native speaker's discourse and non-native speaker's discourse, previous studies of L2 discourse have shown that discourse involving a non-native participant is characterized by a large amount of negotiation, and that the role of negotiation is studied as one of the central variables that contributes to SLA. Thus, in order to understand the way in which Japanese learners do talk or do not talk, the investigation of interaction strategies is important.

The frame for investigating interaction strategies was primarily guided by Long's (1983) classifications of interactional modifications (e.g., confirmation checks, clarification requests, repetitions) and partly by Tarone's (1981) categories of communication strategies (e.g., use of Ll, avoidance). This framework will be discussed in detail in the following chapter.

Thirdly, 'avoidance' behavior is examined closely in interviews with the Japanese learners. It is Tarone's notion of 'avoidance' as a strategy that primarily led me to this study of strategies of Japanese learners. Thus, another goal of this study is aimed at finding the reasons why Japanese learners tend to use avoidance 
strategies in the language classroom.

\section{RESEARCH QUESTIONS}

This study describes the speech/interaction produced by Japanese learners in three settings (i.e., teacherfronted, group work, and NS-NNS conversation) and compares results with that of more interactive non-Japanese learners in the same ESL class. Specifically, this study is intended to answer three major research questions:

1. How much do Japanese learners talk compared with non-Japanese learners in each of the three settings, and what kinds of utterances do they produce?

2. What interaction strategies do Japanese learners use in each of the three settings?

3. Why do Japanese learners speak less and take fewer turns in the classroom?

To answer the first and second questions, this study reports on quantitative analyses of both syntactic features (such as amount of talk measured by number of words) and interaction features (such as negotiation of meaning measured by frequency of use of confirmation checks). To answer the third question, this study also reports on a qualitative analysis of 'avoidance' behavior of Japanese learners. The reasons for Japanese learners' less interactive behavior in the classroom are obtained from two sources: a) the interpretations formed by this researcher, and b) the explanations given by the Japanese learners through 
interviews done in Japanese, the Ll for both the learners and the researcher.

\section{SUMMARY}

This study examines Japanese ESL learners' production/interaction by describing their syntactic and interactional features in three settings and by comparing those features with those of more interactive non-Japanese learners.

The study of language learners' discourse has been refined and has provided increasing evidence pointing out the importance of interaction in order for learners to develop communicative competence. However, few studies have been done on ethnicity or individual differences. Although the findings in this study can be generalized only within the subject group, I hope that the study provides initial information about Japanese learners' speech and interaction for ESL teachers who are willing to modify their communicative approach to promote the development of communicative competence of quiet learners in the language classroom. 


\section{CHAPTER II}

\section{LITERATURE REVIEW}

This chapter reviews the relevant literature for this study in three sections: 1) an overview of the notion of communicative competence; 2) theoretical issues in the study of negotiation, including a) input hypothesis, b) input-interaction hypothesis, c) comprehensible output hypothesis, d) interactionist view, e) study of communication strategies; and 3) empirical studies of interaction in L2 discourse.

\section{NOTION OF COMMUNICATIVE COMPETENCE}

This section briefly reviews several definitions of communicative competence, which has been the underlying principle in communicative language classrooms. Because it has been noted that ESL Japanese learners appear to show less communicative competence than other ESL learners, it is important to review the notion of such competence.

Departing from the behavioristic view of language, Chomsky (1965) distinguishes 'competence' from 'performance', and develops a mentalistic linguistic theory, i.e., a mental reality underlying actual behavior. Chomsky 
clearly contrasts what the speaker knows (competence) from what the speaker does (performance) and proposes that the linguistic theory should be concerned primarily with competence, not performance. He writes:

Linguistic theory is concerned primarily with an ideal speaker-listener, in a completely homogeneous speech community, who knows its language perfectly and is unaffected by such grammatically irrelevant conditions as memory limitations, distractions, shifts of attention and interest, and errors (random or characteristic) in applying his knowledge of the language in actual performance. (Chomsky, 1965, p. 3)

For Chomsky, the main concern is the rules of grammar, that is, the 'knowledge' of the language a native speaker possesses.

In opposition to Chomsky's view of language, Hymes (1972), who initially used the term 'communicative competence', looks at language as 'social interaction' and introduces the notion of communication and culture into linguistic studies. He refers to sociolinguistic evidence that a speech community is not homogeneous in order to explain that "a theory of competence must go beyond the notion of ideal fluency in a homogeneous community" (p. 287). For Hymes, competence is not only 'knowledge' of language, but also 'ability' to use it. In other words, competence includes interactional competence in a certain social context.

Hymes' notion of communicative competence has had great influence on SLA studies. Adopting the sociolinguistic 
perspective of language, Canale and Swain (1980) propose an important model of communicative competence. Their model (conceptual scheme) consists of four components:

1) grammatical competence -- knowledge of lexical items and of rules of morphology, syntax, semantics, and phonology

2) discourse competence -- ability to connect sentences to form meaningful utterances

3 ) sociolinguistic competence -- knowledge of sociocultural rules (appropriateness) of language

4) strategic competence -- communication strategies that compensate for communication breakdown due to performance variables or to insufficient competence

Canale and Swain emphasize language in use (discourse

-- intersentential relationships) and interactive

skills/ability for language use (such as appropriateness and strategies for successful communication), are as important as grammatical knowledge. For them, communicative competence clearly includes functional aspects of language use. Furthermore, the notion that communication strategies are part of communicative competence has influenced the study of the language of the language learner. Savignon (1983) also focuses on the interactive nature of communication. She notes, "communicative competence is relative, not absolute, and depends on the cooperation of all the participants involved" (p. 9). For Savignon, communicative competence is "dynamic", i.e., it depends on the negotiation of meaning between interlocutors, and is "context specific", i.e., success depends on the knowledge of appropriateness in a certain 
situation. She suggests that communicative competence is an "interactional rather than an intrapersonal trait" (p. 8).

With this sociolinguistic perspective, some have posited a continuum model of discourse styles. Tarone (1983) proposes the "capability continuum" model. She applies the term 'capability', instead of 'competence', to "refer more broadly to that which underlies 'all' regular language behavior" (p. 151). Tarone explains that a speaker's style changes from vernacular to careful styles as the speaker pays more attention to language forms.

Another continuum model has been proposed by Ellis (1985). In his "variable competence" model, a continuum of discourse ranges from unplanned to planned. Ellis points out that the learner's language is variable. He describes two types of contexual variation; situational context and linguistic context. Ellis explains that variability of L2 learner's production is due to both a variable competence (a heterogeneous rule system) and variable application of rules in discourse (performance). Widdowson (1989) reviews the notion of competence in these previous studies and points out the difficulty of defining a contrast between 'knowledge of language' and 'ability for use'. He suggests that the ability to use language might be independent from the analytical knowledge of grammar as defined in Chomsky's concept of 
competence.

In summary, it seems that although the definition of communicative competence varies in different models, the notion of communicative competence has provided certain assumptions in teaching and learning L2: 1) the language learner's goal is to develop ability to use the language in real communication, rather than to know rules of language;

2) L2 learner's competence is variable, but systematic;

3) the study of SLA should investigate the learner's language in use.

The next section deals with the question "What aids development of communicative competence?"

\section{SLA STUDIES OF NEGOTIATION}

This section reviews studies of negotiation in second language acquisition (SLA) in five areas: a) the input hypothesis, b) the interaction-input hypothesis, c) the comprehensible output hypothesis, d) the interactionist view, and e) the study of communication strategies. According to Long (1981), most early research on SLA was product oriented (e.g., morpheme study, error analysis). In the mid-1970s, factors external to the learner (i.e., input to the learner) were explained in 'foreigner talk' studies, and recently interest has shifted to the features of the interaction between native (NS) and nonnative (NNS) speakers. Most recently, studies 
of L2 discourse (e.g., NNS-NNS interaction in group work) in and out of the classroom have focused on learner's output and interaction. The following sections briefly review major SLA studies which have contributed to the notion that 'negotiation' for meaning is a key for SLA.

\section{Input Hypothesis}

Krashen (1982) states that learners need

"comprehensible input" for their SLA. Comprehensible input refers to input that contains a linguistic item that is a bit beyond the learner's current level of competence (Krashen, 1982, p. 21). Krashen refers to findings in 'foreigner talk' studies to support his hypothesis. The foreigner talk studies have introduced some evidence that native speakers modify their speech when they talk with nonnative speakers. For example, native speakers produce syntactically less complex utterances and speak more slowly. It has been suggested that such speech modification made by native speakers aids learners' SLA. This claim has become a general assumption that comprehensible input is the type of input that facilitates learner's SLA. Thus, the question 'what makes input comprehensible?' has been one of the central issues in SLA studies for both theory and teaching.

Input-Interaction Hypothesis

Long (1981, 1983, 1985) has provided significant 
evidence to support the input hypothesis. In these studies, Long suggests that linguistic modification alone is not sufficient, and that interactional modifications are optimal for SLA.

In his series of empirical studies based on the assumption of the input hypothesis, Long found that NS speech with a NNS is characterized by various linguistic modifications (e.g., shorter average length of T-units, higher proportion of copulas in total verbs) and conversational modifications (e.g., different types of questions, more confirmation checks, more clarification requests).

Long (1983) compares NS-NS to NS-NNS conversation to examine the effect of both linguistic modification and interactional modification. He has found that the NSs produced more interactional modifications in their discourse with the NNSs than syntactic modifications. Again, Long suggests that modified input itself is not sufficient for comprehensibility, but rather interaction in which meaning is negotiated is necessary.

To examine the effect of modified input on the degree of NNS' Comprehension, Long (1985) uses two versions of lectures: a NS version and a foreigner talk version. The foreigner talk lecture was a modified NS version in terms of l) linguistic modifications (e.g., syntactically less complex), and 2) conversational modifications (e.g., 
many rephrases, slower speech, clear articulation). The results of comprehension tests indicated that speech modifications for non-native listeners resulted in greater NNS comprehension. With this evidence, he writes:

If we accept that there is already substantial evidence of a second causal relationship between comprehensible input and SLA, then one can deduce the existence of an 'indirect' causal relationship between linguistic and conversational adjustments and SLA. (Long, 1985, p. 388)

It should be noted that Long suggests a causal relationship, rather than correlation, between comprehensible input and SLA.

Long's proposition has been confirmed in an empirical study by Pica, Young, and Doughty (1987). They compare two types of NS-NNS interactions with respect to different types of input (premodified vs. interactionally modified) in an information gap game. They have found that interactional modifications of input lead to significantly greater comprehension than premodified modifications. They conclude that reduction in linguistic complexity in input is not a facilitative factor in NNS' comprehension.

In summary, based on an assumption that comprehensible input aids SLA, input-interaction studies have contributed an importanc perspective of 'negotiation' to L2 discourse study. Some input studies of 'teacher talk' have provided useful information for teacher-training (e.g., a study of question types in teacher's input, as presented by 
Pica and Long, 1986). More recently, there have been studies of the negotiated discourse of learners in the classroom (e.g., teacher-fronted, group work) as well as L2 discourse in NS-NNS conversation. These are reviewed in the last section of this chapter.

It has been found that there is a significant correlation between modified input and comprehension, and a stronger effect of interactionally modified input on comprehension than that of linguistically modified input. However, the relationship between comprehensible input and SLA has not been explained. Porter (1986) suggests :

All the modifications found in both these registers [i.e., foreigner talk and teacher talk] are thought to aid in communication with learners, but just how and whether such modifications aid the acquisition process is still undocumented. (p. 201)

Thus, although modifications of speech or interaction seem to be important to help NNS' comprehension, it is still unclear whether or not comprehensible input is a prerequisite for SLA. Theories based on the assumption that "comprehensible input aids SLA" are generally not concerned much about the role of output of the learner. Krashen (1982) notes that "we acquire spoken fluency 'not' by practicing talking but by understanding input, by listening and reading" (p. 60). For Krashen, output is not optimal for SLA. Speaking and interaction are important only because they provide additional comprehensible input 
to the learner. Krashen believes that 'comprehensible input' is a facilitating factor for SLA. This notion that comprehensible input is the causative variable in SLA underlies a large number of studies, even those that focus on interaction features (e.g., Long's interactional modification). The following section describes the claim for an independent role of 'output' from input for SLA.

Comprehensible Output Hypothesis

Contrasted with Krashen's input hypothesis, Swain (1985) has proposed the 'comprehensible output hypothesis'. He argues that comprehensible input is not enough for SLA and that comprehensible output is a more important prerequisite facilitator for SLA. He notes that French immersion students who supposedly have had enough comrehensible input for seven years rarely demonstrate a native-level oral proficiency. Swain tested the oral and written production of immersion students with respect to three traits: grammar, discourse, and sociolinguistics, and compared results with NSs. Swain found that immersion students showed lower productive competence than iss. He also interviewed the students and observed their classroom, and found that the students understood everything they heard, but still had difficulty in producing the L2. Two reasons for this phenomenon were predicted: first, the students simply have very little opportunity to use the $\mathrm{L} 2$ in the classroom; second, there is little "social 
or cognitive pressure" to produce such output (Swain, 1985, p. 249). In other words, the immersion students have little experience in making their production comprehensible to others.

Eased on these findings, Swain explains the crucial role of output for SLA. He writes:

Its role is, at minimum, to provide opportunities for contextualizing meaningful use, to test out hypotheses about the target language, and to move the learner from a purely semantic analysis of the language to syntactic analysis of it. Comprehensible output is, unfortunately, generally missing in typical classroom settings, language classrooms and immersion classrooms being no exceptions. (Swain, 1985, p. 252)

Thus, the comprehensible output hypothesis focuses on the role of learner's output, which had been minimized in the view based on the input hypothesis.

A study by Pica et al. (1989) provides empirical validation for the theoretical claim of comprehensible output. Pica and her collegues looked at ways in which NNSs responded when asked by NSs to clarify or confirm what they had said. This study examined processes by which the NNSs attempt to make their output comprehensible to their interlocutors. The negotiated interactions between the NS and NNS were examined in the frame of 'trigger-signalresponse.' A 'trigger' is INNS' production that is problematic for a NS to understand. A 'signal' refers to NS' indication of difficulty (e.g., clarification requests, confirmation checks). A 'response' is Nis' 
modification (e.g., repetitions, paraphrases). Pica et al. found that the NNSs modified their output in various ways to make it more comprehesible to their listeners. They suggest future research which "views as vital to the acquisition process 'all' productions of learners and their interlocutors as they negotiate the meaning of their message to each other" (Pica et al., 1939, p. 94).

Thus, the notion of comprehensible output has shed light on the role of the learner in negotiation of meaning for successful communication. The following section examines a view that focuses on interaction itself, rather than input or output.

Interactionist View

The interactionist view is concerned with the role of cognitive mechanisms in SLA. Ellis (1934a) explains:

Language development is the result of an interaction between the learner's existing state of knowledge (Iinguistic and conceptual) and the linguistic environment to which he is exposed. (p. 13)

Note that the notion of interaction in this view is different from that in Long's claim. Long's interaction refers to an exchange of input between interlocutors, whereas for Ellis, interaction occurs between the learner's internal system and external factors.

In this perspective, conversation or interaction is regarded as an essential process for SLA. Ellis (1984a) 
writes:

It is by negotiating the exchange of meaning

through conversation that the learner typically obtains information about the target language which enables him to revise his

existing interlanguage system. Thus, both the negotiatio of conversation itself and the way in which this contributes to development must be seen in terms of 'process'. (p. 14)

Studies based on this view focus on discourse involved with the learner.

Discourse analysis was first introduced into SLA studies by Hatch (1978). With evidence from first language acquisition of children, she points out that syntactic systems grow out of social interaction. She suggests that children acquire language because they have "conscious desire... to say something, to talk about something" (p. 405). Hatch states:

It is assumed that one first learns how to manipulate structures, that one gradually builds up a repertoire of structures and then, somehow, learns how to put the structures to use in discourse. We would like to consider the possibility that just the reverse happens. One learns how to do conversation, one learns how to interact verbally, and out of this interaction syntactic structures are developed. (1978, p. 404)

Thus, the notion of interaction proposed by Hatch seems to be quite different from the view in input-interaction studies. Krashen and Long explain comprehensible input is a prerequisite for SLA, whereas Hatch proposes meaningful communication is a prerequisite for L2 systen construction. What Hatch means by "syntactic structure" is "autonomous 
grammar", which, she believes, grows through hypothesis testing (Hatch, 1983, p. 187).

The interactional view has been developed by Hatch and her colleagues (1986) in their "experience model" for SLA. They assert that "The continuous interaction of experience with interlinked cognitive, social, and linguistic systems should show how development evolves" (p. 5). Hatch et al., with a view of language as a "knowledge structure", explain the language acquisition process using a scaffolding metaphor; "one part may form a framework to which another system might attach its material" (p. 17). They suggest that the role of the teacher is to find those essential experiences that contribute to learning and to provide ways in which the learners can experience such interaction/discourse in the classroom.

In his studies of classroom interactions, Ellis $(1980,1984 a)$ found that the range of interactional patterns of learners was quite limited in the formal teaching setting (i.e., teacher-fronted situation), which requires students mainly 'to respond', but rarely 'to initiate' or 'to develop' conversation. Ellis states, "In classrooms the predominant type of discourse is three phase -- a teacher initiation, a pupil response, teacher feedback", the pattern called "IRF" exchange (1984a, p. 97). Ellis points out that teacher-class interaction does not aid learners to use 
'initiating' or 'repair' strategies, which are supposed to be necessary to promote SLA.

Thus, the interactional view and the experience model provide a way to see learner's discourse as a whole.

Study of Communication strategies

Learners make various 'errors' when they try to communicate using insufficient L2 systems. For example, if they lack a certain word in their L2 inventory, they might use an approximate word (e.g., missile for atomic bomb) or their Ll (e.g., Japanese 'one piece' for aress). Selinker (1972) describes such attempts by learners as strategies, rather than errors. Communication strategies have since been studied by a number of researchers (e.g., Corder, 1981; Tarone, 1981; Faerch and Kasper, 1983; El1is, 1984); yet, there is little consensus about communication strategies in the Iiterature concerning either their definition or taxonomy.

Tarone (1981) defines communication strategies as follows:

They are attempts to bridge the gap between the linguistic knowledge of the secondlanguage learner and the linguistic knowledge of the target language in real communication. (p. 288)

Tarone believes that communication strategies have an interactional function; that is, they are used for negotiation of meaning between speaker and hearer. 
of communication strategies.

Paraphrase

Approximation: use of a semantically similar word (e.g., pipe for waterpipe)

Word coinage: a new word (e.g., airball for balloon)

Circumlocution: description of features of the

Borrowing object (e.g., its color, size)

Literal translation: word-for-word translation from the native language

Language switch: use of the native language Appeal for assistance

the learner asks for the correct term (e.g., "What do you call this?")

Mime

Avoidance

use of nonverbal signals (e.g., illustrating a shape with one's hands)

Topic avoidance: the learner tries not to talk about the item

Message abandonment: the learner starts to talk about a concept but stops

Also, these strategies can be divided into two main types: reduction strategies, and achievement strategies (Faerch and Kasper, 1983; Ellis, 1985). Achievement strategies are supposedly more communicative; reduction strategies are means for avoiding communication.

Tarone and Yule (1989) see communication strategies as part of 'strategic competence', a component of communicative competence defined by Canale and Swain. Tarone and Yule explain strategic competence as "the ability to successfully 'get one's message across'" and relate it closely to the use of communication strategies. They see these strategies as "part of the ability to repair, or compensate for, breakdown in communication" (p. 19). In their interpretation, communication strategies are 
seen more generally as equivalent to the speaker's ability. Communication strategies are used by native speakers as well as language learners. Tarone (1981) suggests a different role of communication strategies in L2 discourse:

.. in native language interactions we may suspect that such communication strategies are used primarily with lexical items, or perhaps to clarify referents for pronouns, whereas in interlanguage they may occur with syntactic, morphological or even phonological structures. (p. 289)

In this sense, communication strategies are important devices through which learners compensate for their transitional L2 competence. Therefore, it is essential to investigate the use of communication strategies in order to understand language learner's discourse.

Ellis (1984b) suggests that the study of communication strategies may be used to evaluate communicative proficiency of L2 learners. He predicted: 1) more advanced learners use fewer communication strategies, and 2) less competent learners preferred an avoidance strategy, while more advanced learners use a paraphrase strategy. Findings supported his hypotheses, suggesting that communication strategies could be a reliable assessment of a learner's communicative competence.

These findings were supported in Labarca and Khanji's study (1986) examining recorded speech of learners in an oral interview. They found that more advanced students used fewer communication strategies. More advanced learners 
seemed to rely on $\mathrm{L} 2$ competence, rather than on extensive use of communication strategies.

Ellis (1985) suggests that situational factors may influence the type of strategy used. He found frequent use of the avoidance strategy used by American students in a Russian language classroom, and pointed out that learners may use fewer achievement strategies in the classroom.

Thus, three assumptions have been supported by some evidence: 1) more advanced learners use fewer communication strategies; 2) less competent learners use more avoidance strategies; and 3) fewer strategies are used in classroom interaction, except for avoidance.

A facilitative effect of communication strategies on SLA has been pointed out by Faerch and Kasper (1983). They explain that three essential processes of learning for SLA are promoted by achievement strategies: I) hypothesis formation -- establishing hypothetical rules; 2) hypothesis testing -- testing them out; and 3) automatization -increasing availability of rules (p. 53). That is, communication strategies are devices for solving problems that often inhibit learner's use of $\mathrm{L} 2$.

From a pedagogical view, it has been suggested that communication strategies are 'teachable' in the classroom. Tarone and Yule (1989) introduced various classroom activities designed specifically to help learners develop 
strategic competence. Dörnyei and Thurrell (1991) have also proposed several strategy training activities.

Although the study of communication strategies is a useful source for SLA research, there are several methodological problems. Raupach (1983) describes problems in identifying strategies. He suggests that 'successful' strategies are usually unnoticed and that it is important to look for 'strategy markers' such as hesitation and other signals of uncertainty. Raupach also explains that introspective comments made by the learners are useful for investigating the intended meaning that the learner tried to convey. Ellis (1985) argues that learners' introspection is not always a reliable source for analysis because strategies are sometimes used unconsciously. Corder (1981) points out a lack of study on strategies used in the process of comprehension:

Since communication is a cooperative enterprise, one must suppose that we may adopt both productive and perspective strategies of communication. So far no one has attempted within the framework of interlanguage studies to investigate the latter. (p. 103)

With regard to difficulty in identifying types of strategies, qualitative studies, rather than quantitative studies, may be more suitable for investigating communication strategies. 
on negotiation in $L 2$ discourse. Long's input-interaction hypothesis views the negotiation process from a native speaker side, whereas Tarone's concept of communication strategies focuses on the learner's efforts to make conversation successful. Both are devices to keep a communication channel open, or to repair communication breakdown. In SLA studies, there are a few comments on this connection of these two concepts. Richards (1980) includes Tarone's communication strategies in his category of 'repairs'. He explains that those strategies can be categorized as self-repairs and requests for assistance. Ellis (1984a) points out a more explicit connection between the two perspectives:

Foreigner talk and the learner's
communicative strategies are, in fact, two
sides of the same coin. . It is sought
jointly by the native-speaker and learner
working together to estabilsh and maintain
a mutually acceptable topic. What is
important is, therefore, the 'negotiation
of an agreement on meaning' ... (p. 9l)

The learner's role in negotiation has not been studied in SLA studies as much as that of native speakers (e.g., foreigner/teacher talk studies). More studies on learner's negotiated discourse are essential before the theory and teaching of L2 can provide a complete picture of discourse involving the learner and the interlocutor(s) in various contexts. 
EMPIRICAL STUDIES OF INTERACTION IN L2 DISCOURSE

This section presents some SLA research focusing on interaction patterns in discourse involving L2 learner(s). Most studies reviewed are concerned with L2 discourse studies focusing on different types of settings such as NS-NNS dyads, NNS-NNS dyads, teacher-NNSs class. It also reviews studies by Sato (1982) and by Duff (1986), concerning Asian learners' participation patterns and the effects of ethnicity.

L2 Discourse in Different Settings

Many studies dealing with interactions in L2 discourse are based on Long's 'input-interaction hypothesis' as described previously. With the assumption that comprehensible input aids SLA and that interactional modifications enhance comprehensible input, different types of interactions in various settings have been examined and compared.

Dyads. Varonis and Gass (1985) compared ins-NNS dyaús and NNS-NNS dyads in terms of frequency of negotiation measured by features such as indication of nonunderstanding and repair sequence. They found that learners' pair interactions contained more negotiation of meaning than NS-NNS interactions. Their study suggests that learners' peer interactions in a small group (i.e., pair- or group-work) promote learners' SLA. 
Another study of dyads by Porter (1986) investigated discourse produced by speakers with various proficiency levels, including native-speakers and advanced, and intermediate L2 learners. Porter found that the advanced learners produced an almost equal number of words and similar repairs as did the native speakers. Her study also indicates that learners in NNS-NNS dyads produced more negotiation than they did in NS-NNS dyads. Porter suggests that a pairing of an advanced learner and an intermediate learner seems to be most beneficial in terms of communicative practice, including the negotiation of meaning.

The studies mentioned above indicate important suggestions about interactions between learners. First, learners are capable of negotiating meaning in L2 communication. Second, learners' peer interactions contain more negotiation than NS discourse contains. Third, with the assumption that interactional modifications aid SLA by providing comprehensible input, small-group activities are facilitating for learners' SLA.

Teachers'Talk. Negotiation carried out in the classroom was first investigated in teacher's talk studies. Among interactional modifications, the three devices most commonly examined are confirmation checks, comprehension checks, and clarification requests.

Long and Sato (1983) compared speech by teachers 
in the whole-class interactions to speech by NSs in a one-on-one conversation with a NNS. They found that comprehension checks (e.g., OK? Did you understand?) were the device most frequent in the classroom interaction, and least frequent in the NS-NNS dyads. More confirmation checks were found in the dyads than in the classroom. Clarification requests were not frequently produced in either setting.

Another teacher's talk study by Pica and Long (1986) also suggested that not many confirmation checks or clarification requests were found in teacher-class interactions.

The two studies above indicate that the teacher-fronted classroom may contain very little negotiated interactions, and that the types of interactional modifications may vary in different settings. These suggestions have been investigated more precisely in the following comparison studies of teacher-fronted and group-work interactions. Teacher-fronted vs. Group-work. A summary of advantages of group work activities over teacher-fronted classes is presented by Long and Porter (1985). They pointed out that, compared to the teacher-fronted classroom, small group activities provide more practice opportunities, a more positive affective climate (i.e., less threatening), and more interactional modifications (i.e., more negotiation of meaning). In other words, they suggested that small 
group activities facilitate learners' SLA more than do teacher-fronted classes.

Findings in an early study by Long et al. (1976) parallel this claim. It was found that learners took a significantly greater number of turns and produced more varieties of speech acts (e.g., defining, negating) in the group-work discussions than they did in the teacher-class interactions.

Pica and Doughty (1985) examined speech data including teachers and learners in both the teacher-fronted and group-work settings. Contrary to their prediction, interactional modifications (i.e., comprehension checks, confirmation checks, clarification requests) were more frequently used in the teacher-fronted classroom than in the group work task. It was noted that teachers' talk which comprised almost half of the total talk as a whole may have greatly affected the results. An important finding in their study is that the amount of talk produced by an individual student was significantly greater in the group work than in the teacher-fronted. They pointed out that learners have more opportunities to use L2 in group than in teacher-fronted activities.

Such opportunities may have had a positive effect on students' development of linguistic and strategic competence in giving them practice in hypothesizing about interlanguage structures which were still at variable levels of accuracy, or in enhancing their development of second Ianguage fluency. (Pica and Doughty, 1985, p. 131) 
Rulon and MCCreary (1986), also comparing teacher-fronted and small group interactions, examined only learners' speech. They focused on two types of negotiation: negotiation of 'meaning' (i.e., meaning of utterances produced by interlocutors) and negotiation of 'content' (i.e., meaning of something learners have previously heard, such as content of lectures, instructions by the teacher). It was found that speech in a small group contained a greater number of words and s-nodes, as well as more clarification requests and confirmation checks, than that in teacher-fronted interactions. However, statistically significant differences between the two settings were found only for negotiation of 'content', but not for negotiation of 'meaning.' Rulon and McCreary described two problems in their analysis, which may have caused non-significance of the results. First, the communication unit (c-unit) used in the analysis was too broad. Minimal expressions (e.g., 'mhm' or 'yeah'), which are, in general, more frequently found in a small group situation than in a teacher-fronted one, were caluculated as c-units, and such expressions lowered the average length of the c-units produced by the students in the group work task. Second, it was suggested that very little negotiation was found in both settings. Two reasons for this result explained by the researchers are a high proficiency level of the students in the study and the task type. Rulon 
and McCreary concluded, "very little 'negotiation' of either content or meaning was actually taking place in these teacher-fronted classes" (p. 194).

Effects of settings were also investigated by Doughty and Pica (1986). Following their earlier study, Pica and Doughty (1985), they investigated speech data of interactions by ESL learners and teachers in three different settings (i.e., teacher-fronted, group work, dyad). They too found that interactional modifications were greater in the group work than in the teacher-fronted setting. Furthermore, there was no significant difference between the group work and dyads, and a very similar amount of modifications were found in the two situations. On the other hand, contrary to their hypothesis, more total interactions (as measured by number of T-units and fragments) were found in the teacher-fronted setting than in the group work. The researchers explained this result by referring to the excessive amount of teachers' talk in the teacher-fronted classroom. They noted, "teachers spoke as much as the total number of students combined" (Doughty and Pica, 1986, p. 320).

Also, Doughty and Pica suggested that task type is important; that is, a task needs to be 'required exchange', rather than 'optional exchange'. Learners need to be in an obligatory environment for participation $($ e.g., two-way task). It was pointed out that a group-work 
setting does not automatically guarantee increased interaction among learners without careful considerations of task types. Based on these findings, a question for future research was raised: "How much of the time do individual students actually engage in modification during a required information exchange?" (Doughty and Pica, 1986, p. 321 ).

In short, most studies examined in this section indicate that interaction in a small group (i.e., pairor group-work) promotes more production and interactional modifications from individual learners than that in the NS-NNS dyads or teacher-fronted classroom. Yet, results of some studies (e.g., Pica and Doughty, 1985; Rulon and McCreary, 1986) did not statistically support superiority of group work. Also, it seems to be difficult to formulate an accurate comparison of the results from those studies because of inconsistent methods of measurement and scope of focus (e.g., teachers' speech in data). Long and sato (1983) pointed out this methodological problem in SLA studies as follows:

As with the development of almost any set of categories for classifying functions of human behavior, it is possible to make ever finer distinctions (and more categories). This is a practice that can result in unwieldy coding systems whose increasingly subtle distinctions are accompanied by no parallel increase in understanding (predictive power) of the phenomenon under investigation ... (p. 275) 
Thus, in order to have more effective comparisons across different studies of L2 discourse, more future studies need to be conducted in the area of research methodology. At the same time, however, these studies suggest that learners' interaction in the small group setting is more facilitative for their SLA than that in the teacher-fronted setting; specifically, individual learners have more opportunity to use $L 2$ in a small group than in a whole-class situation if they have a task that structurally reinforces their participation (e.g., two-way task). Long and Porter (1985) suggest:

.. it appears to be the 'combination' of small-group work (including pair work) with two-way tasks that is especially beneficial to learners in terms of the amount of talk produced, the amount of negotiation work produced, and the amount of comprehensible input obtained. (p. 224)

Thus, the type of setting seems to be an important variable that affects learners' production and interaction.

\section{Effects of Ethnicity}

Ethnicity is another important variable that affects learners' interaction in SLA. In previous SLA studies, however, effects of ethnicity have not been examined much. This section presents the results of two studies which dealt with ethnic styles in L2 discourse.

Sato (1981) examined effects of ethnicity on participation patterns in the classroom. She compared different turn-taking styles of Asian and non-Asian students. 
Interaction patterns were studied in terms of frequency of self-initiated turns and solicited turns. Sato found that the Asians, which were a larger group, took significantly fewer turns than the non-Asians. The former took 348 of the total turns; the latter $66 \%$. Sato also found that the Asians preferred being solicited. She concluded that Asian students have very different participation patterns from those preferred in the communicative language classroom.

In another study of Asian students, Duff (1986) compared the dyadic interaction of Chinese and Japanese learners. She found that Chinese subjects significantly dominated the interactions in terms of linguistic productivity (e.g., number of turns, length of utterances). She also found that the Chinese learners interrupted and stole a significantly greater number of Japanese turns than the reverse. She writes:

Chinese, we found, are indeed "dynamic" subjects, and tend to participate much more actively in pedagogic tasks than Japanese, even when global proficiency is comparable. Consequently, Chinese not only speak more in terms of words, they also take more turns and ask more questions to encourage their partners to participate in the discussion with them. (Duff, 1986, p. 169)

Thus, Duff's study suggests that even among Asians, there are still group differences in participation patterns.

The two studies examined above point out that participation patterns may differ according to learners' cultural background. Further research on ethnic styles 
is necessary to promote awareness of cultural differences in learners production and interaction in the classroom.

\section{SUMMARY}

This chapter reviewed the notion of communicative competence, theoretical issues in the study of negotiation, and empirical studies of interaction in L2 discourse. Studies of classroom interaction have focused on communicative competence, which assumes the goal of language learning is real communication. Learners' competence in $\mathrm{L} 2$ is regarded as being variable depending on context.

This chapter also reviewed various studies of the role of interaction in SLA. Despite some theoretical differences, many researchers have stressed the importance of negotiated interactions in SLA.

Finally, in reviewing empirical studies of interaction in L2 discourse, two important variables were identified: setting and ethnicity. There seems to be an assumption that the small group setting is more facilitative for learners' SLA than the teacher-fronted class. It is also noted that ethnicity may be an important variable affecting learners' participation patterns. 
CHAPTER III

\section{METHOD}

In this chapter, the research methodology applied in this study is presented. In order to investigate characteristics of Japanese ESL learners' I2 aiscourse, I observed and collected the data of speech/interaction produced by a group of ESL learners, both Japanese and non-Japanese, enrolled in the same ESI course throughout one term of study. Then, from the primary data, two types of variables were selected, ethnicity (i.e., Japanese vs. non-Japanese) and setting (i.e., teacher-fronted, group work, and NS-NNS dyads).

\section{PARTICIPANTS}

Primary Subjects

The primary subjects in the study were a group of 22 university students enrolled in a low-intermediate ESL course, and their three teachers. They were selected after a two-week observation of many ESL classes at the beginning of a term. Because of the nature of the ESL classes, I could not predict which Japanese subjects would be available after the term started. The proficiency 
level of all students in the group was considered similar because the students had been grouped according to the results of a standardized test, the Michigan Test of English Language Proficiency. Students' scores on this test ranged from 40 to 61 .

This subject group was selected for several reasons. First, there were 10 Japanese students who were willing to participate in the study. Second, the cultural/linguistic background of the students in the class was quite mixed (10 Japanese, 3 Koreans, 3 Chinese, 3 Arabic, 2 Spanish, 1 German) and was representative of the student population in that ESL program. Third, their teachers all used a communicative approach, and were willing to participate in this study.

The research purpose was briefly explained to the class (i.e., it was introduced as "a study of ESL learners' interaction in the classroom"), but the fact that the main focus was on Japanese students was not revealed because I did not want to affect their natural behavior in participation.

Subjects for Analysis

After the primary data were collected, the number of Japanese (JP) subjects for analysis in this study was set as 8. Because this study was based on the data of natural lessons (i.e., not experimental), a few students were absent for some recording sessions. Therefore, in 
each setting, the data from 8 (out of 10) JP students were used for analysis. Table I shows the ethnographic profiles of all JP students and the 8 students who were available in each setting (i.e., marked with ' $\mathrm{X}$ ').

\section{TABLE I}

PROFILES OF JAPANESE SUBJECTS

\begin{tabular}{|c|c|c|c|c|c|c|c|}
\hline Subject & Sex & Age & Plan* & $\begin{array}{l}\text { Length of } \\
\text { stay }\end{array}$ & $\begin{array}{l}\text { In } \\
\text { TF }\end{array}$ & $\begin{array}{c}\text { Data } \\
\text { GW }\end{array}$ & $\begin{array}{l}\text { of } \\
\text { INS }\end{array}$ \\
\hline$J I$ & $F$ & 25 & Eng & $6 \mathrm{mo}$ & $\mathrm{x}$ & $x$ & $\mathrm{x}$ \\
\hline J2 & $\mathrm{F}$ & 27 & UG & $6 \mathrm{mo}$ & $\mathrm{X}$ & $x$ & $\mathrm{x}$ \\
\hline J3 & $F$ & 20 & UG & $4 \mathrm{mo}$ & $\mathrm{X}$ & $\mathrm{x}$ & $\mathrm{x}$ \\
\hline J4 & $\mathrm{F}$ & 21 & Eng & $5 \mathrm{mo}$ & $\mathrm{X}$ & $\mathrm{x}$ & $\mathrm{x}$ \\
\hline J5 & $\mathrm{F}$ & 21 & Eng & $1 \mathrm{yr}$ & $\mathrm{x}$ & $\mathrm{x}$ & $\mathrm{x}$ \\
\hline 36 & $F$ & 27 & UG & 4 mo & - & $\mathrm{x}$ & $\mathrm{X}$ \\
\hline J 7 & $\mathrm{~F}$ & 24 & Eng & 3 mo & $\mathrm{x}$ & - & $\mathrm{X}$ \\
\hline J8 & $\mathrm{F}$ & 23 & UG & $1 \mathrm{yr}$ & $\mathrm{x}$ & - & $\mathrm{x}$ \\
\hline J9 & $F$ & $2 I$ & UG & $6 \mathrm{mo}$ & $\mathrm{x}$ & $\mathrm{x}$ & - \\
\hline J10 & M & 18 & UG & $4 \mathrm{mo}$ & - & $\mathrm{x}$ & - \\
\hline & $\begin{array}{l}\overline{=} \\
\text { unc }\end{array}$ & & & $\begin{array}{l}\text { ishing } \\
=\text { only }\end{array}$ & $\begin{array}{l}\text { our: } \\
\text { ish }\end{array}$ & & \\
\hline
\end{tabular}

The age of the JP students ranged from 18 to 27 , and J10 was the only male. Six students were studying ESL to prepare for undergraduate study, while the other four were studying only English.

As a comparison group to JP, 4 non-Japanese (NJP) students were chosen to represent a variety of $\mathrm{LI}$ backgrounds; I Chinese, I Spanish, I German, and I Arabic. Because the Arabic student was absent in the group work setting, data from a second Arabic student were used for that part of the study. These 5 NJP students were all active participants in the classroom. (see the chart 
of participation frequency of the learners in Appendix B.) The profiles of the 5 NJP students are found in Table II, and the participation of each NJP subject in each setting is marked by ' $X$ '.

TABLE II

PROFILES OF

SELECTED NON-JAPANESE SUBJECTS

\begin{tabular}{|c|c|c|c|c|c|c|c|c|c|}
\hline Subject & Country/LI & Sex & Age & Plan & $\begin{array}{l}\text { Le } \\
\text { of }\end{array}$ & $\begin{array}{l}\text { ingth } \\
\text { stay }\end{array}$ & $\begin{array}{l}\text { In } \\
\text { TE }\end{array}$ & $\begin{array}{c}\text { Data } \\
\mathrm{GW}\end{array}$ & 01 \\
\hline C & Hong $K$ & M & 20 & UG & 5 & mo & $\mathrm{x}$ & $\mathrm{x}$ & \\
\hline$S$ & Venezuela/span & $\mathrm{F}$ & 28 & Eng & 2 & mo & $\mathrm{X}$ & $\mathrm{X}$ & \\
\hline G & Switz/Germ & $F$ & 38 & Eng & 3 & mo & $\mathrm{X}$ & $\mathrm{X}$ & \\
\hline AI & Saudi Arab/Arab & $M$ & 20 & $\mathrm{GR}^{* *}$ & 3 & mo & $\mathrm{x}$ & - & \\
\hline A2 & Saudi Arab/Arab & F & 21 & Eng & & mo & - & $\mathrm{x}$ & \\
\hline
\end{tabular}

$\star \star{ }^{\prime} \mathrm{GR}^{\prime}=$ graduate course

In the NJP group, S, G, and A2 were enrolled in the ESL course just to study English, while $C$ and $A l$ planned to enter regular courses (undergraduate and graduate respectively).

All members of both groups were staying in the united stated for the first time. The average length of residence in the U.S. at the beginning of the term of the JP group was 6.2 months, and that of the NJP group was 3.4 months. They were all in the same ESL course at the low-intermeaiate level determined by their scores on the Michigan Test, placement test. The mean of the scores of the JP group was 49.4 (range $=4 I-6 I$ ) and the mean of those of the NJP group was 50.2 (range $=47-55$ ). 
NS Participants

Although the focus of this study was JP learners' output and interaction, rather than 'input' from a native speaker (NS), it is useful to briefly describe the NS participants. The NS participants in this study were three ESL teachers in the classrooms and three interlocutors in the native-nonnative (NS-NNS) conversation outside of the class, all female.

Of the three ESL teachers, one had a Master's degree in TESOL with 10 years teaching experience; the other two were graduate assistant teachers in TESOL with two years teaching experience. A teacher-fronted activity from the most experienced teacher's class was chosen for analysis.

Three native speakers of English participated in recording the NS-NNS conversations. Two were students in a TESL certificate program, and one was a faculty member in the applied linguistics department. (They were all introduced to the students as a 'friend' of this researcher.) All had experience in communicating with non-native speakers of English.

\section{DATA COLLECTION}

In this section, research methodologies used in this study are presented. To investigate characteristics of Japanese learners' production/interaction from various 
perspectives, I applied the 'triangulation' approach that is often introduced in classroom-oriented studies of second language acquisition (e.g., Long, 1980; van Lier, 1988; Allwright, 1988). 'Triangulation' is characterized by a combination of three or more methodologies. The methodologies used in this study were: 1) participant observation (anthropological approach), 2) recording speech (interactional approach), and 3) interviews (introspective approach). The three methodologies are described separately in the following sections.

Participant Observation

I observed the learners in the subject group for one term by participating in their classes as an assistant teacher. I sat in a back corner of the classroom taking notes and usually participated in the lessons when the students had pair or group activities. Because I am a native speaker of Japanese and a learner of English as a second language, some learners in the group said that they also regarded me as an advanced peer learner.

The information recorded in my field notes includes: coding of the learners' participation, types of classroom activities, seating arrangement, descriptions of interaction between teachers and learners, and memos of informal conversations I had with teachers and learners after class. I found both advantages and disadvantages to the participant observation. The advantages were: a) precise 
information about learners' interaction in different setting and different tasks was attainable; b) the subject learners became comfortable with the researcher and relatively open in the interview sessions; and c) because of frequent interaction with the subject learners, I became familiar with learners' voices, so I could transcribe each learner's speech in the teacher-fronted and group work in spite of noise. (I found this was the most beneficial.) There were also some disadvantages in the participant observation. First, it was time consuming to collect all the ata for this type of research. Secondly, as a teacher's assistant, I concentrated on interaction, rather than observation, with the students, so I might have missed recording interesting instances.

\section{Recording Speech}

In the primary recording, the subject learners' speech was recorded on audio and video tapes in and out of the classroom. In the classroom, 3 teacher-fronted activities and 3 group activities were recorded on audiotapes, and 3 teacher-fronted activities and 1 group activity were videotaped. Also the speech/interaction in their mid-term and final tests in the speaking section were videotaped. (Tasks in the tests were discussions and role plays.) Additionally, pronunciation data were collected. (Tasks were reading a list of words and reading a paragraph.) Also, selected learners' speech in NS-iNNS 
conversation was videotaped outside of the classroom. Problems in Recording. Classroom recording on videotapes was not successful in this study for the following reasons: first, the size of the class was too large to be filmed as a whole; second, one Arabic female learner refused to be videotaped. Because of the noise level, the quality of the data from the classroom sessions was not as good as I had hoped. Also, it was impossible to record learners' speech in pair work. When they had a pair-work activity, the noise level increased so that individual speech was not audible from tapes. The following section presents more detailed description of the three recording situations used for the analysis in this study. Procedures for Recording. The procedures for recording speech in the three different settings (i.e., teacherfronted, group work, and NS-NNS dyads) were as follows: 1. Teacher-fronted (TF) setting: A tape-recorder was placed on the teacher's desk. The students were seated as in an ordinary classroom (i.e., lecture class). Using an over-head projector, the teacher asked questions related to a story the students had previously read. The students could take turns freely to answer the questions. (Besides recording the speech in discussion, I coded and took notes on their turns, in order to compensate for difficulty in identifying individuals in the later transcribing process.) The whole activity lasted about 20 minutes.

2. Group work (GW) setting: After the introduction of the topic, the students were divided into four small groups. A tape-recoder was placed on the desk at each group. On this occasion, the 4 non-Japanese learners (C, S, G, and A2) were separated into different groups by chance. Three groups had 5 participants while one had 4. The task of the $G W$ was to gather information about "Jobs and Professions" in different countries, and the learners were guided by related questions in their textbook. The 
whole activity lasted about 20 minutes.

3. NS-NNS (NS) setting: One-to-one conversations with a native speaker were videotaped with the assistance of technicians in the university TV studio. Each subject and a NS were seated side by side in chairs placed in front of a small table. Two video cameras were fixed on each side of the speakers, one was operated by me and the other by an American friend. Two technicians assisted in the control booth of the studio in order to operate the machine and to instruct the cameramen. The technicians remained out of sight of the subjects. Subjects were given instructions initially. They were told that they did not have to worry about what to talk about because the NS would ask them many questions but if they wanted to say something, they could say anything. The interaction was designed as a conversation between a NS and an ESL student newly arrived in the United States. The topics of the conversations were controlled by the NS for two reasons; to reduce learners' anxiety about finding what to talk about, and to balance the content of conversation in each dyad. Filming of each conversation lasted between 9 minutes and 13 minutes.

Interview

I interviewed the learners and their ESL teachers, formally and informally, to gain insights into the behavior observed. The use of the introspective approach combined with other approaches has been found to be effective in order to investigate 'why' questions in the study of second language acquisition. Cohen (1987) points out that classroom observations cannot capture what learners are thinking about or how they feel. He states, "observations regarding language learning behavior are generally limited to the students who speak up. Such observations tell us nothing about those who remain quiet, and not a great deal about those who do not" (Cohen, 1987, p. 82). In my interviews with the learners, I found the introspective approach 
useful for studying quiet Japanese learners.

In the process of reviewing the NS-NNS conversations with the subjects, I used a 'stimulated recall technique.' That is, while watching the play back of the recorded conversation, the subjects were asked to describe fully what they were thinking and feeling at points throughout the interaction. Also, they were asked questions by the researcher. I had review sessions with all JP subjects except J4, and we spoke in Japanese. Among the 4 NJP subjects in the NS setting, I had a review session with only $S$, in English, but not with the rest. The review sessions took place in three different places (i.e., a small review room in the TV studio, the ESI teachers' office, and a room belonging to an acquaintance of the researcher). In most cases, pairs of learners reviewed the videotaped conversation. (See Haastrup (1987) for more information about advantages of pair introspection.) The sessions were all audiotaped. Each session lasted approximately one and a half hours.

\section{DATA FOR ANALYSIS}

After all the data collected in one term were examined, the segments for analysis in this study were extracted. This study is based on the transcripts of recorded speech produced by 8 Japanese learners and 4 non-Japanese learners in three settings (i.e., teacher-fronted, group work, 
NS-NNS conversation). A segment from each setting was determined as 9 minutes, the length of the briefest NS-NNS conversation.

In the teacher-fronted activity, two 9 minute segments of the same lesson were transcribed and coded, and the one occurring later in the lesson was chosen on the assumption that these students usually became more active as time passed in the activity. In the group-work data, a 9 minute segment was transcribed and coded from each of 4 small group discussions. From the transcribed 12 NS-NNS dyads, a 9-minute segment of each was extracted and coded.

\section{ANALYSIS}

In order to investigate Japanese learners' production and interaction in their L2 discourse in the three settings (i.e., teacher-fronted, group work, NS-NNS dyads), three categories were used: quantitative analysis of both syntactic features (e.g., number of turns or words) and interaction strategies (e.g., comprehension checks) and qualitative analysis of interview results focusing on avoidance behavior of Japanese learners in the teacher-fronted setting.

\section{Research Questions}

1. How do Japanese learners talk compared with non-Japanese learners in each of the three settings, and what kinds of utterances do they produce? 
2. What interaction strategies do Japanese learners use in each of the three settings?

3. Why do Japanese learners speak less and take fewer turns in the classroom?

\section{Analysis of Syntactic Features}

The following ten measures were selected to answer the first question: How much do JP learners talk and what kinds of utterances do they produce?

Measures. Amount of talk was measured by examining the mean total number of turns and words, and the mean total number of words per turn. Complexity of talk was figured by examining features of S-nodes, words in S-nodes, and fragments. (See Appendix $\mathrm{C}-1$ for a coding sample.) There were ten different measures used for syntactic analysis.

1. Total number of turns

2. Total number of words

3. Average number of words per turn

4. Total number of $S$-nodes

5. Total number of words in $\mathrm{s}$-nodes

6. Total number of fragments

7. Average number of $s$-nodes per turn

3. Average number of fragments per turn

9. Proportion of words consisting of $s$-nodes in total words

10. Proportion of fragments in total words

Definitions. The definitions of terms are described below. Sub-categories of fragments (e.g., responses, repetitions, false starts) were also coded but not used in this study.

turn: A turn is "any speaker's sequence of utterances bounded by another speaker's speech" (Chaudron, 1988, p. 45). 
S-nodes: An S-node is a clause including a subject and a finite verb (Brock, 1986, pp. 42-43). fragment: A fragment is any utterance "which does not constitute a complete proposition (i.e., with explicit subject and verb)" (Chaudron, 1988, p. 45).

Problems in coding. I found two major problems in determining segments of turns in the data: fragmented communication units and back-channel expressions. First, the Japanese learners tended to stretch their communication units over a few separated turns. (For a review of fragmented talk of Japanese, see Maynard 1989.) The final boundaries of those fragmented turns were marked by rising intonation which may function as 'affirmation' or 'verification' requests from their interlocutors. Such a case is observed in the following example:

(Topic -- clothing among university students in Japan)

(a) J7: Umm .... I don'-, I didn't wear ah pan-, 'short pants'?

NS: Short pants ... uh huh.

(b) J7: Yeah ... umm .. American, um in Japan (NS: uh huh) I, I wear ah ... pu-, 'pumps'?

NS: Pumps, oh!

(c) J7: And skirts ...

NS: Oh oh ..

(d) J7: Yeah.

In this study, the utterances (b) and (c) were counted as separated units in different turns despite their continuity as a communication unit. In other words, the sentence, 'In Japan, I wear pumps' in (b) was counted as an S-node (with 5 words) and 'and skirts' in (c) was counted as 2 fragments, because the turn (c) was bound with the NS' turn 'Pumps? oh!.' 
The frequent use of back-channel expressions found in the data was another problem in counting frequency of features. According to Maynard (1989), back channel refers to short messages (e.g., 'yes', 'uh huh') and head nods given as feedback while someone is speaking (p. 160). Maynard suggests that Japanese use back channel more often in their native language than Americans do in theirs. For the purpose of this study, only the back-channel cues which formed independent turns were counted. Additionally, fillers (such as 'uh' and 'umm') were not counted in the syntactic analysis but were considered to be interaction strategies, as discussed in the following section.

\section{Analysis of Interactional Features}

To answer the second research question, what interaction strategies do Japanese learners use in their L2 discourse, selected strategies adopted by Long (1983) and Tarone (1981) were examined. Those features found in learners' negotiation were categorized into two processes, comprehension and production. That is, the strategies used by learners when they have the role of addressee are conventionally called 'comprehension strategies', while those used by learners when they have the role of addresser are 'production strategies.'

Interaction strategies. In this study, the following four comprehension strategies and seven production strategies were counted. (See Appendix $\mathrm{C}-2$ for a coding sample.) 
Comprehension Strategies:

1. Clarification requests

2. Confirmation checks

3. Expansions

4. Other completions

Production Strategies:

1. Comprehension checks

2. Repetitions/rephrases

3. Indication of difficulty in production

4. Verification requests

5. Use of $\mathrm{LI}$

6. Avoidance

a. non-verbal (silence)

b. incompletion

c. declining to respond

7. Long initial pauses

Definitions. Most definitions of interaction strategies were adopted from Pica and Doughty (1985), who refined Long's (1983) definitions of interactional modifications to include non-native speakers' roles in negotiation. Additionally, from Tarone's (1981) categories of communication strategies, some overtly observable strategies were included. Also, some definitions were moäifications of those used in previous studies. An extralinguistic feature, use of long initial pauses, was frequently observed in the data, so it was also included in the interaction analysis in this study. The definition of each strategy is presented with several examples below.

\section{Comprehension Strategies}

I. Clarification requests: "all expressions designed to elicit clarification of the preceding utterance(s), and consisting of wh-, yes-no, uninverted intonation, and tag questions, as well as statements such as 'I don't understand' or 'Try again'" (Pica and Doughty, 1985, p. I19) e.g. I beg your pardon? Um? 
2. Confirmation checks: "elicitations immediately following the previous speaker's utterance to confirm that the utterance has been understood or heard correctly. They are characterized with rising intonation of all or part of the speaker's preceding utterance." (Pica and Doughty, 1985, p. 120)

e.g. NS: where are you from?

J3: Where?

NS: Uh huh.

J3: I'm from Chiba.

3. Expansions: another type of strategy usd to confirm the previous utterance(s) by "supplying missing formatives or by adding new semantic information" (Ellis, 1985, p. 136)

e.g. NS: What do you usually do when you have free time?

\section{J4: Weekend or after school?}

4. Other completions: "utterances by the addressee which interrupted an immediately preceding utterance or occurred immediately after an utterance left incomplete through rising intonation and/or pause" (Pica and Doughty, $1985, \mathrm{p} .121)$

e.g. J4: Maybe .. they are, they are working umm .. for..

J2: Factory?

J4: Yeah, factory, factory.

\section{Production Strategies}

1. Comprehension checks: "expressions designed to establish whether the speaker's own preceding utterance has been understood by the addressee" (Pica and Doughty, 1985, p. 120)

$$
\begin{gathered}
\text { e.g. Do you understand? (explicit) } \\
\text { You know? OK? }
\end{gathered}
$$

2. Repetitions/rephrases: "partial or complete, and exact or semantic repetition (i.e., paraphrase) of any of the speaker's utterances which occurred within five conversation turns (by both speakers) of the turn containing the repetition" (Long, 1983, p. 138)

e.g. Ns: What do you sing?

J7: ( laugh) umm ... un ... maybe umm ah young, young singer.

NS: Young singer?

J7: Young singer, yeah. 
3. Indication of difficulty in production: explicit appeal for assistance by verbalizing difficulty e.g. I can't speak well.

What do you say ...?

4. Verification requests: implicit appeal for assistance with requests for affirmation or verification of an uncertain item using rising intonation

e.g. Ah, private schools? They wear uniform, 'uniform'?

5. Use of Ll: use of items in one's native language (LI) to substitute L2 items

e.g. (in a group-work discussion)

J2: I can, uh not not holiday, I can use (in Ll to J10) "yuukyuukyuuka" (lit: paid holiday) (laugh)

J4 and Ji0: (understand) Ahhh ..

J2: Um un I can, I can use ..

C: Oh, OK, I know, you can pick up the, pick the holiday?

J2: Yes.

C: And you can take the holiday ..

J2: I get pay-off.

6. Avoidance: reduction strategies to avoid taking risk in communicating in L2 including the following:

a. no-verbal (silence) -- the learner remains silent in an obligatory turn

e.g. NS: When will you go back to Japan? J5: Umm .. ah- .. I'm, I'm, I don't decide.

NS: you haven't decided yet?

J5: Yeah.

NS: Do you have some ideas? You want to start your own business? or ...

J5: (silence)

NS: You don't have any ideas? You don't know?

J5: No.

b. incompletion -- the learner begins to talk but stops in mid-utterance e.g. (in a group discussion, topic: holiday)

A2: And in Japan?

J5: Yeah, we have many ...

A2: Uh huh.

J3: Holiday. 


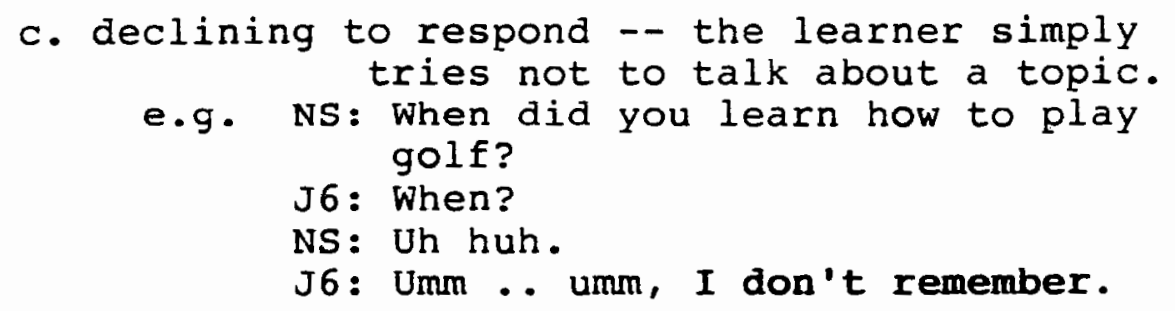

7. Long initial pauses: nonlinguistic fillers or pauses lasting more than 2 seconds at the beginning of a turn

e.g. NS: And then, what do you do?

J7: Ah-n ... go back to Japan.

Avoidance and long initial pauses are reduction strategies. They are strategies because they indicate certain difficulty in production and they may trigger the addressee's assistance. However, compared to other interaction strategies, avoidance and long initial pauses are less communicative.

In contrast, repetitions/rephrases are more communicative than reduction strategies, because the addressee can get some verbal cues from the speaker. Initial fillers (e.g., 'well', 'Let's see') are more communicative than long pauses. An explicit appeal for assistance (e.g., 'what do you call a shop where you buy meat?') may be more communicative.

Inter-rater Reliability

To determine the inter-rater reliability of coding frequency in terms of the syntactic and interactional features, a random sample from the transcripts in each of the three settings was coded by another TESOL M.A. 
student. Each segment contained approximately one third of a 9-minute segment used for analysis in this study. Each sample was coded according to five syntactic features (i.e., number of turns, words, s-nodes, words in $\mathrm{s}$-nodes, and fragments) and the eleven interactional features listed in the previous section. Agreement between the two coders for the syntactic features was .97 , and reliability ranged from .93 on $s$-nodes to 1.00 on turns and words. Agreement between the coders for the interactional features was .63 ; and reliablity showed .50 on avoidance strategies, .63 on repetitions/rephrases, and 1.00 on the rest (except confirmation checks, other completions, and use of LI, which did not appear in the sample).

Tests for Statistical Analyses

Quantitative analyses of both syntactic features and interactional features were examined from three perspectives using the following statistical tests.

1. comparison between Japanese (JP) learners and non-Japanese (NJP) learners -- the unpaired t-test and the Mann-Whitney $\mathrm{U}$ test

2. JP learners' features across the three settings -- the paired t-test and the wilcoxon test

3. overall effect of variables on features -- ANOVA

For the first and second sections, two types of tests were used for the following reasons. The t-test is a parametric test. The Mann-Whitney $U$ test is a non-parametric 
test that is analogous to the 'unpaired' t-test; and the wilcoxon test is also a non-parametric test that is equivalent to the 'paired' t-test. Because of the type of data in this study, non-parametric tests are statistically appropriate. However, due to the fact that the t-test is frequently used for an analysis of speech data in SLA studies, for both readers' convenience and for the purpose of comparison with previous findings, the t-test was used, as well as the two non-parametric tests. Alpha level for all statistical decisions was set at $p<.05$; and in all the tables in this study, statistically significant differences were marked with an asterisk.

Analysis of Interview Results

To answer the third and final research question, why do Japanese learners speak less and take fewer turns in the classroom, results of interviews with the Japanese learners and their ESI teachers were examined, focusing on Japanese learners' avoidance behavior in the teacherfronted class. Reasons for their silence were analyzed according to the results of interviews with the learners. The analysis of the interview results is descriptive and qualitative, without any statistical analysis.

\section{SUMMARY}

This study was aimed at investigating the characteristics of oral behavior of Japanese ESL learners 
in different settings, by comparing it to that of non-Japanese learners who were active participants in class. Three main foci of this study were: 1) amount and complexity of production, 2) amount and types of interaction strategies, and 3) reasons for their silence. Interactions in the three settings were audio and videotaped, transcribed, and coded using two categories: syntactic features (e.g., number of words and s-nodes) and interactional features (i.e., interaction strategies such as confirmation checks, avoidance, long initial pauses). Also, to investigate reasons for Japanese learners' silence in the classroom, the learners were interviewed in Japanese. Chapter IV presents results of syntactic analysis. Chapter $V$ exposes results of interaction analysis. Chapter VI introduces results of interviews. 


\section{CHAPTER IV}

\section{RESULTS AND DISCUSSION OF SYNTACTIC ANALYSIS}

Results of this study are presented and discussed in three separate chapters: Chapter IV syntactic analysis, Chapter $V$ interaction analysis, and Chapter VI interview results. This chapter and the following present results of statistical analyses on the production/interaction of Japanese (JP) learners in contrast to those of non-Japanese (NJP) learners in three settings; teacher-fronted (TF), group work (GV), and NS-NNS conversation (NS). Thus, two types of dependent variables, ethnicity and setting, were investigated in the statistical analyses. Chapter VI is a qualitative analysis (content analysis) of interview results. Transcription samples of the speech data in the three settings are shown in Appendix D, and raw frequencies of features used for statistical analyses are found in Appendix $\mathrm{E}$.

In this chapter, results of syntactic analysis are reported. As it has been explained in Chapter III (Nethod), the syntactic analysis focuses on amount of talk (measured by such as number of turns and words) and complexity of talk (measured by such as number of $\mathrm{S}$-nodes and fragments). 
The results of syntactic analysis are presented in three perspectives: 1) comparison between Japanese learners and non-Japanese learners in each setting, 2) comparison of settings for effect on syntactic features of JP learners, and 3) overall comparison of both ethnicity and settings and interaction between two dependent variables.

The unpaired t-test and the Mann-Whitney $U$ test were used to compare JP and NJP, and the paired t-test and the wilcoxon test were used to compare two settings at a time. To analyze overall effect of variables, ANOVA was used. A criterion level for all statistical decisions was set at $p<.05$. In all of the following tables, statistically significant differences are marked with an asterisk. Raw frequencies of syntactic features are shown in Appendix E-1.

COMPARISON OF JP VS. NJP IN EACH SETTING

Overall, JP produced significantly fewer words and less complex utterances than did NJP in all three settings. However, in terms of number of turns, JP had a smaller number only in the TF setting and statistically a larger number in the NS setting, than did NJP.

Teacher-fronted

Table III shows amount of talk as examined by the mean total number of the turns and words and the mean average number of words per turn in 9 minutes in the 
TABLE III

JP VS. NJP: AMOUNT OF TALK IN TE

\begin{tabular}{|c|c|c|c|c|c|c|}
\hline \multirow[b]{2}{*}{ Measure } & \multicolumn{2}{|c|}{ JP } & \multicolumn{2}{|c|}{$\overline{N J P}$} & \multirow{2}{*}{$\begin{array}{l}t \text { value } \\
\mathrm{p} \text { level }\end{array}$} & \multirow{2}{*}{$\begin{array}{l}\mathrm{U} \text { value } \\
\mathrm{p} \text { level }\end{array}$} \\
\hline & $\bar{M}$ & $\overline{S D}$ & $\overline{\mathrm{M}}$ & $\overline{S D}$ & & \\
\hline Total turns & $\begin{array}{l}1.38 \\
(1-2)\end{array}$ & .52 & $\begin{array}{c}18.5 \\
(10-26)\end{array}$ & 6.61 & $\begin{array}{l}t=7.67 \\
p=.0001\end{array}$ & $\begin{array}{l}U=32 \\
p=.0045 *\end{array}$ \\
\hline Total words & $\begin{array}{l}1.38 \\
(1-2)\end{array}$ & .52 & $\begin{array}{c}37 \\
(24-51)\end{array}$ & 12.62 & $\begin{array}{l}t=8.4 \\
p=.0001 *\end{array}$ & $\begin{array}{l}U=32 \\
p=.0045 *\end{array}$ \\
\hline Words/turn & 1 & 0 & 2.12 & .73 & $\begin{array}{l}t=4.57 \\
p=.001\end{array}$ * & $\begin{array}{l}\mathrm{U}=32 \\
\mathrm{p}=.0012 *\end{array}$ \\
\hline
\end{tabular}

teacher-fronted (TF) setting. Not surprisingly, JP took

fewer turns and produced fewer words than NJP. The total words of JP ranged from 1 to 2 and the mean number of words was approximately 1 , whereas the total words of NJP ranged from 24 to 51 and the mean of the total words was 37. Thus, significant differences in amount of talk in TF between JP and NJP were found in both total turns and total words. A significant difference between JP and NJP was also found in number of words per turn. Table IV shows complexity of talk of JP and NJP as measured by features of S-nodes and fragments. Again, significant differences were found. JP produced no s-nodes whereas NJP produced a mean of $4 \mathrm{~s}$-nodes. Also, JP produced fewer total fragments than NJP (approximately l vs. 19). Findings indicate that JP produced less complex speech than NJP. 
TABLE IV

JP VS. NJP: COMPLEXITY OF TALK IN TF

\begin{tabular}{|c|c|c|c|c|c|c|}
\hline \multirow[b]{2}{*}{ Measure } & \multicolumn{2}{|c|}{ JP } & \multicolumn{2}{|c|}{ NJP } & \multirow{2}{*}{$\begin{array}{l}t \text { value } \\
p \text { level }\end{array}$} & \multirow{2}{*}{$\begin{array}{l}\text { U value } \\
\mathrm{p} \text { level }\end{array}$} \\
\hline & $\bar{M}$ & $S D$ & $\bar{M}$ & $S D$ & & \\
\hline Total s-nodes & 0 & 0 & 4 & 2.16 & $\begin{array}{l}t=5.52 \\
p=.0003 *\end{array}$ & $\begin{array}{l}U=32 \\
p=.0012 *\end{array}$ \\
\hline $\begin{array}{l}\text { Total words in } \\
\text { s-nodes }\end{array}$ & 0 & 0 & 17.25 & 10.31 & $\begin{array}{l}t=4.99 \\
p=.0005^{\star}\end{array}$ & $\begin{array}{l}U=32 \\
p=.0012 *\end{array}$ \\
\hline Total fragments & 1.38 & .52 & 19.75 & 9.29 & $\begin{array}{l}t=5.88 \\
p=.0002 \star\end{array}$ & $\begin{array}{l}U=32 \\
p=.0045 \star\end{array}$ \\
\hline $\begin{array}{l}\text { Avg } s \text {-nodes } \\
\text { per turn }\end{array}$ & 0 & 0 & .25 & .19 & $\begin{array}{l}t=3.89 \\
p=.003\end{array}$ * & $\begin{array}{l}U=32 \\
p=.0012 *\end{array}$ \\
\hline $\begin{array}{l}\text { Avg fragments } \\
\text { per turn }\end{array}$ & 1 & 0 & 1.02 & .21 & $\begin{array}{l}t=.27 \\
p=.7948\end{array}$ & $\begin{array}{l}U=24 \\
p=.1059\end{array}$ \\
\hline
\end{tabular}

Table $V$ shows proportions of words consisting of S-nodes and fragments in total words. In JP's utterances $0 \%$ of words were in 5 -nodes and $100 \%$ in fragments, while in NJP's $45 \%$ of words were in 5 -nodes and $55 \%$ in fragments. These differences between JP and NJP were statistically significant.

TABLE V

JP VS. NJP IN TF: PROPORTION OF WORDS IN S-NODES AND FRAGMENTS

\begin{tabular}{|c|c|c|c|c|c|c|}
\hline \multirow[b]{2}{*}{ Measure } & \multicolumn{2}{|c|}{$\mathrm{JP}$} & \multicolumn{2}{|c|}{ NKP } & \multirow{2}{*}{$\begin{array}{l}t \text { value } \\
p \text { level }\end{array}$} & \multirow{2}{*}{$\begin{array}{l}\text { U value } \\
\text { p level }\end{array}$} \\
\hline & $\mathrm{M}$ & $S D$ & $\mathrm{M}$ & SD & & \\
\hline Words in $s$-node & $S 0 \%$ & 0 & $45 \%$ & 26 & $\begin{array}{l}t=5.28 \\
p=.0004 *\end{array}$ & $\begin{array}{l}U=32 \\
P=.0012 \text { * }\end{array}$ \\
\hline Fragments & 1008 & 0 & $55 \%$ & 26 & $\begin{array}{l}t=5.28 \\
p=.0004^{\star}\end{array}$ & $\begin{array}{l}U=32 \\
p=.0012^{*}\end{array}$ \\
\hline
\end{tabular}

The results of syntactic features shown through Table III to $\mathrm{V}$ indicate that JP produced only 'one-word' utterances and much fewer words than NJP in the TF setting. 
Group Work

As Table VI indicates, the means of turns of JP and NJP in the GW setting were not significantly different. However, again, JP produced significantly fewer total words than NJP (approximately 127 vs. 467).

TABLE VI

JP VS. NJP: AMOUNT OF TALK IN GW

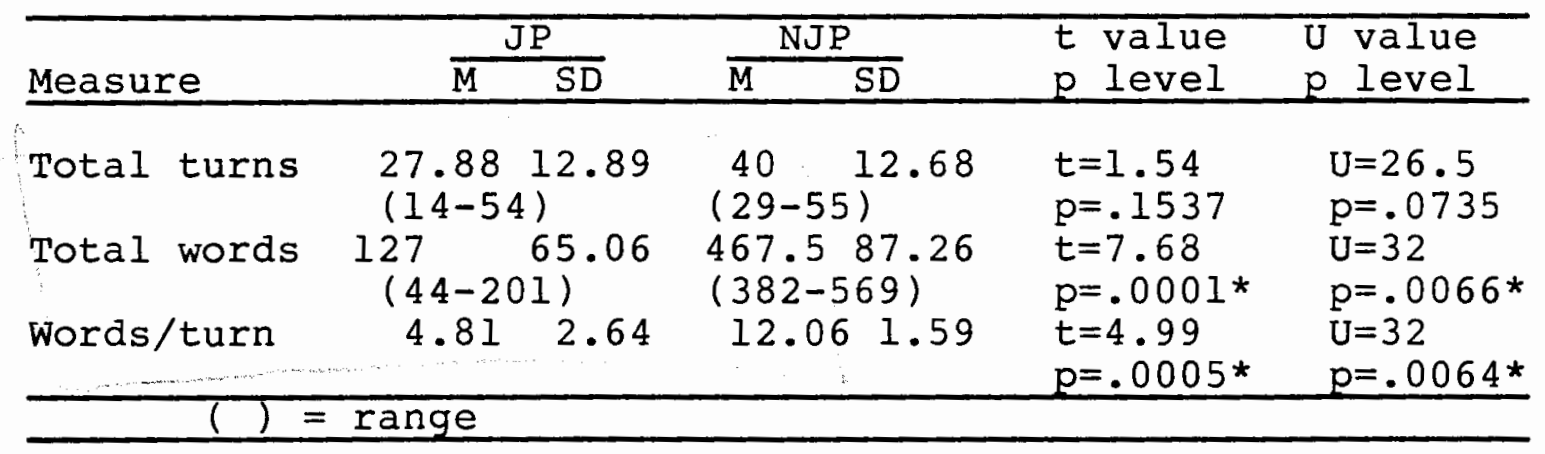

Table VII shows complexity of talk in GW as measured by numbers of $s-n o d e s$, words in $s$-nodes and fragments. Results from both the t-test and $U$ test indicate that the utterances produced by JP were significantly less complex than NJP. These significant differences are reflected in the ranges of both groups presented in parentheses in Table VII (e.g., for total words in s-nodes, $J P=4-93$ vs. NJP $=273-308)$. Although the difference for the average number of fragments was not significant, it showed a strong trend of JP<NJP $(\mathrm{p}=.0512)$. Thus, in $\mathrm{GW}$ as well as in TF, JP produced fewer $S$-nodes and fewer fragments than NJP; in other words, JP's discourse was both briefer and much less complex than NJP's. 
TABLE VII

JP VS. NJP: COHPLEXITY OF TALK IN GW

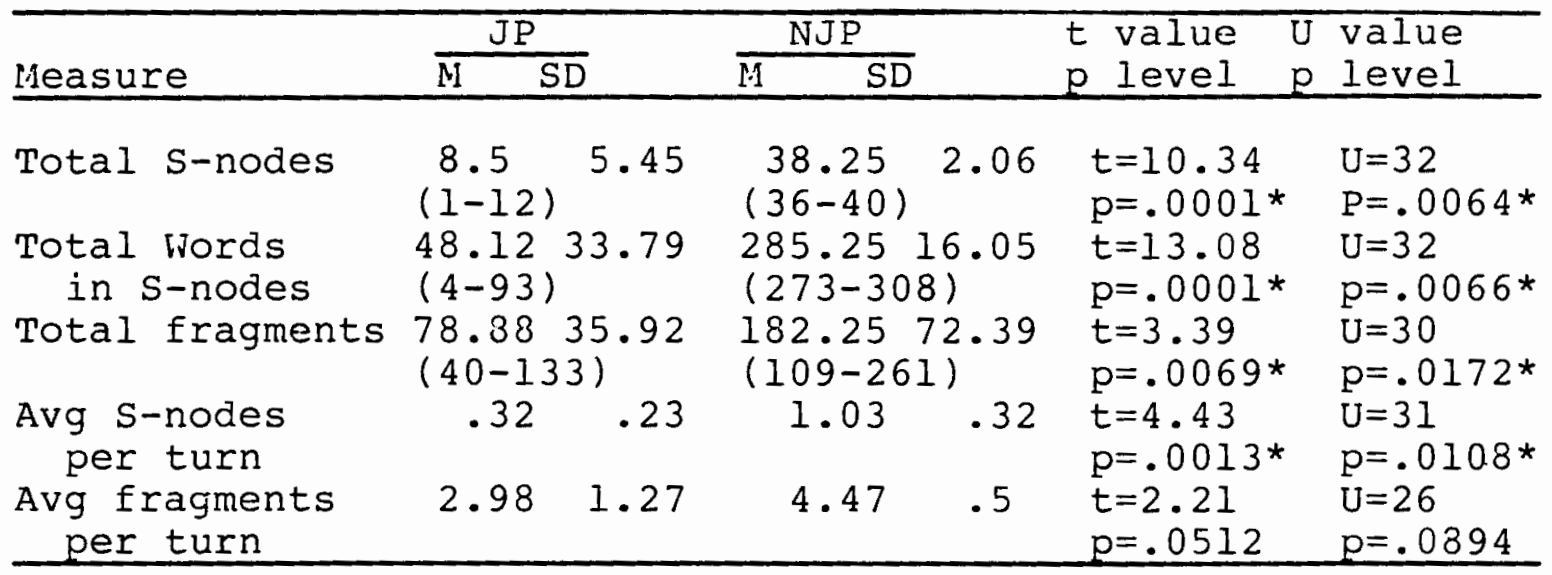

Table VIII shows the relative proportion of vords contained in S-nodes and fragments. In JP discourse, $33 \%$ of total words were found in S-nodes and $67 \%$ in fragments, while in NJP discourse, the reverse was true: $62 \%$ of vords were in s-nodes and $38 \%$ in fragments. The differences were significant.

\section{TARLE VIII}

JP VS. NJP IN GW: PROPORTION OF WORDS IN S-NODES AND FRAGIIENTS

\begin{tabular}{|c|c|c|c|c|c|c|}
\hline \multirow[b]{2}{*}{ Measure } & \multicolumn{2}{|c|}{ JP } & \multicolumn{2}{|c|}{ NJP } & \multirow{2}{*}{$\begin{array}{l}t \text { value } \\
p \text { level }\end{array}$} & \multirow{2}{*}{$\begin{array}{l}\text { U value } \\
\mathrm{p} \text { level }\end{array}$} \\
\hline & $\bar{M}$ & $\overline{S D}$ & II & $\overline{\mathrm{SD}}$ & & \\
\hline $\begin{array}{l}\text { Words in } \\
S-\text {-nodes }\end{array}$ & $33 \%$ & 16 & $62 \%$ & 8 & $\begin{array}{l}t=3.34 \\
p=.0074 \text { * }\end{array}$ & $\begin{array}{l}U=31 \\
p=.0108 *\end{array}$ \\
\hline Fragments & $67 \%$ & 16 & $38 \%$ & 8 & $\begin{array}{l}t=3.34 \\
p=.0074 *\end{array}$ & $\begin{array}{l}U=31 \\
p=.0108 *\end{array}$ \\
\hline
\end{tabular}




\section{NS-NNS Conversation}

Table IX presents the results of amount of talk in NS-NNS conversation (NS) setting. The mean number of turns of $J P$ in this setting was significantly greater than that of NJP ( 88 vs. 53), and the difference was statistically significant. However, with regard to the average number of words per turn, each turn taken by JP contained less than half as many words as did the turns taken by NJP ( 6 vs. 16). Thus, the length of JP's discourse in each turn was much shorter than that of NJP's.

TABLE IX

JP VS. NJP: AMOUNT OF TALK IN NS

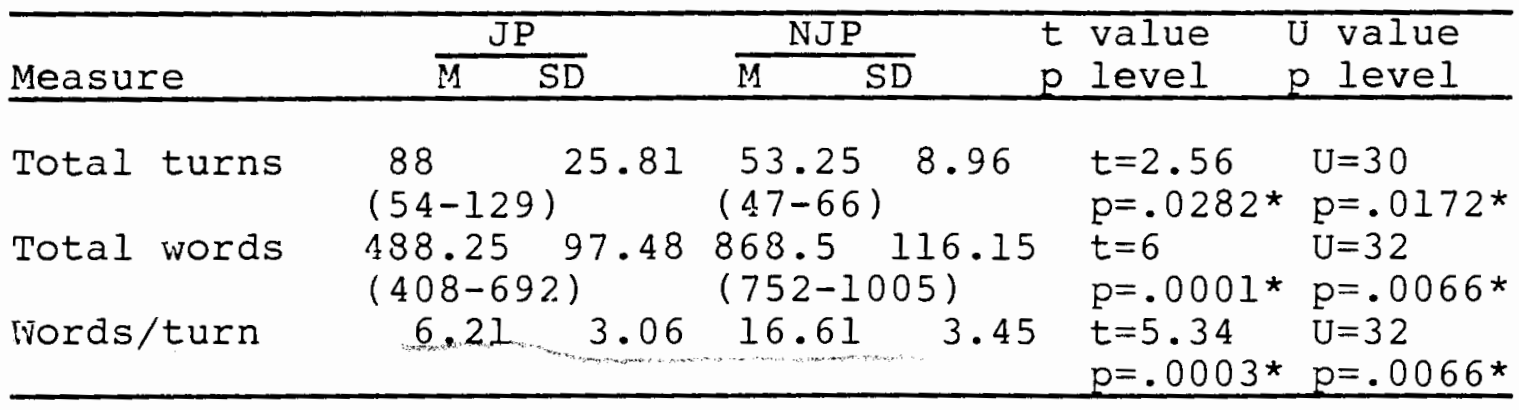

Table $X$ presents complexity of talk in the NS setting. While JP produced significantly fewer s-nodes than NJP (approximately 46 vs. 25), both JP and NJP produced an almost equal total number of fragments (225 vs. 256). The average number of $S$-nodes per turn of JP was 0.59 , whereas that of NJP was 1.63. The syntactic complexity of JP in the NS setting was, again, less complicated than that of NJP. 
TABLE X

JP VS. NJP: COMPLEXITY OF TALK IN NS

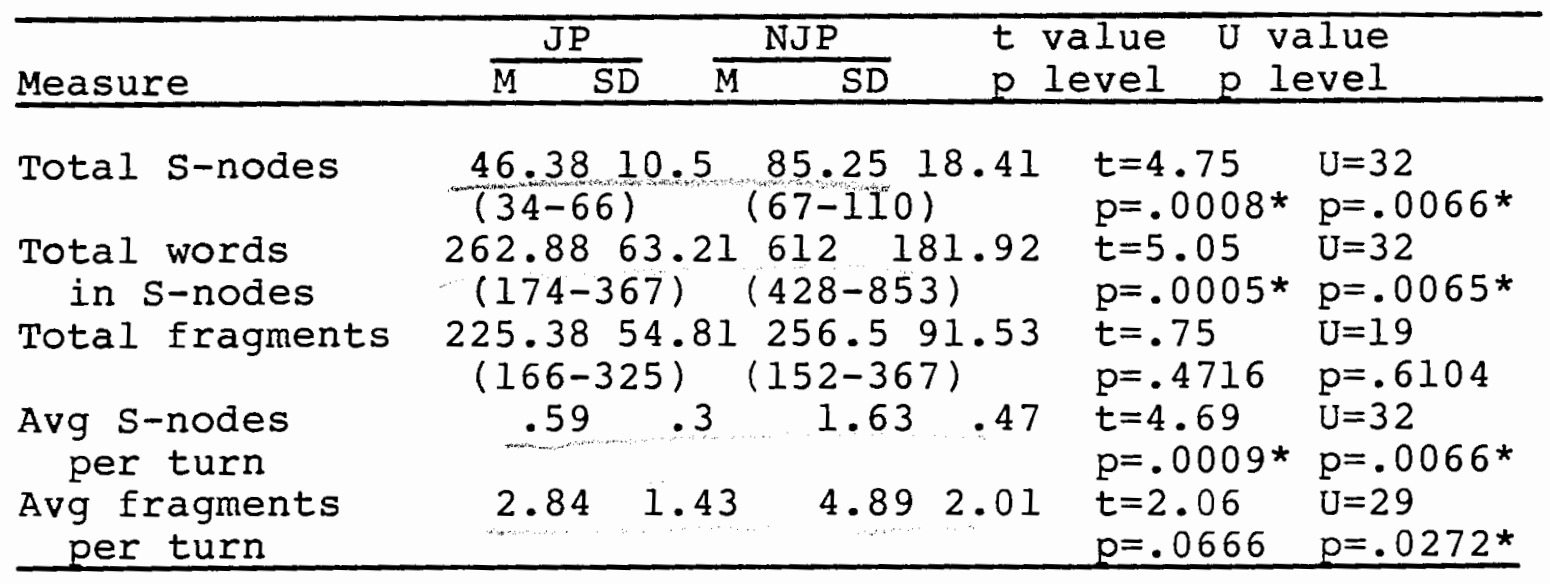

Table XI shows proportion of S-nodes (by words) and fragments in total words. In JP's discourse, proportion of words in s-nodes averaged $54 \%$, while in NJP's $71 \%$; and proportion of fragments was $46 \%$, while in NJP $30 \%$. The results of the t-test show significant differences $(p=.0187)$, and those of the $U$ test show a great trend, but not significant $(p=.0617)$.

\section{TABLE XI}

JP VS. NJP IN NS: PROPORTION OF

WORDS IN S-NODES AND FRAGMENTS

\begin{tabular}{|c|c|c|c|c|c|c|}
\hline \multirow[b]{2}{*}{ Measure } & \multicolumn{2}{|c|}{$\mathrm{JP}$} & \multicolumn{2}{|c|}{ NJP } & \multirow{2}{*}{$\begin{array}{l}t \text { value } \\
p \text { level }\end{array}$} & \multirow{2}{*}{$\begin{array}{l}U \text { value } \\
p \text { level }\end{array}$} \\
\hline & $M$ & $\bar{S} D$ & $\bar{M}$ & $\overline{S D}$ & & \\
\hline $\begin{array}{l}\text { Words in } \\
\text { s-nodes }\end{array}$ & $54 \%$ & 7 & $70 \%$ & 13 & $\begin{array}{l}t=2.8 \\
p=.0187 *\end{array}$ & $\begin{array}{l}U=27 \\
P=.0617\end{array}$ \\
\hline Fragments & $46 \%$ & 7 & $30 \%$ & 13 & $\begin{array}{l}t=2.8 \\
p=.0187 *\end{array}$ & $\begin{array}{l}U=27 \\
p=.0617\end{array}$ \\
\hline
\end{tabular}

In sum, except for the total number of turns, JP produced less amount of talk and less complex talk in 
the NS-NNS setting compared to NJP.

\section{SYNTACTIC FEATURES OF JP \\ ACROSS THREE SETTINGS}

In this section, Japanese (JP) learners' production is examined across three settings. Table XII shows a summary of JP's mean syntactic features in 9 minutes from each setting and results of comparison of settings. For statistical analysis, the paired t-test and the Wilcoxon test, which is a non-parametric test equivalent to the t-test, were applied. Because the two tests showed highly parallel results, for convenience, only the results of the t-test are presented in the table.

\section{TABLE XII}

SUMIMARY OF MEANS OF JP'S SYNTACTIC FEATURES ACROSS THREE SETTINGS

\begin{tabular}{|c|c|c|c|c|c|c|}
\hline \multirow[b]{2}{*}{ Variables } & \multicolumn{6}{|c|}{ Means } \\
\hline & $\overline{T F}$ & $\mathrm{GW}$ & $\mathrm{NS}$ & $\mathrm{TF} / \mathrm{GW}$ & GW/NS & $T F / N S$ \\
\hline Turns & 1.38 & 27.83 & 88 & $\begin{array}{l}t=4.38 \\
p=.0119 *\end{array}$ & $\begin{array}{l}t=3.43 \\
p=.0266 *\end{array}$ & $\begin{array}{l}t=8.19 \\
p=.0012 \text { * }\end{array}$ \\
\hline Woras & 1.38 & 127 & 488.25 & $\begin{array}{l}t=4.07 \\
p=.0153 *\end{array}$ & $\begin{array}{l}t=10.58 \\
p=.0005 *\end{array}$ & $\begin{array}{l}t=9.49 \\
p=.0007 *\end{array}$ \\
\hline S-nodes & 0 & 8.5 & 46.3 & $\begin{array}{l}t=3.2 \\
p=.0328 *\end{array}$ & $\begin{array}{l}t=11.37 \\
p=.0003 *\end{array}$ & $\begin{array}{l}t=10.86 \\
p=.0004\end{array}$ \\
\hline $\begin{array}{l}\text { Words in } \\
S \text {-nodes }\end{array}$ & 0 & 48.12 & 262.88 & $\begin{array}{l}t=2.88 \\
p=.045\end{array}$ * & $\begin{array}{l}t=9.05 \\
p=.0008\end{array}$ & $\begin{array}{l}t=10.11 \\
p=.0005 *\end{array}$ \\
\hline Fragments & 1.38 & 78.8 & 225.38 & $\begin{array}{l}t=4.37 \\
p=.0119 *\end{array}$ & $\begin{array}{l}t=13.27 \\
p=.0002 *\end{array}$ & $\begin{array}{l}t=8.67 \\
p=.001\end{array}$ \\
\hline
\end{tabular}

Results indicate that JP learners' production significantly increased in the order of $\mathrm{TF}<\mathrm{GW}<\mathrm{NS}$. Also, JP's discourse became more complex in the same order. 
Thus, the results show that setting had a strong effect on JP's amount of talk and complexity of talk.

\section{OVERALL EFFECT OF ETHNICITY AND SETTING ON SYNTACTIC FEATURES}

Because of the large amount of data generated by the subjects in three settings, ANOVA was applied for only a subset of measures: total turns, total words, total $\mathrm{S}$-nodes, words in $\mathrm{S}$-nodes, and fragments. In ANOVA analysis, the data of five Japanese learners and three non-Japanese were used, because those were consistently available across three settings (i.e., JP $n=5$ and $N J P n=3$ ).

Results of ANOVA on total turns are reported in table XIII. The main effect of ethnicity was not significant $(p=.5568)$. For setting, however, there was a significant main effect on the total turns $(p=.0001)$. Also, the twoway interaction of ethnicity and setting was found to be significant $(p=.0336)$. Thus, in terms of total turns, setting accounts for more variation in the number of turns than ethnicity. In other words, the overall difference

\section{TABLE XIII}

ANOVA DEPENDENT MEASURE: TOTAL TURNS

Source

Main effects

JP VS. NJP

settings

Two-way interaction 1644.072

\section{SS}

DF

MS

F

Significance 
in total turns between JP and NJP was not significant; but the overall difference in total turns by both JP and NJP in different settings was significant.

Table XIV presents ANOVA results on total words.

According to the $\mathrm{p}$ levels shown in the table, both ethnicity and setting are responsible for a significant amount of variation (JP vs. NJP, $p=.0004$; settings, $p=.0001$ ). Also, a significant two-way interaction effect was found $(p=.0007)$.

TABLE XIV

ANOVA DEPENDENT MEASURE: TOTAL WORDS

Source SS DF MS Significance

Main effects

$\begin{array}{lcllrl}\text { JP VS. NJP } & 395678.4 & 1 & 395678.4 & 51.36 & .0004 * \\ \text { settings } & 1706953.08 & 2 & 853476.54 & 156.13 & .0001 \text { * }\end{array}$
Two-way interaction

$\begin{array}{lllll}154918.74 & 2 & 77459.37 & 14.17 & .0007^{*}\end{array}$

Tables XV through XVII show ANOVA results on total S-nodes, words in S-nodes, and fragments, which were chosen as indicators of complexity of talk. The results show that, except on the measure of fragments, there is a significant main effect of ethnicity on the values for the measures of $S$-nodes and words in $S$-nodes across settings $(p=.0012$ and $p=.001$ respectively). And the tests found that another main effect, setting, had a strong effect on these dependent variables. Thus, regardless of ethnicity, the subjects produced more $S$-nodes and more fragments in the order of $\mathrm{TF}<\mathrm{GW}<\mathrm{NS}$. A significant two-way 
interaction of ethnicity and setting was also found in the analysis of each measure.

TABLE XV

ANOVA DEPENDENT MEASURE: TOTAL S-NODES

\begin{tabular}{|c|c|c|c|c|c|}
\hline Source & SS & $\overline{\mathrm{DF}}$ & MS & $\mathrm{Si}$ & ificance \\
\hline effects & & & & & \\
\hline $\begin{array}{l}\text { JP vs. NJP } \\
\text { settings }\end{array}$ & $\begin{array}{c}3097.6 \\
16723.08\end{array}$ & $\begin{array}{l}1 \\
2\end{array}$ & $\begin{array}{l}3097.6 \\
8361.54\end{array}$ & $\begin{array}{r}32.66 \\
106.08\end{array}$ & $\begin{array}{l}.0012 * \\
.0001 *\end{array}$ \\
\hline Two-way interaction & 722772 & 2 & 67086 & 775 & $0069 *$ \\
\hline & $1<21 \cdot 72$ & & 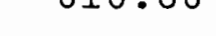 & נו. & 800 \\
\hline
\end{tabular}

TABLE XVI

ANOVA DEPENDENT MEASURE: WORDS IN S-NODES

\begin{tabular}{|c|c|c|c|c|c|}
\hline Source & SS & $\overline{D F}$ & MS & $F$ & \\
\hline
\end{tabular}

Main effects

JP Vs. NJP

setting

234651.34

$1 \quad 234651.34$

$35.93 .001 *$

Two-way interaction

$114505.04257252 .52 \quad 9.43 \quad .0035^{*}$

TABLE XVII

ANOVA DEPENDENT MEASURE: FRAGMENTS

\begin{tabular}{|c|c|c|c|c|c|}
\hline Source & SS & $D F$ & MS & $F$ & Significance \\
\hline
\end{tabular}

Main effects

JP vs. NJP

settings

$$
20915.38 \quad 1 \quad 20915.38
$$

$3.83 \quad .0982$

$224202.582112101 .29 \quad 69.38 \quad .0001 *$

Two-way interaction

$$
13114.4426557 .22 \quad 4.06 \quad .0451 \text { * }
$$

A summary of means on syntactic features is reported in Table XVIII; that is, the summary of means of dependent measures according to the effect of two types of independent 
variables, ethnicity (JP vS. NJP) and setting (across TF, GW and NS).

TABIE XVIII

SUMMARY OF SYNTACTIC FEATURES

\begin{tabular}{llllll}
\hline $\begin{array}{l}\text { Independent } \\
\text { variables }\end{array}$ & $\begin{array}{l}\text { Total } \\
\text { turns }\end{array}$ & $\begin{array}{l}\text { Total } \\
\text { words }\end{array}$ & S-nodes & $\begin{array}{l}\text { Words in } \\
\text { S-nodes }\end{array}$ & Eragments \\
\hline $\begin{array}{l}\text { Ethnicity } \\
\text { JP }(n=5)\end{array}$ & 35.07 & 213.33 & 19.53 & 109.87 & 103.47 \\
NJP $(n=3)$ & 38.33 & 478.56 & 43 & 314.11 & 164.44 \\
Setting & & & & & \\
TF & 7.62 & 13 & 1.25 & 5.12 & 7.88 \\
GW & 34.88 & 264.5 & 19.62 & 138 & 126.5 \\
NS & 65.33 & 660.88 & 64.12 & 416.25 & 244.62 \\
\hline
\end{tabular}

The overall results on ethnicity in Table XVIII show that JP took almost equal total turns as iNJP did (approximately 35 vs. 38), but with regard to the rest of the features, JP produced approximately half the amount of talk and their discourse was much less complex than that of NJP.

The overall results on setting in the table inaicate that greater number of features were found in the sequence of $\mathrm{TF}<\mathrm{GW}<\mathrm{NS}$.

In summary, it was found that both independent variables significantly influenced outcomes on most dependent measures. Except for total turns, JP produced less speech than NJP, and both JP and NJP produced the least in the $\mathrm{TF}$ setting and the most in the NS-NNS setting. A significant interaction of ethnicity and setting was found for all 


\section{SUMMARY}

In the syntactic analysis of the Japanese learners' production, overall it was found that both ethnicity and setting had a strong effect on quantity and complexity of talk. In comparisons with NJP, JP generally produced fewer words, S-nodes, average words per s-nodes, and fragments, with significant differences. The results seem to confirm a general assumption about 'quiet' Japanese learners in the classroom. However, interesting results were found with respect to number of turns. Although JP took significantly fewer turns in TF, statistically, they took an almost equal amount of turns in GW, and significantly more turns in NS-NNS, than NJP. The findings suggest that infrequent participation of JP may only be true in the TF setting.

In terms of complexity of utterances, it was found that both JP and NJP produced almost equal amounts of Eragments, but JP speech was proportionally more fragmented than NJP; i.e., NJP speech contained significantly more complete sentences than JP. These results suggest that JP learners' oral proficiency in spontaneous speech may be lower than NJP.

In the analysis of JP production across the three settings, it was found that the amount and complexity of JP production increased significantly in the order of $\mathrm{TF}<\mathrm{GW}<\mathrm{NS}$. For example, the number of words per turn 
in $\mathrm{TF}$ was approximately 1 ; in $\mathrm{GW}, 27$; and in NS, 88 . The number of words contained in s-nodes in TF was 0 ; in GW, 48; and in NS, 262. The differences across settings were all statistically significant.

These findings indicate that Japanese learners' oral proficiency may not be evaluated correctly in the teacher-fronted setting. In $\mathrm{GW}$ and NS, the JP learners were not silent. In these settings, the JP learners produced a significantly greater amount of talk and more complex utterances than they did in the TF setting. Although the overall proficiency of JP seems lower than that of NJP, the stereotype of Japanese learners as silent reflects their behavior only in the teacher-fronted situation. Their silence is situation specific. 
CHAPTER V

\section{RESULTS AND DISCUSSION OF INTERACTION ANALYSIS}

In this chapter, results of interaction analysis are reported and discussed in three sections: 1) JP vs. NJP in each of the three settings (teacher-fronted, group work, and NS-NNS dyad), 2) effect of setting on Japanese learners: interaction strategies, and 3) overall effect of ethnicity and setting. The unpaired t-test and the Mann-Whitney $U$ test were used to compare JP and NJP, and the paired t-test and the Wilcoxon test were used to compare two settings at a time. To analyze the overall effects of variables, ANOVA was used. A criterion level for significance was set at $p<.05$ for all statistical decisions. Summaries of raw frequencies of the interaction strategies produced by each subject are found in Appendices E-2 through E-4. Categories of interactional strategies are shown in Chapter III (Method, pp. 52-56).

\section{COMPARISON OF JP VS. NJP IN EACH SETTING}

In this section, interaction strategies used by JP and NJP are compared in each of the three settings. Overall, both groups produced fewer strategies in the 
teacher-fronted (TF) setting than in the group work (GW) or the NS-NNS (NS) conversation. More repetitions/rephrases were produced by NJP, whereas more avoidance and long initial pauses were used by JP.

Teacher-fronted.

In the TF setting, neither JP nor NJP produced any interaction strategies, except a small number of repetitions/rephrases. (See Appendix E-2 for the raw frequencies of interaction strategies in TF.) This finding confirms an assumption that very little negotiation occurs in the TF setting (e.g., Rulon \& McCreary, 1986).

Results of comparison of JP and NJP for repetitions/ rephrases are shown in Table XIX. JP produced fewer repetitions/rephrases than NJP (0.12 vs. 1.75), and the difference was statistically significant.

TABLE XIX

JP VS. NJP: REPETITIONS/REPHRASES IN TF

\begin{tabular}{|c|c|c|c|c|c|c|}
\hline \multirow[b]{2}{*}{ Measure } & \multicolumn{2}{|c|}{ JP } & \multicolumn{2}{|c|}{ NJP } & \multirow{2}{*}{$\begin{array}{l}t \text { value } \\
p \text { level }\end{array}$} & \multirow{2}{*}{$\begin{array}{l}\text { U value } \\
\text { p level }\end{array}$} \\
\hline & $\overline{\mathrm{M}}$ & $\overline{S D}$ & $\overline{\mathrm{M}}$ & $\overline{S D}$ & & \\
\hline $\begin{array}{c}\text { Repetitions/ } \\
\text { Rephrases }\end{array}$ & .12 & .35 & 1.75 & .5 & $\begin{array}{l}t=6.58 \\
p=.000 I^{*}\end{array}$ & $\begin{array}{l}U=31.5 \\
p=.003 *\end{array}$ \\
\hline
\end{tabular}

The results indicate that there was very little evidence for negotiation of meaning in the TF setting.

Group work

A summary of mean numbers of interaction strategies 
in the group work (GW) are reported in Table XX. Because both the t-test and the Mann-Whitney $U$ test showed parallel results, only results of the t-test are presented in the table. (See Appendix E-3 for the raw frequencies in GW.)

TABLE XX

SUMMARY OF MEAN FREQUENCIES

OF INTERACTION STRATEGIES IN GW

\section{Variables \\ Comprehension strategies}

M

SD

$t$ value

p level

Clarification requests

$\begin{array}{lllll}\text { JP } & .38 & .52 & .4 & .6987 \\ \text { NJP } & .25 & .5 & & \end{array}$

Confirmation checks

$\begin{array}{lllll}\text { JP } & 3.25 & 2.43 & .72 & .4853 \\ \text { NJP } & 4.75 & 4.92 & & \end{array}$

Expansions

$\begin{array}{lllll}\text { JP } & 2.12 & 1.96 & .78 & .4539 \\ \text { NJP } & 1.25 & 1.5 & & \end{array}$

Other completions

$\begin{array}{lllll}\text { JP } & .38 & .74 & 3.06 & .0121 \text { * } \\ \text { NJP } & 2.5 & 1.73 & & \end{array}$

Production Strategies

Comprehension checks

$\begin{array}{lllll}\text { JP } & .25 & .46 & 2.27 & .0463 \\ \text { NJP } & 2.75 & 3.2 & & \end{array}$

Repetitions/Rephrases

$\begin{array}{lcccc}\text { JP } & 5.5 & 3.66 & 3.16 & .0102 \\ \text { NJP } & 12.75 & 3.95 & & \end{array}$

Indication of difficulty

$\begin{array}{lllll}\text { JP } & .12 & .35 & 1.41 & .1877 \\ \text { NJP } & .5 & .58 & & \end{array}$

Verification requests

$\begin{array}{lllll}\text { ation requests } & & & & \\ \text { JP } & .38 & .52 & 1.64 & .1321 \\ \text { NJP } & 1 & .82 & & \end{array}$

Use of $\mathrm{LI}$

JP

NJP

$\begin{array}{llll}1.38 & 1.3 & 2.06 \quad .0663\end{array}$

Avoidance

$\begin{array}{lllll}\text { JP } & 1.88 & 1.89 & 1.94 & .0809 \\ \text { NJP } & 0 & 0 & & \end{array}$

Long initial pauses

$\begin{array}{lllll}\text { JP } & 1.25 & 1.16 & 1.61 & .1378 \\ \text { NJP } & .25 & .5 & & \end{array}$


Overall, not many significant differences between groups were found in the GW setting, but it was found that NJP had a significantly higher frequency of other completions, comprehension checks and repetitions/rephrases than JP and that JP produced more use of $\mathrm{Ll}$ and avoidance than NJP.

In terms of comprehension strategies in the GW setting, only a few clarification requests (e.g., 'What?', 'Try again') were produced by both JP and NJP ( 0.38 and 0.25 respectively). Instead, more implicit comprehension strategies such as confirmation checks (i.e., repetition of previous utterance) and expansions (i.e., adding semantic information to previous utterance) were found almost equally in the discourse of both groups. For all three strategies, there were no significant differences between groups. An interesting finding is that one type of repair strategy, other completions (i.e., assistance for other's production), was found only in learners' group-work discourse. A greater number of completions was produced by NJP than JP (2.5 vs. 0.38), and a significant difference was found. If it can be that completion strategies are often made by relatively dominant participants (e.g., Chinese students compared to Japanese students in Duff's 1986 study), this finding suggests that JP may have had less active roles in the group work.

With regard to production strategies, statistically 
significant differences between groups were found for two types of strategies: comprehension checks and repetitions/rephrases. Generally, JP produced many fewer such strategies than NJP. Comprehension checks were made less frequently by JP than NJP $(0.25$ vs. 2.75), and the difference was significant. Fewer repetitions/rephrases were made by JP than NJP ( 5.5 vs. 12.75$)$, with a significant difference.

Two types of appeal for assistance, indication of difficulty in production (e.g., 'I can't say') and verification requests (e.g., 'There are a lot of forest, forest?) rarely occurred in either JP or NJP discourse in GW. Instances of use of $\mathrm{Ll}$ and avoidance strategies were found in JP discourse, but never in NJP discourse. Differences were not statistically significant, but indicated a strong trend of JP NJP. More long initial pauses were used by JP than NJP ( 1.25 vs. 0.25$)$, but the difference was not significant.

To summarize the comparison of the two groups in the GW setting, the following should be noted. First, both JP and NJP produced an almost equal number of confirmation checks and expansions, but used very few clarification requests. Second, NJP produced more communicatively facilitative strategies than JP. That is, NJP made more completion of others, comprehension checks and repetitions/rephraes than JP, whereas JP had 
a higher frequency of use of Ll, avoidance and long initial pauses than NJP. The strategies used by NJP are more verbally productive; in other words, the strategies used by JP seem to be categorized into 'reduction strategies', which, according to Ellis (1985), are less facilitative for communication. This suggests that there may be a difference between $J P$ and NJP in the group work setting in terms of degree of dominance.

\section{NS-NNS Conversation}

A summary of mean frequencies of interaction strategies in the NS-NNS dyads is presented in Table XXI. Overall, it was found that JP used more confirmation checks, avoidance, and long initial pauses than did NJP; whereas NJP used more repetitions/rephrases than did JP. In this setting, JP produced more interaction strategies, except repetitions/rephrases strategy, than NJP. (Also see Appendix E-4 for the raw frequencies of strategies produced by each subject in NS.)

With respect to comprehension strategies, clarification requests were not made frequently by either group $(0.75$ and 0 , respectively), similar to the GW setting. JP produced more confirmation checks ( 4.75 vs. 0.25 ) and more verification requests ( 2 vs. 0.5) than NJP, although differences for the two features between groups were not statistically significant. Yet, although the t-test in the table shows nonsignificant $(p=.053)$ for confirmation 
TABLE XXI

SUMMARY OF MEAN FREQUENCIES

OF INTERACTION STRATEGIES IN NS

Variables M

SD

$t$ value

p level

\section{Comprehension Strategies}

Clarification strategies

$\begin{array}{lllll}\text { JP } & 0^{75} & .89 & 1.65 & .1297 \\ \text { NJP } & 0 & 0 & & \end{array}$

Confirmation checks

JP

NJP

Expansions

$\begin{array}{lclll}\text { JP } & 2 & 2.27 & 1.24 & .2432 \\ \text { NJP } & .5 & 1 & & \end{array}$

Production Strategies

$\begin{array}{llll}4.75 & 3.99 & 2.19 & .053\end{array}$

$.25 \quad .5$

$\begin{array}{rccc}.25 & .46 & 1.25 & .2389 \\ 1.75 & 3.5 & & \end{array}$

Repetitions/Rephrase

$\begin{array}{lllll}\text { JP } & .25 & .46 & 1.25 & .2389 \\ \text { NJP } & 1.75 & 3.5 & & \end{array}$

$\mathrm{JP}$

Indication of difficulty

$\mathrm{JP}$

NJP

$\begin{array}{llll}28.5 & 13.06 & 2.42 \quad .036 \\ 48.5 & 14.46 & \end{array}$

Verification requests

$\begin{array}{lllll}\text { JP } & 4.25 & 3.37 & 1.18 & .2666 \\ \text { NJP } & 2 & 2.45 & & \end{array}$

Use of $\mathrm{Ll}$

$\begin{array}{lllll}\text { JP } & 1.38 & 1.69 & .54 & .6018 \\ \text { NJP } & 2 & 2.31 & & \end{array}$

Avoidance

\begin{tabular}{lrrrr} 
JP & 2.37 & 2.07 & 1.98 & .0755 \\
NJP & .25 & .5 & & \\
itial pauses & & & & \\
JP & 13.88 & 7.1 & 3.09 & .0115 * \\
NJP & 2.25 & 2.87 & & \\
\hline
\end{tabular}

checks, the U test, which was applied as well, showed a significant difference $(U=29.5, p=.0185)$.

In terms of production strategies, JP had a significantly higher frequency of long initial pauses than NJP (approximately 13 vs. 2), while NJP produced 
more repetitions/rephrases than JP. In both cases, the differences between the two groups were significant. More avoidance strategies were used by JP than NJP (2.37 vs. 0.25). The difference was not statistically significant $(p=.0755)$, but showed a strong trend of JP $>$ NJP.

In summary, interestingly, JP produced more interaction strategies for negotiation of meaning in the NS-NNS setting than NJP. In previous studies, it was pointed out that less competent learners tend to depend on more strategies, especially reduction strategies (e.g. Ellis, 1984b). Findings in this study suggest that JP may have had more difficulty in comprehension/production than NJP. In other words, JP's oral proficiency in spontaneous speech seems to be less competent than NJP.

\section{INTERACTION STRATEGIES OF JP}

ACROSS THREE SETTINGS

In this section, interactional features of Japanese learners are analyzed across three settings. Summaries of JP's mean frequencies of interaction are reported in Table XXII (for comprehension strategies) and Table XXIII (for production strategies). For statistical analyses, the paired t-test and the Wilcoxon test were applied. When a difference between two test results occurred, the results of the wilcoxon test, a more accurate test for the data, were used for interpretation. 
by JP, shown in table XXII, indicates that very few clarification requests were found, regardless of setting (TF 0 , GW 0.38 , NS 0.75$)$. On the other hand, confirmation checks and expansions were made by JP in both GW and NS, but not in TF. For confirmation checks, the difference between $T F$ and $G W$ and difference between $T F$ and NS were statistically significant $(p<.05)$. For expansions, the difference between $T F$ and GW was significant, but the difference between $\mathrm{TF}$ and NS showed only a high tendency for $\mathrm{TF}<\mathrm{NS}(\mathrm{p}=.0656)$.

\section{TABLE XXII}

SUMMARY OF IIEANS OF JP'S COIPREHENSION STRATEGIES ACROSS THREE SETTINGS

\section{Variables}

Means

TF VS.GW GW VS. NS

TF Vs. NS

Clarification requests

$\begin{array}{lllll}\text { TF } & 0 & t=1.63 & t=1 & t=1.5 \\ \text { GW } & .38 & p=.1778 & p=.3739 & p=.208 \\ \text { NS } & .75 & W=1.41 & w=1 & W=1.34 \\ & & p=.1573 & p=.3173 & p=.1797\end{array}$

Confirmation checks

$\begin{array}{lllll}\text { TF } & 0 & t=5.25 & t=.36 & t=2.45 \\ \text { GW } & 3.25 & p=.0063 * & p=.7362 & p=.0705 \\ \text { NS } & 4.75 & W=2.03 & W=.36 & W=2.06 \\ & & p=.0422^{*} & p=.7362 & p=.0394 \text { * }\end{array}$

Expansion

$\begin{array}{lllll}\text { TF } & 0 & t=2.75 & \text { H } & t=2.27 \\ \text { GW } & 2.12 & p=.0514 & & p=.0858 \\ \text { NS } & 2 & W=2.06 & & \\ & & p=.0394 * & & p=.064 \\ & & & \end{array}$

it $=$ statistically no difference

Table XXIII presents the results of production strategies produced by JP in three settings. It shows 
TABLE XXIII

SUMMARY OF MEANS OF JP'S PRODUCTION STRATEIES ACROSS THREE SETTINGS

Variables

Means

Comprehension checks

$\begin{array}{lc}\text { TF } & 0 \\ \text { GW } & .25 \\ \text { NS } & .25 \\ & \\ \text { rs/Rephrases } \\ \text { TF } & .12 \\ \text { GW } & 5.5 \\ \text { NS } & 28.5\end{array}$

Indication of difficulty

$\begin{array}{ll}\text { TF } & 0 \\ \text { GW } & .12 \\ \text { NS } & .75\end{array}$

Verification requests

$\begin{array}{ll}\text { TF } & 0 \\ \text { GW } & .38 \\ \text { NS } & 4.25\end{array}$

Use of LI

$\begin{array}{ll}\text { TF } & 0 \\ \text { GW } & 1.38 \\ \text { NS } & 1.38\end{array}$

Avoidance

$\begin{array}{ll}\text { TF } & 0 \\ \text { GW } & 1.88 \\ \text { NS } & 2.37\end{array}$

Long initial pauses

$\begin{array}{ll}\text { TF } & 0 \\ \text { GW } & 1.25 \\ \text { NS } & 13.88\end{array}$

TF VS. GW

GW VS. NS

$t=1$

$\mathrm{p}=.3739$

$w=1$

$\mathrm{p}=.3173$
$\#$
$t=1$
$\mathrm{p}=.3739$
$\mathrm{W}=1$
$p=.3173$

$\begin{array}{lll}t=5.72 & t=4.38 & t=4.92 \\ p=.0046 * & p=.0119 * & p=.0079 * \\ W=2.03 & w=2.02 & w=2.02 \\ p=.0422 * & p=.0431 * & p=.0431 *\end{array}$

$t=1 \quad t=1$

$p=.3739 \quad p=.3739$

$\mathrm{W}=1 \quad \mathrm{~W}=1$

$p=.3173 \quad p=.3173$

$t=1.63$

$t=1.91$

$t=1.98$

$\mathrm{p}=.1778$

$\mathrm{W}=1.41$

$\mathrm{p}=.1293$

$\mathrm{W}=2.06$

$\mathrm{p}=.1191$

$p=.1573$

$p=.0394$ *

$\mathrm{W}=2.04$

$\mathrm{p}=.0412$ *

$t=3.14$

$t=.23$

$t=1.51$

$\mathrm{p}=.0349$ *

$\mathrm{p}=.8276$

$\mathrm{W}=.37$

$p=.2056$

$\mathrm{W}=1.84$

$\mathrm{p}=.7127$

$W=1.63$

$p=.0656$

$t=2.24$

$t=.23$

$p=.1025$

$\mathrm{p}=.089$

$\mathrm{w}=1.63$

$\mathrm{p}=.8303$

$w=.41$

$t=1.99$

$p=.1025$

$p=.6803$

$\mathrm{p}=.118$

$\mathrm{W}=1.84$

$p=.0656$

$t=2.24$

$t=3.21$

$t=3.16$

$\mathrm{p}=.089$

$\mathrm{W}=1.63$

$p=.0326$ *

$\mathrm{p}=.0341$ *

$\mathrm{W}=2.02$

$\mathrm{W}=2.02$

$p=1025$

$p=.0431 * p=.0431 *$

\section{\# = statistically no difference}

that, except a small number of repetitions/rephrases, JP used no interaction strategies in the TF setting. However, in terms of avoidance and long initial pause 
strategies in the TF setting, more detailed interpretation is required. Because these reduction strategies appear to be hidden in the TF setting, the statistical results for these in $T F$ seem to have little meaning. A common feature for these two strategies is characterized as 'silence', which can not easily be quantifiea. I observed that avoidance or long initial pause strategies seem to be used quite frequently by Japanese learners in the TF setting, but I found it difficult to count the frequencies of such reduction strategies in TF. The reason is that participation in $T F$ is not obligatory; that is, learners can take a role of listener in the teacher-class interaction. Thus, the data in Table XxIII reflect only overtly observable instances for avoidance, such as a solicited turn, but not instances that may be reported in later interviews of learners. For long initjal pauses, the same observation may be true. If learners hesitate for a few seconds in the $T F$ setting, they usually lose the floor for participation. Referring to "the amount of learning space" in the classroom, Stevick (1980) writes:

The student knows that he has perhaps 3 to 5 seconds in which to respond, before the teacher reasserts initiative by repeating the question, giving a hint, prompting, or calling on someone else. (pp. 20)

Although such cases were not found in the 9-minute segment of TF setting analyzed, it cannot be said only from the statistical results that JP produced more reduction 
strategies in GW or NS than TF. In this sense, statistical analysis for silence seems to reveal very little about what is actually going on with quiet learners.

Comprehension checks and indication of difficulty were, regardless of setting, rarely produced by JP. In the NS setting, to check whether that speaker's preceding utterance has been understood, JP produced more implicit checks, verification requests, using rising intonation. Significant differences were found in terms of verification requests between $\mathrm{NS}$ and $\mathrm{GW}$, and between NS and TF. An equal frequency of use of $\mathrm{Ll}$ was produced by JP in GW and NS. From my observation, if there are more than two JP participants in GW, they tend to speak Japanese, as shown in a sample transcription in Appendix D-2. However, in this statistical analysis, results showed no such significance.

OVERALL EEFECT OF ETHNICITY AND SETTING ON INTERACTION STRATEGIES

To examine overall effect of the two variables, 'ethnicity' (JP VS. iNJP) and 'setting' (TF, GW, and INS-NNS), the ANOVA tests were applied to three interaction strategies found to be frequently produced by JP; they are repetitions/rephrases, avoidance, and long initial pauses. A summary of the three interaction strategies is shown in Table XXIV. The table indicates that JP used more avoidance and long initial pauses than NJP, while 
NJP produced more repetitions/rephrases than JP. Also, the three strategies produced by both groups showed a higher frequency in the order of $\mathrm{TF}<\mathrm{GW}<\mathrm{NS}$.

TABLE XXIV

SUMMARY OF THREE INTERACTION STRATEGIES

\begin{tabular}{|c|c|c|c|}
\hline $\begin{array}{l}\text { Independent } \\
\text { variable }\end{array}$ & $\begin{array}{r}\text { Repetitions } \\
\text { /Rephrases } \\
\end{array}$ & Avoidance & $\begin{array}{c}\text { Long initial } \\
\text { pauses }\end{array}$ \\
\hline \multicolumn{4}{|l|}{ Ethnicity } \\
\hline JP $\quad(n=5)$ & 12.4 & 1.47 & 4.53 \\
\hline NJP $(n=3)$ & 22 & .11 & 1.11 \\
\hline \multicolumn{4}{|l|}{ setting } \\
\hline $\mathrm{TF}$ & .75 & 0 & 0 \\
\hline GW & 9.12 & 1.25 & .75 \\
\hline NS & 38.12 & 1.62 & 9 \\
\hline
\end{tabular}

Results of ANOVA dependent measure analyses are shown in Table XXV through XXVII. Overall, the results show that setting had a significant effect on the use of both repetitions/rephrases and long initial pauses, whereas ethnicity did on avoidance strategies.

Table XXV presents results for repetitions/rephrases. First, in terms of effect of ethnicity, JP made less use of this strategy than NJP, but the difference showed only

TABLE XXV

ANOVA DEPENDENT MEASURE: REPETITIONS/REPHRASES

\begin{tabular}{llllll} 
Source & SS & DF & MS & F & Significance \\
\hline
\end{tabular}

Main effects

JP VS NJP

settings

Two-way interaction

$\begin{array}{lllll}518.4 & 1 & 518.6 & 5.66 & .0548\end{array}$

$6154.75 \quad 2 \quad 3077.38 \quad 42.51 \quad .0001$ *

$\begin{array}{lllll}272.45 & 2 & 136.23 & 1.88 & .1946\end{array}$ 
a high trend for JP $<$ NJP $(\mathrm{p}=.0548)$. Second, it was found that the main effect 'setting' greatly accounts for the variation $(p=.0001)$. Third, no significant interaction of ethnicity and settings was found.

Table XXVI shows ANOVA results for long initial pauses. The results indicate that there was a significant main effect for setting on the values of use of long initial pauses. There was quite a strong interaction between these two variables, but not statistically significant $(p=.079)$. Although, according to the results of ANOVA, ethnicity seems to have little effect on this strategy, it needs to be noted that long initial pauses were never found in the data of the TF setting, and that JP produced more of them in GW and NS.

TABLE XXVI

ANOVA DEPENDENT MEASURE: LONG INITIAL PAUSES

Source

Source

Main effects

JP VS NJP

settings

Two-way interaction
SS

DF $\quad$ MS

$65.88 \quad 1$
399

$107.76 \quad 2$

MS

F Significance


of avoidance in TF appear to be difficult for statistical analysis. Thus, from these data alone, nothing can be concluded about the main effect of setting on avoidance.

TABLE XXVII

ANOVA DEPENDENT MEASURE: AVOIDANCE

$\begin{array}{llllll}\text { Source } & \text { SS } & \text { DF } & \text { MS } & \text { F } & \text { Significance }\end{array}$

Main effects

JP VS NJP

settings

Two-way interaction

10.34

11.58

5.172

10.34

6.23

$5.791 .94 \quad .1869$

$2.59 \quad .86 \quad .446$

\section{SUMMARY}

On the whole, it was found that not many interaction strategies for negotiation were produced in the teacherfronted setting except for a few repetitions/rephrases. In contrast, in GW, both JP and NJP produced more strategies and a wider variety of strategies than in other settings. In the third setting, NS-NNS, both groups of learners produced more interaction strategies than in either the TF or the GW settings. Furthermore, in the NS-NNS, JP generally produced more strategies than NJP. It was found that JP preferred reduction strategies (i.e., avoidance, long initial pauses), while NJP preferred achievement strategies (i.e., repetitions/rephrases).

It was also found that in GW, it was the NJP who produced a significantly higher number of other completions, comprehension checks, and repetitions/rephrases than the 
JP. These results suggest that NJP may have had more dominant roles than JP in the GW setting.

JP's use of strategies varied significantly according to setting. In teacher-fronted situations, JP used almost no strategies; whereas, in both GW and NS settings, JP used interaction strategies with greater frequency.

With respect to type of strategies produced by JP in the NS-NNS setting, JP preferred implicit echoic confirmations to explicit clarification requests, and verification requests to comprehension checks.

In terms of avoidance strategies, it was found that the results in the $T F$ setting were difficult to quantify. This suggests that avoidance behavior may be studied more effectively in a qualitative study.

In summary, the results suggest two major points:

I) the teacher-fronted setting provides very little space for negotiation; so, for Japanese learners who depend on interaction strategies to compensate for the difficulty in communication in $\mathrm{L} 2$, the $\mathrm{TF}$ is not a situation suitable for promoting negotiation; and 2) the frequency and type of interaction strategies may differ depending on setting and ethnicity. 


\section{CHAPTER VI}

\section{RESULTS AND DISCUSSION OF INTERVIEWS WITH JAPANESE LEARNERS}

The two previous chapters focused on a quantitative analysis of the syntactic features and interactional features. This chapter describes a qualitative analysis of Japanese learners' oral behavior to answer the following question: "Why are Japanese learners quiet in the classroom?" The data come from interviews with Japanese ESL students and their ESL teachers.

The Japanese learners whom I interviewed in Japanese all complained of feeling frustrated during classroom interaction situations. Three main types of reasons were extracted as central factors: psychological, linguistic, and sociocultural. These are discussed in the following sections.

\section{PSYCHOLOGICAL FACTORS}

This section presents psychological reasons reported by the Japanese learners. Hymes (1972), concerning the role of noncognitive factors (e.g., motivation) in the specification of ability of use, writes: 
In speaking of competence, it is especially

important not to separate cognitive from affective and volitive factors, so far as the impact of theory on educational practice is concerned; but also with regard to research design and explanation ... (p. 283)

Thus, to understand Japanese learners' quiet behavior in the classroom, it is important to investigate feelings and affective factors that Japanese learners have, especially in the teacher-fronted clasroom.

Motivation

According to comments by the three ESL teachers I interviewed, and those of many others with whom I have spoken in the field, Japanese learners' silence in the classroom was sometimes seen as reflecting a motivation problem. Language teachers sometimes look at frequency of participation to evaluate learners' degree of motivation. Because of that criterion, most JP learners appear to lack strong motivation to learn English, and ESL teachers feel somewhat frustrated with quiet Japanese learners. (See Appendix A for teachers' memos commenting on Japanese learners.) However, all JP subjects in my study reported that they were motivated and that, as a matter of fact, they wanted to participate more in the class discussions, but they could not speak in the whole class situation. This is not to suggest that all JP ESL students are motivated. On the contrary, it has been observed that some young Japanese ESL learners who have no work 
experience tend to lack motivation, as reported in one teacher's comment shown in Appendix A-1. However, such students might be found in any ethnic groups. In other words, lack of motivation may be an individual factor which would require a different type of study from this one. Thus, it should be noted that the following discussion is based on the assumption that although Japanese learners are quiet in the classroom, they are hoping to participate in the class if possible. Then, what makes it almost impossible for them to participate?

Feelings that Hinder JP Learners' Speech

\section{Inferiority complex in spontaneous speech. All the}

JP subjects were aware of the fact that their silence was regarded as a problem in the ESL classroom. They knew they were expected to speak more in the classroom even if they had to force themselves. Yet, they felt uncomfortable with 'spontaneous speech' in the whole class situation. They said that they usually did well in role plays and in presentations of results from group discussions. In these cases, learners are not required to produce L2 spontaneously; instead, they can depend on previously prepared discourse usually in written form (e.g., model dialogues, memos). Thus, all JP learners, comparing themselves with non-Japanese learners, reported an 'inferiority complex' in speaking, especially in spontaneous. speech, (even though they reported a 'superiority complex' 
in their grammatical competence).

Fear of losing face. The JP learners pointed out that they were afraid of losing face in front of other learners by making errors. Long and Porter (1985) describe this fear, using Barnes' term "audience effect." They explain, "the 'audience effect' of the large class, the perception of the listening teacher as judge, and the need to produce a short, polished product all serve to inhibit" spontaneous language production (Long and Porter, 1985, p. 211). Thus, it seems that most students, regardless of ethnicity, have some degree of fear in the teacher-fronted situation. The fact that JP learners tend to feel greater fear of losing face may be explained by certain cultural factors that will be reported later.

Fear of incompletion of speech. Even when the JP students in this study wanted to say something, they usually chose to avoid taking a turn, for the following reasons. They thought that it would take a long time for them to convey their thoughts or that they might not be able to complete what they wanted to say under pressure in the whole class situation.

Consideration for other learners. Most JP learners

felt that individual learners should not take too much time from the teacher. They felt that some talkative learners unnecessarily talked too long in the teacher-fronted situation. Consequently, even if they had a question 
when the teacher asked "Any questions?", they preferred to wait until after the class to speak privately with the teacher. (See Appendix A-2 for a teacher's comment on JP students' question-asking behavior.)

\section{Summary}

In short, phychological reasons reported by the JP learners suggest that the teacher-fronted class is an uncomfortable and threatening speech setting for them when they have to speak spontaneously. All said that they felt more comfortable speaking in pair or group activities than in the teacher-fronted situation.

\section{LINGUISTIC FACTORS}

This section explains linguistic problems reported by the JP learners, which seem to inhibit their production/interaction in the classroom.

\section{Comprehension Problems}

Most JP learners reported problems in comprehension. They said that they sometimes did not understand the teacher's questions or instructions for activities. In such a case, they said they usually waited to observe what other learners would do rather than ask questions to clarify the teacher's meaning. 
Production Problems

The JP learners also claimed that they were less competent in spontaneous speech than other non-Japanese (NJP) learners. They said they almost always construct a complete sentence before speaking. They attributed this to two habits developed in their previous English education in Japan, translation and monitoring, as described below.

Habit of translation. All JP learners pointed out their habit of speaking after translating a Japanese sentence into English. They report the need for 'discourse planning' beforehand; otherwise they feel uncomfortable. In the interaction analysis, it was found that JP learners used more turn-initial long pauses as a conversation device than NJP learners. The JP learners' comments about their planning process confirms the frequent use of initial pauses.

Habit of monitoring. Another learned habit reported by JP learners was that of monitoring. They tried to produce 'errorless' utterances. They said that it was a habit from the education system in Japan to pay attention to grammatical correctness. The following examples from the data illustrate corrections of verb tense by the JP learners.

EXAMPLES: (in NS-NNS conversations)

$\mathrm{J} 2$ : But I I was working, I worked and (..)

J6: I tried, I try ... to speak.

J6: I would, I would, I will live here. 
J7: Always I I took, ah ah I take dinner outside. J8: My parents' acquaintance lived, live, is living in Portland.

This monitoring indicates that JP learners seem to pay more attention to 'form' rather than 'meaning' or 'communication'. Due to the careful planning of their discourse, they responded more slowly than NJP learners in the classroom. Most JP learners complained that while they were silently planning sentences, other learners who were more competent in spontaneous speech usually took turns and JP learners often lost a chance to participate in the teacher-fronted activity. On the other hand, the JP felt more comfortable in taking time to create utterances in the NS-NNS conversation. Apparently, native speakers in the dyads were more tolerant of this need to take time to plan discourse before speaking and to monitor form while speaking.

Linguistic Differences between Ll and L2

The JP learners also reported their apparent disadvantages resulted from their Ll, Japanese, which is not in the Indo-European language group. In the following example from my field notes, a Japanese student (J7) had trouble verbalizing her thoughts in her solicited turn in the teacher-fronted activity and then she had to give up her speech. This description is based on my observation and her comment given soon after the class. 
EXAMPLE: The topic of the lesson was the concentration camps for Japanese Americans during World War II. I should note that J7's hesitation in her response was not related to the topic, becase she later said that it was an interesting topic and that she wanted to participate in the class discussion. The teacher asked a question and solicited $\mathrm{J} 7$ as follows:

T: Why were American people particularly angry about Pearl Harbor? ... What do you think, J7?

J7: Ah-n ummm ...umm, without saying, without saying ummm ...

The teacher responded to $\mathrm{J} 7$ by saying "Uh huh", probably in order to encourage more explanations from J7. After a few seconds, the teacher called upon another student.

Between the teacher's solicitation and her response, the following things happened in J7's verbalization process according to her recall after the class:

1) The answer that came into her mind (intended meaning $\mathrm{X}$ ) was in Japanese (Translation follows the Japanese.) sensen-fukoku shinaide, koogeki-shita kara (declaration of war without doing, attacked because)

2) J7 immediately realized there was no equivalant vocabulary in her inventory of $\mathrm{L} 2$, so she looked for another way to say it with what she had. (Her long turn-initial pauses indicate the time in which she was searching for the English expressions.)

3) Then, she came up with an idea that the intended meaning $X$ basically means 'to say something'; thus, she managed to answer by using paraphrasing strategy, a type of communication strategy.

4) But, she was not sure whether or not her answer made any sense in English. She tried to find better expressions, but she could not find any more because she was quite upset.

(Her uncertainty about correctness is reflected in the use of repetition and pauses at the end of the turn.)

J7's message was not understood by the teacher, for the following possible reasons: first, J7's utterances were too fragmented (i.e., they did not contain any s-nodes such as "because Japanese attacked .."); second, the verb 
'saying' had no direct object (i.e. this seems to be a direct interference of learner's Ll rule--'object deletion' rule in Japanese); and third, J7's original meaning $\mathrm{X}$ in Japanese did not contain any agents of actions (i.e., a subject for verbs 'attack' and 'declare').

In SLA studies, it has been suggested that the degree of parallelism between $\mathrm{L} 1$ and $\mathrm{L} 2$ is related to the degree of difficulty in learning a second language (Hatch, 1986). Linguistically, the Japanese language seems to be considerably less parallel to English than Indo-European languages such as Spanish and German. In J7's utterances reported above, for example, the following linguistic differences can be found: a different word order (e.g., the connector 'because' appears at the end of the sentence in Japanese), lexical differences, frequent 'deletion rules' in Japanese (e.g., deletion of subject or object). Thus, it seems that Japanese have very little 'positive transfer' (Corder, 1981) from their Ll for the development of L 2 .

Lower Intelligibility

The JP learners pointed out that the degree to which their message can be understood may be lower than that of NJP learners. Some of them mentioned that American teachers appeared to understand the speech produced by learners with Arabic or Spanish Ll background more easily than that of Japanese. The following reasons for this 
phenomenon have been considered.

Soft talking. Low intelligibility of JP learners' L2 may be due to low volume of their talk. I observed JP learners speaking so softly that their teachers appeared to have difficulty in hearing what the JP learners were saying.

Different rhetorical patterns. Japanese rhetorical patterns are not as linear as those in English (Kaplan, 1966; Ishii, 1985; Yamada, 1989). Consequently, the meaning of JP learners' discourse is often difficult for American teachers to understand. The following is an example of typical JP learners' discourse, which shows that their discourse is sometimes unclear until a listener hears the end:

EXAMPLE:

NS: What about other places? Do you go to the store? to the movies?

J4: Ah- ... not ah- ah, yeah ummm, I go to grocery store (NS: yeah) ah-often, but umm, so she (J5's host mother), she is a very active, umm 'active woman'? (NS: uh huh), so ah I never, I never umm go to watch the movie with her (NS: oh), just umm so ah- we went to Mt. Hood (NS: yeah) or or and umm ... ah- ah- ah, we ah- we can enjoy umm the nature (NS: yeah) with her.

The NS was confused when $J 4$ used the word 'active' to describe her host mother and said that she never went to the movies. However, eventually the NS understood what J4 meant by saying 'active' when J4 made a contrast between an indoor activity (e.g., watching a movie) and an outdoor activity (e.g., going to mountains) at the end. 
This example suggests that JP learners' discourse may be unclear to a native speaker of English in terms of rhetoric.

Frequent hesitation pauses. The example above also shows JP learners' use of hesitation pauses. As examined in the interaction analysis (Chapter V), JP learners used more long turn-initial pauses than NJP learners. This supports evidence by Yamada (1989), who has reported that Japanese speakers use more pauses as fillers and closing devices than Americans. It is suggested that the frequent use of pauses is cultural specific. Combined with the habit of minitoring, JP learners thus tend to produce frequent pauses in their L2 discourse.

If a JP student hesitates in the teacher-fronted setting as much as J4 did in the one-to-one conversation presented above, she might lose the floor (i.e., turn) before conveying her point. The teacher usually coes not wait as long as the NS aid in the dyad. In a group discussion, JP learners' excessive hesitation may obstruct their listeners' comprehension.

Less extended discourse. As found in the syntactic analysis in Chapter IV, the JP learners' discourse was less complex than that of the NJP leaners. Because of less extended discourse, JP learners' speech could appear to be ambiguous. In the data of NS-NNS conversations, it was observed that the NJP learners had the skill to 
start a turn by saying something and adding more sentences later. In contrast, the JP learners seldom produced extended discourse as freely as the NJP did. (See Appendix D for transcription samples including both JP and NJP learners' speech.) One of the NS interlocutors who participated in recording of dyads commented, after conversing with a few JP and a NJP, that she felt NJP's discourse level seemed to be much higher than that of JP learners. The following two examples show such a contrast between a JP learner's discourse and an Arabic learner's:

EXAMPLE (1):

NS: What made you decide to come to Portland?

J4: Ah-so- umm, I had, I had a American teacher, umm who ah ... she lives in Portland, so she recommended me to come to study here.

EXAMPLE (2):

NS: Why did you decide to come to Portland? You have friends here?

Al: Well, no, I I just came here from Saudi Arabia to here, um my country, just I was, actually I was in uh ... in a Washington state before I came here, for two months only, also. Then I came, I um it was relly the depressed city, it was, it was in a small place in a college town, so I just, I I get bored.

The Arabic student answered the 'why' question with a longer discourse than the JP student. Although this finding should not be generalized beyond the discourse of the subjects in this study, it is also true that most JP learners reported that they often simplify what they want to say and usually do not try to stretch their speech in order to avoid an awkward communication breakdown. 
Linguistic Environment outside of the Classroom

Finally, it should be noted that all JP learners said that it was difficult to find Arnerican friends. They also explained that they could survive without speaking English because there were many Japanese students in ESL classes and on campus. They reported that they spoke English most with non-Japanese classmates in their ESL classes and their ESL teachers.

$\underline{\text { Summary }}$

JP learners often think that they are less sufficient in conversation than other learners in the classroom. Many pointed out that their placement test (the Michigan Test of English Language Proficiency) did not correctly evaluate their interactional ability in communication, which is probably related to 'strategic competence' described by Canale and Swain (1980). Findings in the previous chapters also indicated that the JP learners' oral proficiency may be lower than that of the NJP learners, especially in spontaneous speech. (See Appendix D-3 for transcription samples of JP and NJP discourse. These show that the NJP's fluency level is higher than the JP's.) The following section describes JP learners' problems related to their 'sociolinguistic competence.' 
their silence in the classroom. These are all related to ethnic differences in terms of norms and values both in the classroom and society in general.

Cultural Differences in the Classroom

What the JP learners suggested about the educational environment they used to have in Japan is described well in the following explanation made by Tarone and Yule (1989):

Some adult learners have quite powerful preconceptions about the form a language learning experience should take. We simply cannot ignore the fact that many learners are used to an education setting in which teachers overtly control the activities of the group in a relatively formal manner, emphasize the memorization of grammatical rules and vocabulary, often via mechanical procedures such as repetition and rote learning, administer frequent achievement tests, and generally require their students to maintain a passive and subordinate role. (pp. 9)

The JP leaners found that rules and expectations about learning and teaching in the United States seem to be very different from what they had experienced at school in Japan, as described in the following sections.

Differences in roles of teacher/learners. The role of teacher in Japan reported by the JP subjects can be described as 'authoritarian'; that is, the teacher has an explicit dominant status in the classroom. The JP subjects said that they were not expected to participte in the teacher-learner interaction and that they had not experienced communicative techniques (e.g., discussions between a teacher and students or in groups). In the 
teacher-fronted setting in Japanese schools, good learners are those who listen carefully to what the teacher says. Students are supposed to respond to the teacher only when the teacher questions a specific learner. Thus, there is a wide distance between teacher and students, and the power relationship between the teacher and students is unequal in classrooms in Japan. The JP subjects said that they had not interacted with a teacher or other students in classrooms in Japan as much as they were expected to do in the ESL classroom.

In contrast, students in American education are expected to take a more active role in the classroom. Scollon and scollon (1985) describe a communicative emphasis in American classroom interaction and explain its "equalization of power differences" between a teacher and learners. However, they recognize that the teacher-student relationship is still unequal:

it is the difference between the teacher's power as an adult and representative of the school and the student's power as an immature and single member of society. In some cases the power difference is very much greater as when the teacher also represents an ethnic or social group of economic or technological dominance and the student represents a minority ethnic or social group. (scollon and scollon, 1985, p. 177)

such an unequal power relationship may be perceived strongly by students who are from a culture in which a teacher-student relationship is clearly hierarchical such as that in Japan. 


\section{Different Communication Styles}

Besides problems in classroom interaction, the JP learners also commented on difficulties in communication in English, in general. They said they had rarely been expected to say something as an individual in public. Consequently, they often felt uncomfortable expressing themelves as clearly as most Americans seem to do. Also, because of lack of such experience, they said they could not shape their opinions quickly in a big group discussion. The following reasons for this deficiency were reported by the JP students.

Role sensitivity as a norm in communication. The JP learners said that they were not used to expressing their own opinions explicitly in public. Instead, they focused on their responsibility to fulfill a certain role within a group. In her comparative study of Japanese and American group discussions, Watanabe (1990) describes this characteristic of Japanese communication as "non-reciprocality". She writes:

Information about the interactants such as age, social rank, occupation, gender, the schools they have graduated from, the social profile of their families and so forth, is drawn together to determine the relational position to others in every situation, which enables individual interactants to interpret the communicative intent of others and to make an appropriate move toward it. (Watanabe, $1990, p .84$ )

Thus, Japanese learners may be limited in their public expression in English by their cultural values. They 
may be reluctant to express their individual opinions freely and explicitly.

Negative image of self-assertiveness. Most JP learners expressed a negative feeling about self-assertiveness, and this confirms Barnlund's (1975) finding. Pointing out a difference in the attitude toward oral participation in groups, Coker (1988) writes:

In American culture there is the view that responsible persons talk to accomplish something, that silence does not accomplish anything, and that persons who are quiet are either not very bright or do not have any ideas. In Asian culture, on the other hand, it is believed that it is better to be quiet rather than ramble on and say nothing -- the idea being that talkative persons do not think very much because they are too busy talking and that talkative persons are an annoyance.. (p. 20)

Some JP students said that they felt uncomfortable when students from other cultures expressed their opinions aggressively in the teacher-fronted class or in the group discussion. In other words, silence in public may be evaluated quite 'positively' by Japanese students, rather than 'negatively' as by their ESL teachers. Different expectation for turn-taking. The JP learners felt that active learners did not offer chances for speaking to quiet learners. They said that they usually tend to wait until someone gives a turn to them. This comment by Japanese learners supports a finding by Yamada (1989) that Japanese participants in a group discussion prefer the "even turn distribution strategy" while Americans 
in a group discussion use the "uneven turn distribution strategy" (220). In other words, Japanese shared a relatively equal amount of talk in a group discussion, by giving each participant equal turns.

In the communicative language classroom, on the other hand, turns are usually taken in free competition. That is, each learner is supposed to get the floor individually, unless the teacher points out a specific learner. Therefore, it seems natural that JP learners who tend to wait for a chance to be given often have little opportunity to participate in classroom discussions. The JP learners I interviewed said that the fewer participants a setting contained, the less pressure they felt. This pressure may partially result from this competitive turn-taking aspect.

\section{SUMMARY}

The reasons reported above, which Japanese learners revealed to explain the difficulty they have in their L2 communication, are quite complex. It was found that Japanese learners had quite negative self-images as speakers of English. Especially, the teacher-fronted situation is threatening, and it seems to account for a 'face' issue about which the Japanese are strongly concerned. Also, their communication styles have very little parallel to American ones. Because of these various problems, Japanese 
learners tend to remain silent in the teacher-class activities. This avoidance behavior seems to be a strategy to avoid a risk that often occurs in their spontaneous speech in $\mathrm{L} 2$.

In terms of the type of classroom activity, the reasons for their avoidance seem to be related to two factors: the number of participants and the degree of spontaneity. Overall, they felt more comfortable in a small group setting (including pair-work) than in the teacher-fronted class; and they preferred having time for discourse planning.

These findings suggest that Japanese learners need to have less threatening situations in order to interact actively. In addition, they need to be put in certain situations in which they cannot use avoidance strategies and are obligated to speak. Furthermore, if the teacher-fronted interaction shows an unequal power structure between active learners and quiet learners, it may be the teacher's responsibility to provide even opportunity for participation. 
CHAPTER VII

CONCLUSIONS

SUMMARY OF THE STUDY

This study was aimed at examining Japanese ESL learners' silence in the classroom. To describe characteristics of their production and interaction, the recorded speech of eight Japanese learners was examined by comparing it with that of four non-Japanese learners, across three settings: teacher-fronted, group work, and NS-NNS conversation. A 9-minute segment of speech in each setting was transcribed and analyzed for amount and complexity of syntactic features, as well as for interaction strategies. Also, the Japanese learners were interviewed in their Ll to report reasons for their silence in the classroom.

Findings in the syntactic analysis show two major characteristics of JP production: 1) Japanese learners' silence is situation specific (i.e., it occurs mostly in the teacher-fronted setting); and 2) Japanese learners' oral proficiency in spontaneous speech may be lower than NJP's. Results indicate that JP generally produced significantly fewer words and less complex discourse than 
NJP, but that in terms of number of turns, a significant difference was found only in the TF setting. Besides, it was found that JP in the NS-NNS conversation took significantly more turns than NJP. Overall, the number of words or s-nodes significantly increased in the order of $\mathrm{TF}<\mathrm{GW}<\mathrm{NS}$.

With respect to interaction strategies, it was found that very few strategies were used in $T F$ compared to those in GW or NS. Results indicate that Japanese preferred avoidance strategies and long initial pauses, whereas NJP produced significantly more repetitions/rephrases than JP. Across the three settings, JP produced the least strategies in $\mathrm{TF}$, while the most in NS.

From the results of interviews with the JP learners, it was suggested that the TF situation was, again, not facilitative for JP learners. The reasons students reported for their avoidance behavior in the classroom were mainly related to two factors, the number of participants and the degree of spontaneity. They felt a group work situation or one-on-one conversation was less threatening. Another important factor reported by JP is that Japanese communication styles differ from those expected in American classrooms. In Japanese classrooms, students have a passive role, so when they come to the United States, they continue that role. In addition, because Japanese generally value keeping face and conforming in group communication, they 
are reluctant to risk losing face in a large group situation.

\section{LIMITATIONS}

The limitations of this study are outlined in this section. First, owing to the low number of subjects in this study, the results have low generalizability. Verification with a larger number is essential if these findings are to be established.

Second, most of the Japanese subjects in this study were female, so future researchers may need to consider gender as a variable affecting interaction patterns.

Third, the categories of interaction strategies are only a working taxonomy, and they need to be refined in future research. It was revealed that avoidance behavior was difficult to quantify. The problems that lie in the inconsistent choice of variables in SLA studies are pointed out by Ellis (1985) as follows:

the study of classroom input/interaction, as

it relates to SLA, does require both valid and generally accepted categories so that cross-study comparisons can be made. (p. 144)

Thus, further research is necessary to determine validity of variables in negotiation in L2 discourse.

\section{SUGGESTIONS FOR FUTURE RESEARCH}

In this section, some suggestions for future research are explained, including areas that could not be examined in this study. 
First, the videotaped interactions of learners can be used to investigate roles of 'non-verbal' factors in negotiation. For example, I found that puzzled facial expressions made by learners often functioned as 'clarification requests' in one-to-one conversations. Also, gestures seemed to have an important role in compensating for learners' insufficient L2 systems. Also, 'pauses' appear to have certain functions as strategies. Although this study has included long initial pauses alone, other types of pauses such as fillers in mid-turns and closing are useful communication devices used by L2 learners. Furthermore, it was observed that the Japanese learners showed more facial expressions, gestures, and pauses in the one-to-one conversations and small group discussions than they did in the teacher-fronted classroom. This may indicate that limited use of non-verbal communication devices are another factor that hinder Japanese learners' production/interaction in the teacher-fronted setting. Second, further qualitative analyses of interaction strategies are possible using the Japanese learners' reviews of their videotaped conversations with a native speaker. Verbal reports made by the learners are useful for examination and development of strategy taxonomy. I found it difficult to categorize certain types of strategies overtly from transcripts. For example, Long (1983) defined 'confirmation checks' (e.g., NS: Next to the man. NNS: 
The man?) as a device used by the speaker when presupposition of previous utterances is available, while he defined 'clarification requests' (e.g., Try again.) as a device used by the speaker when no presupposition is available. However, the reports from the learners revealed that confirmation checks may be used without any presupposition. Their use of these strategies did not quite fit Long's categories as he defined them. In the review session, a Japanese learner (J6) reported that she had no understanding of what a native speaker had said, even though she used a 'confirmation check' in the following conversation:

NS: And then do you go directly home?

J6: Directly home?

NS: Do you go ..

J6: Uh huh.

NS: .. directly home? back to the house?

J6: Ah! no no no.

Another learner (J6) reported that she often used repetitions of previous utterances to 'stall for time' while searching for words and expressions for her production.

NS: What made you come here, $\mathrm{X}$ (school name)?

J6: Made?

NS: Yeah, what made you come to $X$ ?

J6: Why?

NS: Uh huh, why did you come to $X$ ?

J6: Why? ummm ... I thought .. umm this school .. has good program.

Thus, learners' reports provide useful information for further investigation of interaction strategies.

Third, what types of strategies facilitate L2 communication and its development needs to be examined 
in future research. It may be the case that the 'successful use' of communication strategies may prevent development of L2 linguistic knowledge. A longitudinal study of interaction strategies is needed to investigate valid correlations between use of strategies for negotiation and SLA.

\section{IMPLICATIONS FOR TEACHING}

Implications for teaching that emerge from this study are described in this section. To aid Japanese learners' active participation in the classroom, the following suggestions are made.

1) Results from this study suggest that a teacher-fronted class does not provide Japanese learners the opportunity to develop their communicative ability. In a communication setting, the number of participants affects JP learners' production, and the fewer the number of participants, the more JP learners will produce. In this sense, small group activities (i.e., a pair- or group task) provide more space for Japanese learners' production and interaction than the teacher-fronted activity. This is not to say that teachers should not use teacher-fronted activities, rather to suggest that teachers need to be aware of the fact that Japanese learners' $L 2$ use is affected by types of setting to great extent.

2) Japanese learners need a gradual shift from planned 
to unplanned speech. It was suggested that, in spontaneous speech, JP learners' oral proficiency may be less competent than that of NJP, and that JP learners feel threatened due to little time for discourse planning. The teachers' comments in Appendix A also point out that Japanese learners are more successful in role-play or drama situations. These findings indicate that JP learners need a gradual transition from planned to unplanned in-class activities. More information on transition activities can be found in Willis and Willis, 1987 (rehearsals), and stevick 1980 (long narrow dialogues).

3) Preferred behavior in the classroom needs to be made explicit. Because Japanese communication styles differ culturally from those expected in communicative language classrooms, it would help JP learners if teachers gave students explicit instructions for preferred classroom interaction.

4) Attention should be paid to the self-esteem of language learners as speakers of English. It may be that their focus on the form of the language is related to their lack of confidence as communicators. In order to convince learners who still believe that the accumulation of forms will provide them with competence in real communication, it is necessary for teachers to introduce a new image of second language learning to learners. That is the notion that a language learner is a L2 user 
who has a whole identity in a language community (Boxter, 1980).

5) A stimulated recall technique is useful for learners to review their speech. The JP learners who participated in a review session of videotaped conversations suggested that they could learn a great deal from reviewing their speech. Often, learners may have the opportunity to review their written production, but perhaps not their spoken production. The importance of reviewing oral production is that learners find their goals for improvement by observing their own performance.

6) Transcribed speech data are another source that help learners to gain insights into their own performance. If learners transcribe their own recorded speech, they can observe various aspects of their L2 use, including grammatical accuracy. Teachers can also use transcribed data to evaluate learners' improvement from several perspectives (e.g., syntactic complexity, use of strategies).

7) Strategies for negotiation need to be taught. The interaction analysis indicates that JP learners depend on avoidance and long initial pauses, rather than achievement strategies (e.g., paraphrases). JP learners need to participate in activities in which they can develop specific strategies to replace avoidance and long initial pauses. Tarone and Yule (1989) explain many such activities. 


\section{CONCLUSIONS}

Japanese learners are described as silent in the language classroom. This study suggests that this behavior is only in the teacher-fronted setting. In other words, in other situations, the same students show more communicative proficiency. And yet, this study also indicates that Japanese learners need to be taught how to develop strategies that facilitate successful communication in $\mathrm{L} 2$.

Japanese learners need more successful experience in $L 2$ communication. That is, they need to feel they can compensate for their developing L2 system by using strategies to converse. In order to gain such experience, a language classroom needs to contain more space for negotiation of meaning. Corder(1981) suggests that teachers "cannot really teach language, we can only create conditions in which it will develop spontaneously in the mind in its own way" (p. 12). What teachers can do to help Japanese learners is to provide a space in which learners can experience a sufficient amount and quality of negotiated interactions. Such modification can occur only when language teachers become aware of ethnic differences in L2 discourse among ESL learners. 


\section{REFERENCES}

Allwright, D. (1988). Observation in the language classroom. London: Longman.

Barnlund, D.C. (1975). Public and private self in Japan and the United States: Communicative styles of two cultures. Tokyo: The Simul Press.

Baxtor, J. (1980). How should I speak English? American-ly, Japanese-ly, or internationally? Unpublished manuscript, East-West Culture Learning Institute, Hawaii.

Brock, C.A. (1986). The effects of referential questions on ESL classroom discourse. TESOL Quarterly, 20, 47-59.

Brown, D.H. (1987). Principles of language learning and teaching. Englewood Cliffs, NJ: Prentice-Hall.

Canale, M., \& Swain, M. (1980). Theoretical basis of comnunicative approaches to second language teaching and testing. Applied Linguistics, 1 , $1-47$.

Chauāron, C. (1988). Second language classrooms: Research on teaching and learning. Cambridge: Cambridge University Press.

Chomsky, N. (1965). Aspects of the theory of syntax. Cambridge, MA: The M.I.T. Press

Cohen, A.D. (1987). Using verbal reports in research on language learning. In C. Faerch \& G. Kasper (Eds.), Introspection in second language research (pp. 82-95). Clevedon, England: Multilingual Matters.

Coker, P.M. (1988, Fall). The Asian student in the classroom. Education and Society, pp. 18-20.

Corder, S.P. (1981). Error analysis and interlanguage. Oxford: Oxford University Press. 
Dörnyei, Z., \& Thurrell, S. (1991). Strategic competence and how to teach it. ELT Journal, $45(1), 16-23$.

Doughty, C., \& Pica, T. (1986). 'Information gap' tasks: Do they facilitate second language acquisition? TESOL \&uarterly, 20, 305-325.

Duff, P. (1986). Another look at interlanguage talk: Talking task to task. In R. Day (Ed.), Talking to learn: Conversation in Second Language Acquisition (pp. 147-181). Rowley, MA: Newbury House.

Ellis, R. (1980). Classroom interaction and its relation to second language learning. RELC Journal, ll, $29-48$.

----. (1984a). Classroom second language development. oxford: Pergamon Press.

----. (1984b). Communication strategies and the evaluation of communicative performance. ELT Journal, $\underline{38}(1), 39-44$.

----. (1985). A variable competence model of second language acquisition. IRAL, 23(1), 47-59.

-.--. (1986). Understanding second language acquisition. New York: Oxford University Press.

Faerch, C., \& Kasper, G. (1983). Plans and strategies in foreign language communication. In $C$. Faerch \& G. Kasper (Eds.), Strategies in interlanguage communication (pp. 20-60). London: Longman.

Haastrup, K. (1987). Using thinking aloud and retrospection to uncover learners' lexical inferencing procedures. In C. Faerch \& G. Kasper (Eds.), Introspection in second language research (pp. 197-212). Clevedon, England: Multilingual Mătters.

Hatch, E. (1978). Discourse analysis and second language acquisition. In E. Hatch (Ed.), Second language acquisition: A book of readings (pp. 401-435). Rowley, MA: Newbury House.

-.-.. (1983). Psycholinguistics: A second language perspective. Rowley, MA: Newbury House. 
Hatch, E., Flashner, V., \& Hunt, L. (1986). The experience model and language teaching. In R. Day (Ed.), Talking to learn: Conversation in second language acquisition (pp. 5-23). Rowley, MA: Newbury House.

Hymes, D. (1972). On communicative competence. In J. Price \& J. Holmes (Eds.), Sociolinguistics (pp. 269-293). Harmondsworth: Penguin.

Ishii, S. (1985). Thought patterns as models of rhetoric: The United States and Japan. In L. Samovar \& R. Porter (Eds.), Intercultural communication: A reader (4th ed.) (pp. 97-102). Belmont CA: Wadsworth Publishing Co.

Kaplan, R. (1966). Cultural thought patterns in inter-cultural education. Language Learning, 16, $1-20$.

Krashen, S.D. (1982). Principles and practice in second language acquisition. Oxford: Penguin.

Labarca, A. \& Khanji, R. (1986). On communicative strategies: focus on interaction. Studies in second Language Acquisition, $8,68-80$.

Long. M.H. (1980). Inside the 'black box': Methodological issues in classroom research on language learning. Language Learning, $30,1-42$.

----. (1981). Questions in foreigner talk discourse. Language Learning, 31, 135-157.

-.-.. (1983). Native speaker/non-native speaker conversation and the negotiation of comprehension input. Applied Linguistics, $\underline{4}(2), 126-141$.

----. (1985). Input and second language acquisition theory. In S. Gass \& C. Madden (Eds.), Input in second language acquisition ( $p p .377 \overline{-393)}$. Rowley, MA: Newbury House.

Long, M.H. \& Porter, P.A. (1985). Group work, interlanguage talk, and second language acquisition. TESOL Quarterly, 19(2), 207-227.

Long, M.H. \& Sato, C.J. (1983). Classroom foreigner talk discourse: Forms and functions of teachers' questions. In H.W. Seliger \& M.H. Long (Eds.), Classroom oriented research in second language acguisition (pp. 268285). Rowley, MA: Newbury House. 
Long, M.H., Adams, L., McLean, M., \& Cantoños, F. (1976). Doing things with words -- verbal interaction in lockstep and small group classroom situation. In R. Crymes \& J. Fanselow (Eds.), On TESOL '76, (pp. 137-153). Washington, D.C.: TESOL.

Maynard, S.K. (1989). Japanese conversation: self-contextualization through structure and interactional management. Norwood, NJ: Ablex Publishing $\mathrm{Co}$.

Mehan, H. (1982, September). The functioning of language in the structuring of schooling. Paper presented at the annual meetings of the American Sociological Association, San Fransisco, CA.

Pica, T. \& Doughty, C. (1985). Input and interaction in the communicative language classroom:

A teacher-fronted and group work activities. In S. Gass \& C. Madden (EdS.), Input in second language acquisition (pp. 115-132). Rowley, MA: Newbury House.

Pica, T. \& Long, M.H. (1986). The linguistic and conversational performance of experienced and inexperienced teachers. In R. Day (Ed.), Talking to learn: Conversation in second language acquisition (pp. 85-98). Rowley, MA: Newbury House.

Pica, T., Young, R., and Doughty, C. (1987). The impact of interaction on comprehension. TESOL Quarterly, $\underline{21}(4), 737-758$.

Pica, T., Holliday, L., Lewis, N., \& Morgenthaler, L. (1989). Comprehensible output as an outcome of linguistic demands on the learner. Studies in second Language Acquisition, $11(1), 63-90$.

Porter, P.A. (1986). How learners talk to each other: Input and interaction in task-centered discussions. In R. Day (Ed.), Talking to learn: Conversation in second language acquisition (pp. 200-222). Rowley, MA: Newbury House.

Raupach, M. (1983). Analysis and evaluation of communication strategies. In C. Faerch \& G. Kasper (Eds.), Strategies in interlanguage communication (pp. 119209). London: Longman.

Richards, J.C. (1980). Conversation. TESOL Quarterly, $\underline{14}(4), 413-442$. 
Rulon, K. \& McCreary, J. (1986). Negotiation of content: Teacher-fronted and small group interaction. In R. Day (Ed.), Talking to learn: Conversation in second language acquisition (pp. 182-199). Rowley, MA: Newbury House.

Sato, C.J. (1981). Ethnic styles in classroom discourse. In M. Hineds and $W$. Rutherford (Eds.), On TESOL '81 (pp. 11-24). Washington, DC.: TESOL.

Savignon, S.J. (1983). Communicative competence: Theory and classroom practice. Reading, MA: Addison-Wesley.

Scollon, R. \& Scollon, S. (1983). Face in interethnic communication. In Richards \& Schmidt (Eds.), Language and communication (pp. 156-190). London: Longman.

Selinker, L. (1972). Interlanguage. IRAL, X, 209-230.

Stevick, E.W. (1980). Teaching languages: A way and ways. Rowley, MA: Newbury House.

Swain M. (1985). Communicative competence: Some roles of comprehensible input and comprehensible output in its development. In S. Gass \& C. Madden (Eds.), Input in second language acquisition (pp. 235-253). Rowley, MA: Newbury House.

Tannen, D. (1985). Silence: Anything but. In D. Tannen \& M. Saville-Troike (Eds.), Perspectives on silence, (pp. 93-1ll). Norwood, NJ: Ablex Publishing Co.

Tarone, E. (1981). Some thoughts of the notion of communication strategy. TESOL Quarterly, 15(3), $285-295$.

---.. (1983). On the variability of interlanguage systems. Applied Linguistics, 4 , 142-163.

Tarone, E. \& Yule, G. (1989). Focus on the language learners. Oxford: Oxford University Press.

van Lier, L. (1988). The classroom and the language learner: Ethnography and second-language classroom research. London: Longman.

Varonis, E. \& Gass, S. (1985). Non-native/non-native conversations: A model for negotiation of meaning. Applied linguistics, $6(1), 71-90$. 
Watanabe, S. (1990). Framing in American and Japanese group discussions. Unpublished doctoral dissertation, Georgetown University, Washington D.C.

Widdowson, H.G. (1983). Teaching language as communication. Oxford: Oxford University Press.

---. (1989). Knowledge of language and ability for use. Applied Linguistics, 10(2), 128-137.

Willis, D. \& Willis, J. (1987). Varied activities for variable languages. ELT Journal, 41(1), 12-18.

Yamada, H. (1989). American and Japanese topic management strategies in business meetings. Unpublished doctoral dissertation, Georgetown University, Washington D.C. 


\section{APPENDIX A}

ESL TEACHERS' COMMENTS

ON JAPANESE STUDENTS 
A-1: ESL Teacher's Comments on Japanese Students (I)

\section{PERCEPTIONS OF JAPANESE STUDENTS IN THE ESL CLASS}

I think it's hard to categorize Japanese students' behavior in the ESL classroom because many factors (economic, social, sexual and educational) impact their behavior in addition to cultural influences. I have experienced extreme-ly motivated diligent students as well as those who have been quite the opposite. contrary to my expectations, the latter have frequently skipped class and/or have arrived late and have handed in tardy and poor quality homework. I should say overall, that these students have been in the minority - usually younger male students from high socio-economic backgrounds, who have come to the USA largely because of their parents' desires rather than their own.

However, I have seen some consistency in the way Japanese students behave when in class. One thing that is very difficult for me to adjust to is not only the passivity of many Japanese students but also their lack of non-verbal feedback. Teaching Americans, I can tell from smiles, grimaces (!), head nodding, and yawning the impact I am having on the students and I can adjust my style accordingly. However, with Japanese students, I am often unable to "read" their facial expressions. Because of a cultural tendency not to display feelings, certain students appear to me to be "blank". I interpret such expressions as signs of boredom or a lack of comprehension, and try to compensate, but of course this "blankness" may mean something totally different (i.e. "I'm listening", "I'm interested", or "I understand"). Consequently, my compensating strategies are frequently inappropriate and result in a cycle of miscommunication where the Japanese student is probably thinking, "Why is she explaining this again? I understood the first time!"

Generally, I would say that Japanese students tend to be more confident communicating in one-on-one or small group situations. Their lack of conversational ability in Englisi and the fear of "losing face" seem to be powerful inhibitors of communication in the teacher-fronted classroom. However, I find that in role-play or drama situations, Japanese students are often the strongest. This is perhaps because they can rehearse their roles (spontaneous speech is not required) and are less likely to make mistakes, and if they do make errors, it is the character they are assuming, and not they, who are making them. 
A-2: ESL Teacher's Comments on Japanese Students

\section{Hy Feelings About Teaching Japanese Students}

Overall, I would say that the majority of Japanese students I have had in my classes are extremely diligent and motivated by grades. Most have made an extreme effort to complete their homework on time and according to my directions. If they are given an opportunity to do their homework again, as in rewrites for a composition class, they are very likely to take the opportunity to get an "A"; Japanese students just don't seem to be satisfied with a second-best grade. I even had one Japanese student who rewrote her composition five times until she got an "At" even though her first draft received a "B."

I know Japanese students care about academic achievement. Therefore, I am often quite bewildered that-their desire for achievement seldom translates into active class participation. In all of my classes, a percentage of the students' grades are determined by class participation, anywhere from 10 to $30 \%$ depending on the subject. Despite this, many Japanese students just don't seem to respond to this way to improve their Brade.

Let me clarify myself a bit. I see participation as twofold: participation in class discussions and participation in pairs or small groups. Before we launch into student-centered work each class period, I like to begin with a class discussion so I can ask students questions to see if they understand what we $r e$ working on and give them a chance to ask questions. It is at these times that Japanese students frustrate me the most. They rarely respond to one of my questions directed to the whole class. It is always the Arabic, Hispanic, Chinese, even Rorean and Vietnamese students who answer. Seldom a Japanese.. If there are few Arabic and other talkative ethnic groups in the class and mostly Japanese, it is like talking to a brick wall. I ask a question and meet with dead silence. It makes me feel as if I am talking to corpses in a morgue. I wonder, "Do they care? They seem bored stiff." One time one of my teacher aides said, "Maybe they don"t understand," but I knew they understood completely that day. I went around to each student working in small groups to find out and sure enough, they were on task and had understood perfectly!

I am particularly bewildered by Japanese students question-asking behavior. During class I repeatedly ask," Are there any questions?" and "Does everyone understand?" Japanese students, rarely if ever, respond. However, after class you can be sure that there will be a line of Japanese students waiting to talk to me individually to tell me they are confused or to ask for clarification. They seem periectly comfortable talking to me one-on-one but refuse to talk to me in front of the class.

I probably could solve this problem by calling on Japanese students: this seems to be what they are accustomed to, but I strongly feel that if they want to attend American universities, they should try to practice American classroom behavior. I feel offended that I am giving them a safe, understanding environment to practice and they do not take advantage of it. In the American university system, we just do NOT wait to be called on by the teacher. That is behavior restricted mostly to elementary school where the teacher is in total control and the students must obey the rules 
(although since I was in elementary school, this has probably changed too). In a university class, it is "the squeaky wheel that gets the grease"; it is the student who speaks up who gets the teacher's attention. I guess American society is so individualistic that students are expected to be different and show their personalities, thoughts, curiosities, etc. to the class. On the other hand, I hear in Japan that "the nail that sticks out gets hammered down." Students are expected to conform to the group. These two proverbs really make it clear the huge difference in thinking between oul cultures.

Japanese behavior in large groups with people of other ethnic groups seems to be to sit quietly and listen but not respond verbally. Even in small groups of three to four people, Japanese students often allow the other more talkative people to lead the conversation. I had a European student. who once expressed extreme frustration that she always had to initiate the discussions and delegate turn-taking. She felt it was very uncomfortable and awkward not to have the Japanese respond "naturally."

I have discovered, however, that Japanese students become much more talkative in pairs and role plays. In pair work they talk quietly but they talk all the same. I think this is because they have no choice. If they don't talk, they' 11 just have to stare at each other which would be very awkward after awhile. Also, I think the group environment is what inhibits the students. They just don't want to stand out. In role plays, on the other hand, Japanese students become bolder and more talkative. In a conversation class, I tried pair role plays and the classroom was buzzing with voices including Japanese voices. I even had to shout, "Can I have your attention please" to get the students to stop talking. In larger role plays, such as a job interview situation that we did in class once, the Japanese students were also quite articulate and bold. It was almost as if they felt more comfortable taking on a role than being themselves. If they take on a role, they don "t have to express their personality and opinions but someone elses'. Therefore, role plays are less threatening.

As for class discussions, I have tried to solve the participation problem with a game I learned at an ORTESOL conference. In the game, individual students are assigned a certain word or phrase to listen for in a lecture. When they hear their word or phrage, they have to ask for clarification, explanation, or repetition. It is my impression that this silly game has worked wonderfully for quiet students of other ethnic backgrounds, particularly for Korean and Vietnamese students. However, it hasn't seemed to work well for Japanese students. Either they don "t respond at all or they respond late and so quietly that I can barely hear them. Even when I make asking and angwering questions an assignment ir. which they are expected to record in writing their questions and answers during whole-class discussions and hand them into me each week, I st1ll get relaiively few completed assignments from Japanese students. I think this technique wil: work if it is used long enough becsuse Japanese students are very conscientious about turning in written homework. I also learned this techrique at an ORTESOL conference. The presenter said it was very successful in encouraging her Japanese students to participate in conversation class, so I still have hope for this method. However, her classes were $100 \%$ Japanese students, so maybe this makes a difference in the method's success.

I think an anecdote will sum up my impressions of Japanese group behavior. When I was teaching a conversation class, we had a class debate over the issue of whether women with young children should work or not. 
The majority of the Japanese students believed that it was the mother' 8 responsibility to stay home and take care of the young children. They formed e large group to discuss their ideas and debate tactics. When working together with a common goal and opinion, the Japanese students were very talkative and cooperative with one another. The other group of usually talkative students from other ethnic groups remained uncharacteristically quiet whey they were told to agree on their position. They just couldn't agree on anything, so they stayed quiet. When it came time for the debate, the group that prepared the least and couldn't agree suddenly came alive and argued forcefully and convincingly. The Japanese students became eerily quiet and refused to argue unless prodded. After all of their preparation as a team, they just couldn't argue and consequently, they lost the debate. This incident make me speculate the reasons. Could it be that Japanese are very good at working cooperatively in homogenous groups with a common goal and collective opinion? Could it be that disagreement is totally unacceptable to them? And if so, could this be the resson for their lack of participation in class discussions? If Japanese students don't know how others feel about an issue or assignment, do they prefer to remain silent until they know for sure that they are in line with the group opinion? Conformity seems to be the rule. 
APPENDIX B

PARTICIPATION FREQUENCIES IN

THE TEACHER-FRONTED CLASSES 


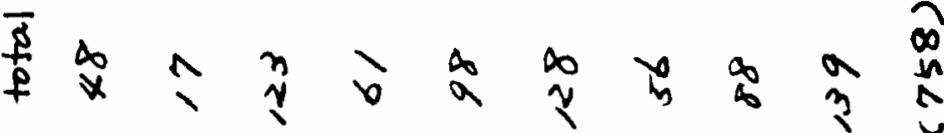

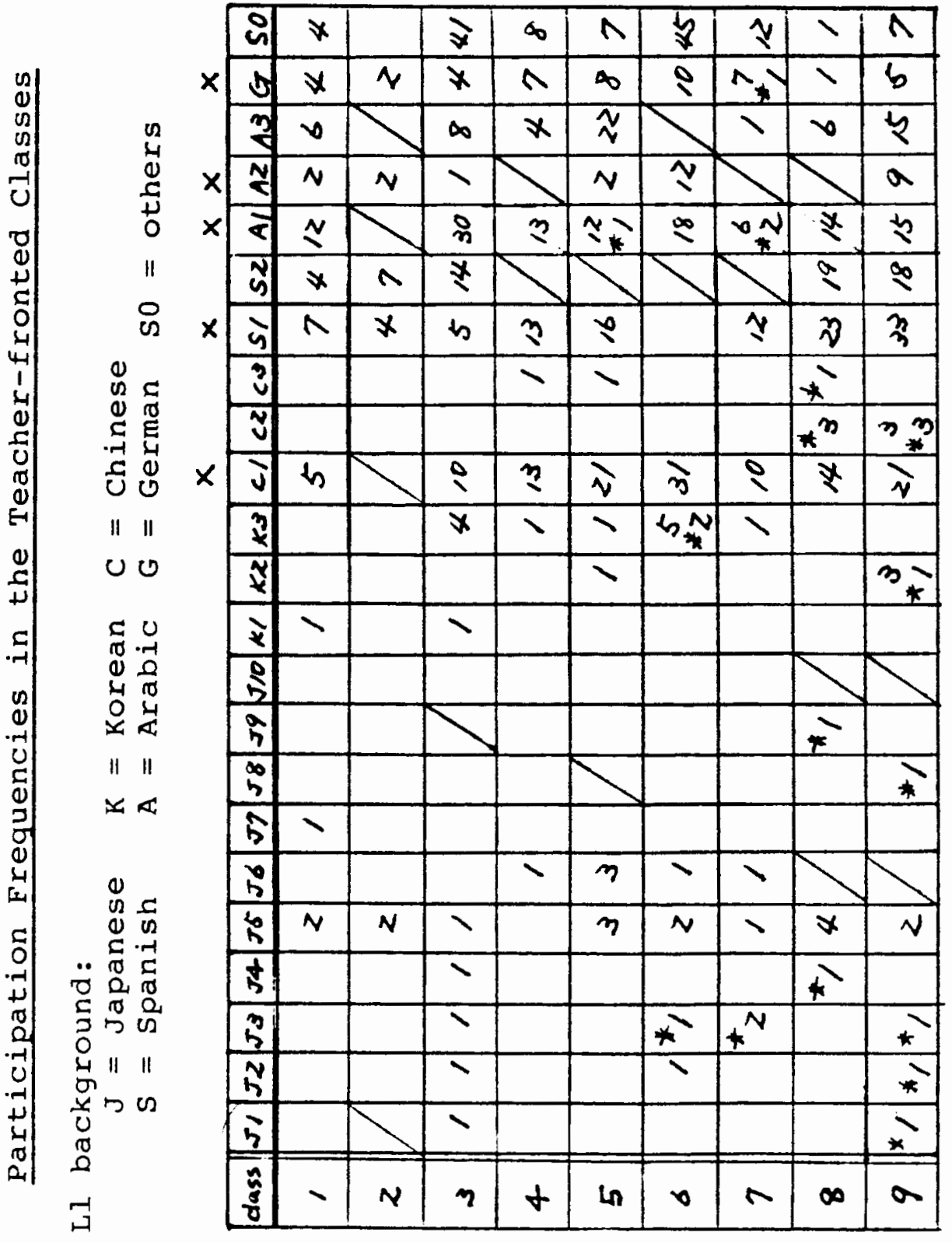

5
8
8
8
5
7
5

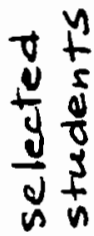

3

II

a $x$

*

2

5
5
+5
+5
-5
0

I)

*

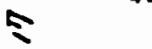

$\begin{array}{ll}N & t \\ 2 & 5 \\ 3 & 0\end{array}$

N II

$\longrightarrow$ 
APPENDIX C

CODING SAMPLES 
C-I: Coding Sample of Syntactic Features

$$
S=S \text {-node } \quad F=\text { fragment }(\quad)=\text { number of words }
$$

furr NS: And, where would you wear the kimono to?

1 NNS: Where? $F(1)$

NS: Yeah, where would you wear, if you are going to wear kimono, where would you wear?

2 NNS: Kimono? $F(1)$

NS: Uh huh.

3 NNS: Mnf ..., what do you say .. to celebrate,

for example, ... What do you say in English $s(7)$

(in LI) "Oshoogatsu" (lit: New Years)?

uphrm, I don't know $\frac{S(4)}{F(1)}$ January .. I forgot it,

Janu- .. January first, 'January first'?

What do you say

NS: New Years?

4 NNS: th, yeah, New Year (lauhgs), New year, New Years and .. or .. when (I got, I get), I became (twenty), twenty years old, $F(3) \quad s(3)$ yeah, I wo- .. I wore it. 
C-2: Coding Sample of Interactional Features

Comprehension strategies:

C-1. clarification request

C-2. confirmation check

$\mathrm{C}-3$. expansion

C-4. other completion
Production strategies:

$\mathrm{P}-1$. comprehension check

P-2. repetition/rephrase

$\mathrm{P}-3$. indication of difficulty

$\mathrm{P}-4$. verification request

$\mathrm{P}-5$. use of $\mathrm{Ll}$

$\mathrm{P}-6$. avoidance

$p-7$. Iong initial pause

NS: And, where would you wear the kimono to?

NNS: Where? $c-2$

NS: Yeah, where would you wear, if you are going to wear kimono, where would you wear?

NNS: Kimono? $C-Z$

NS: Uh huh.

NNS: 4 mm what do you say .. to celebrate, for example, ... What do you say in English P. 5

(in Ll) "oshoogatsu" (lit: New Years)?

umm $P_{-} 3$ January

umm, I don't know .. January .. I forgot it,

$P_{-2} \quad \rho_{-} Z$, $P_{-} Z$

Janu- .. January first, 'January first'?

What do you say $P$..?

NS: New Years?

NNS: Ah, yeah, New Year (lauhgs), New year, P-Z P.Z New Years and .. or .. when I got, I get, $p-Z \quad p-Z$

I became twenty, twenty years old,

$$
P-Z
$$

yeah, I wo- .. I wore it. 


\section{APPENDIX D}

TRANSCRIPTION SAMPLES 
D-1: Transcription Sample from the Teacher-fronted class

$\mathrm{T}$ : Which one?

A3: Two.

$\mathrm{T}$ : A3 (name) has two .. K2?

K2: Two.

SI: Four.

$T$ : Two, four, we got two and four. J10, what do you think?

J10: Two.

$T$ : You think two.

S2: Two.

$\mathrm{T}$ : S2 thinks two .. What do you think, J5?

J5: Two.

T: Sl, you're saying um four, four? Can you give me a reason why it's four?

Sl: I think because .. now it's a really, it's a really hard, difficult for her ( $\mathrm{T}$ : umm) to do these things ( $\mathrm{T}: \mathrm{uhm}$ ) alone. Maybe, when she was married, and her husband helped her.

$\mathrm{T}$ : Umm.

SI: You know, I think .. and then last paragra-, last line (says?) she's been past two years.

$T$ : Two years, yeah, so you think that means she's been married short time?

SI: I think she was married .. short time.

T: For short..

Sl: Maybe, she's divorced and (inaudible) right now ..

$T$ : Yeah, now we got two ideas here, either that she's still married or that she's maybe divorced.

$\mathrm{T}$ : Your eye color, is that genetic or environmental?

Sl: Genetic.

$\mathrm{T}$ : Genetic?

Sl: Genetic.

Al: Genetic.

Cl: Genetic.

$\mathrm{T}$ : What about your height?

Sl: Genetic.

Al: Genetic.

$\mathrm{T}$ : Is that really genetic? It could be genetic and environmental?

$\mathrm{Cl}$ : Both.

Al: Both.

$\mathrm{T}$ : What about your hair color?

Al: Genetic. 
D-2: Transcription Sample from the Group-work Discussion

Cl: How about ah .. how many holiday you pay ah get? How many holiday ..

J10: Once a week.

J2: Once a week!?

$\mathrm{Cl}$ : Once a week!?

J2: Really?

J10: (in Ll) 'ah, horidee-ka.' (lit: oh, holiday)

$\mathrm{J} 4$ : But ah we actually in Japan, we don't have uh uh umm ...

$\mathrm{Cl}$ : Hoilday?

J4: Yeah, we, we have holiday, but we um .. few days, few (inaudible)

J10: Yeah, few days.

$\mathrm{Cl}$ : Oh few days. How about the ah and here is my roommate is the ah (the rest: uh huh) this is a Japan, they, they happen to have, they have Christmas holiday? It's true?

J2: (in Ll) 'kurisumasu holidee-kaa' (lit: Christmas holiday, let me see)

J10: (in Ll pronunciation) 'kurisumasu horidee?' (lit: Christmas holiday?) No.

$\mathrm{J} 4:$ No.

J10: We don't have it.

J4: Just a New Year.

J10: Yeah.

J4: Or kind of 'memorial'?

J10: Yeah, a memorial day.

J 4 : Yeah.

J2: We had, I had a 40 ? uh 404040 days, um a year, a year.

J 4 : 40 days?

$\mathrm{Cl}$ : Uh 40 days ..

J2: I can, uh not, not holiday, I can use (in Ll to J10) 'yuukyuu-kyuuka' (lit: paid holiday) (laugh)

$\mathrm{J} 4$ and 10: Ahhh ...

J2: Um un, I can, I can use..

Cl: Oh, OK, I know, you can pick up the, pick the holiday?

J2: Yes.

C: And you can take the holiday ..

J2: I get pay day-off. 
D-3: Transcription Sample from the NS-NNS Conversation

a. A Japanese student (J7) with a NS:

NS: .. Do you like the campus? Are you comfortable and happy?

J8: Ahh-, yes, I like, yeah.

INS: Uh huh? Do you find the students friendly?

J8: Ah yes.

NS: Yeah? American students?

J8: American students? Ummm ... but I think, ah American student is very um ... ah .. seri-, serious, no (in Ll) 'chigau' (lit:incorrect) ..

NS: Serious?

J8: Serious? no umm ... umm ... I can't speak well umm

NS: But ihey're, they're shy or?

J8: shy? no shy ... umm .. ah! if, if American students (NS: uh huh) um, not um 'chigau' (Ll) aren't, isn't interested in (NS: uh huh) me or (NS:Oh) inter-, international students, (NS:yeah) they, um, they don't, they don't speak.

NS: Oh, I see. They're not-, they don't?

J8: Uh huh.

NS: They're not friendly?

J8: Yeah.

NS: I see.

J8: But um but um ... if they are very interested in

NS: Yes.

(NS:uh huh) ahh-Japanese ..r 'another countries'?

J8: Yeah, they are, they will very friendly.

b. A non-Japanese student (G) with a NS:

NS: Well, you know a reasonable number of words. Thit's good.

G: Yes, more than before.

NS: Nore than before. (laugh)

G: Yes, but that's also a problem because when I, I met some friends the first time, I don't speak. I ask al-, always my friend, "What? Whit did they say?" And when I say something, he has to translate. And then it's difficult because, uh uh, yes, in Zurich, I had my job, I am 5 person, and here I cannot speak English, I haven't a job, and yeah, it's a difficult situation. All the people think, "yeah, I think she's not so intelligent" because I cannot speak English. But I think it's, it's could be better in time, but it's a difficult situation from, from people they cannot speak the language.

NS: Right, at the beginning .. 
APPENDIX E

RAW FREQUJENCIES OF

SYNTACTIC AND INTERACTIONAL FEATURES 

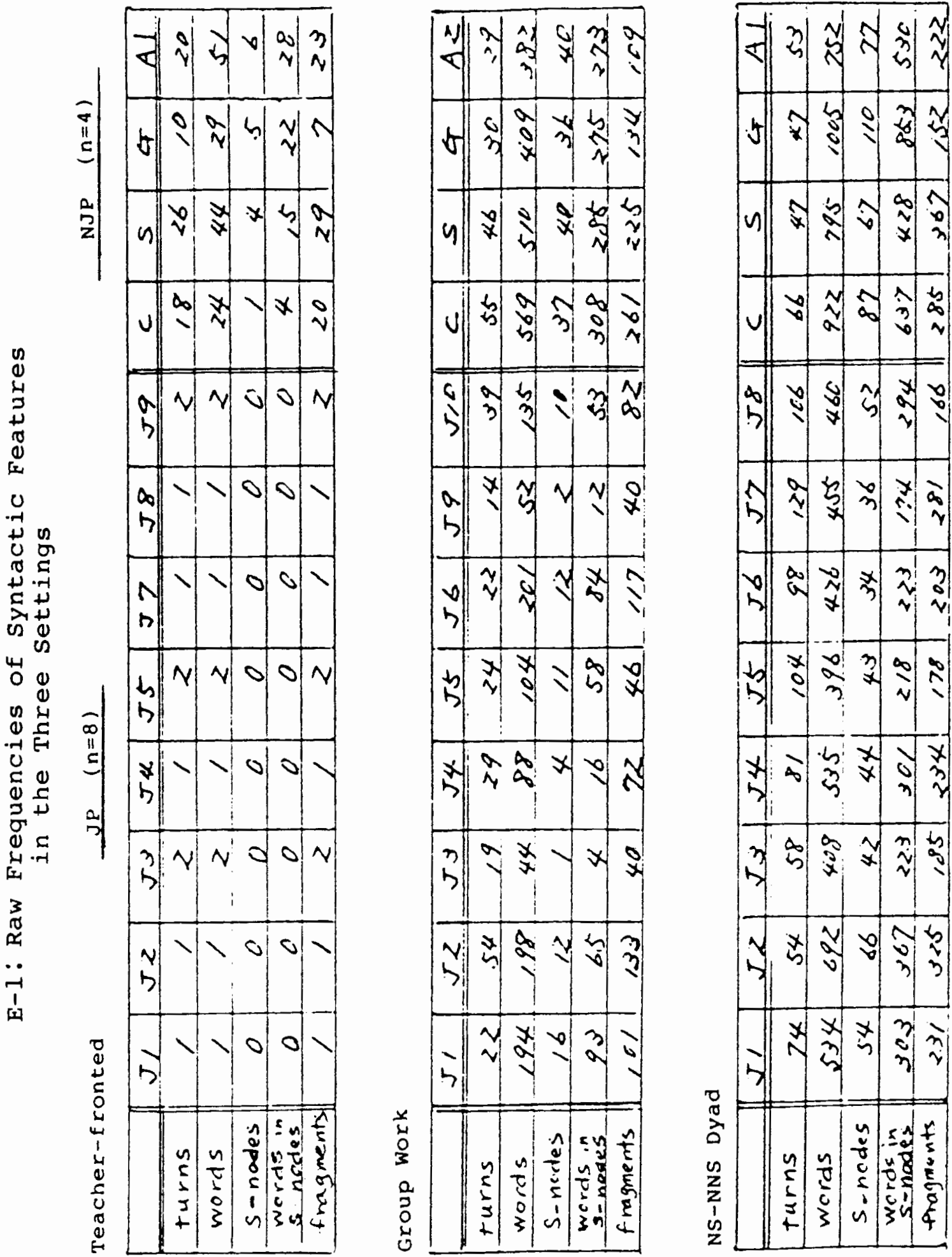


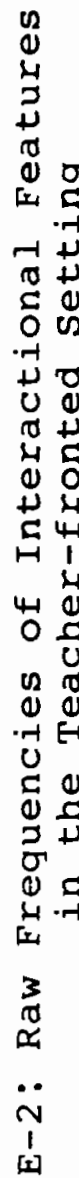

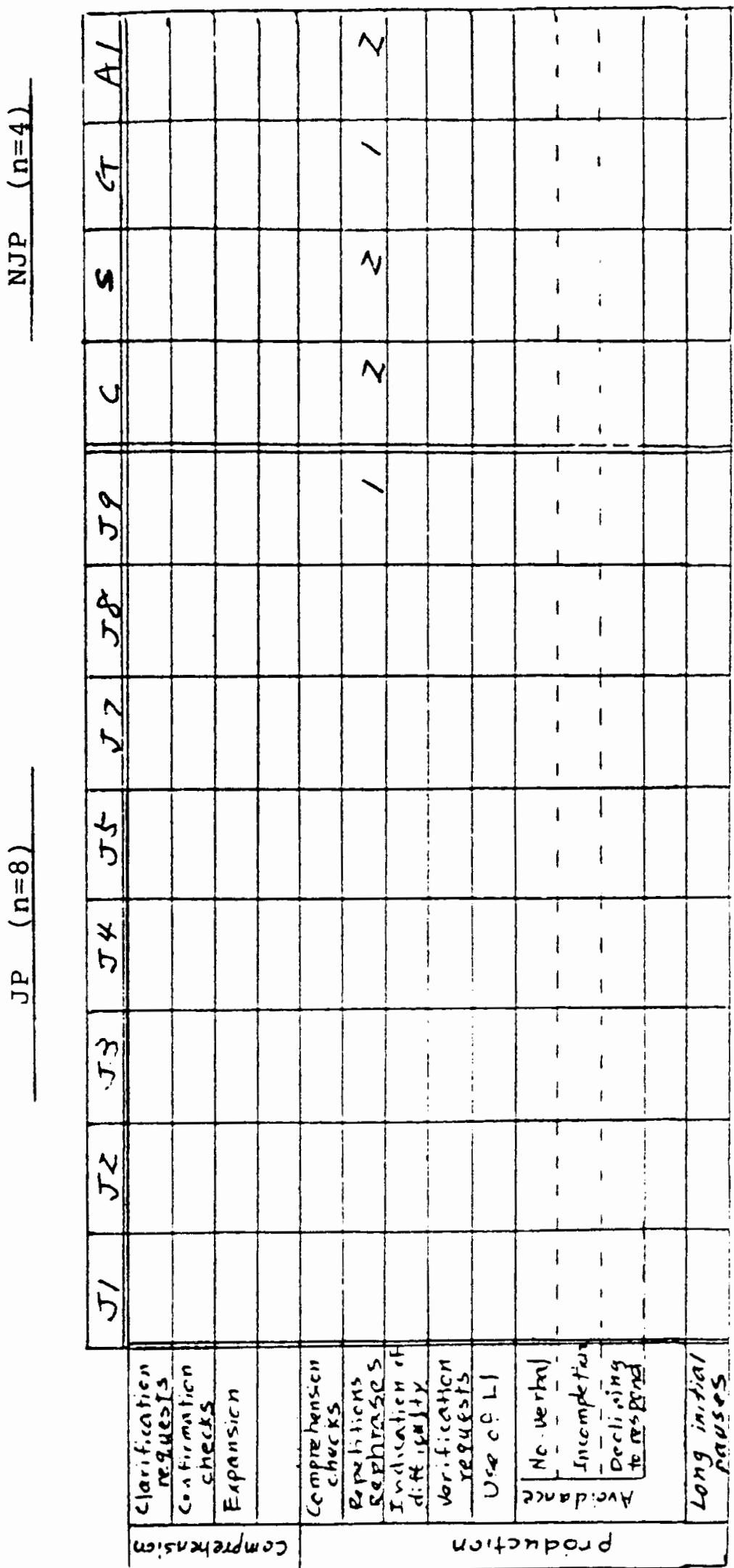



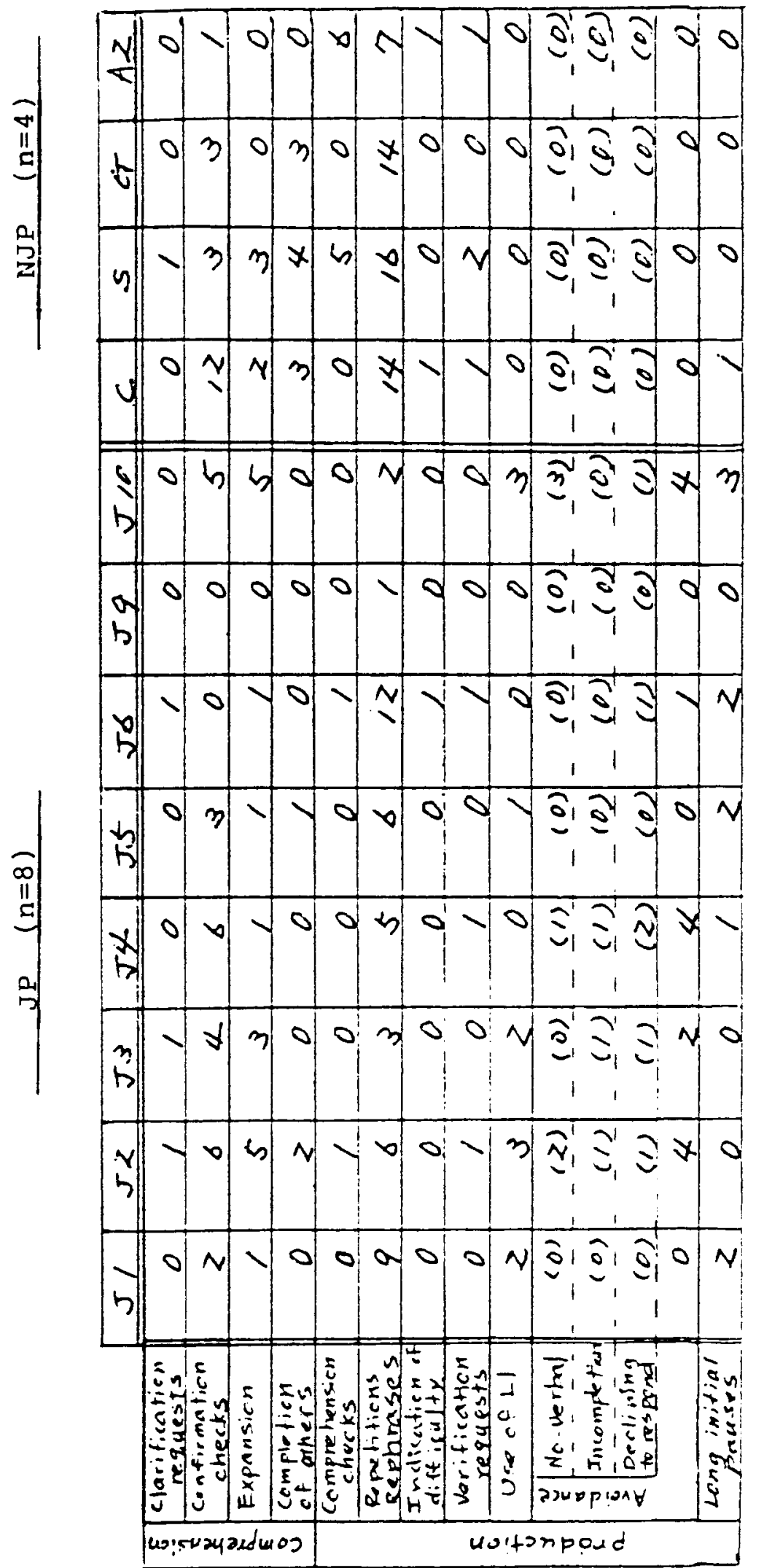

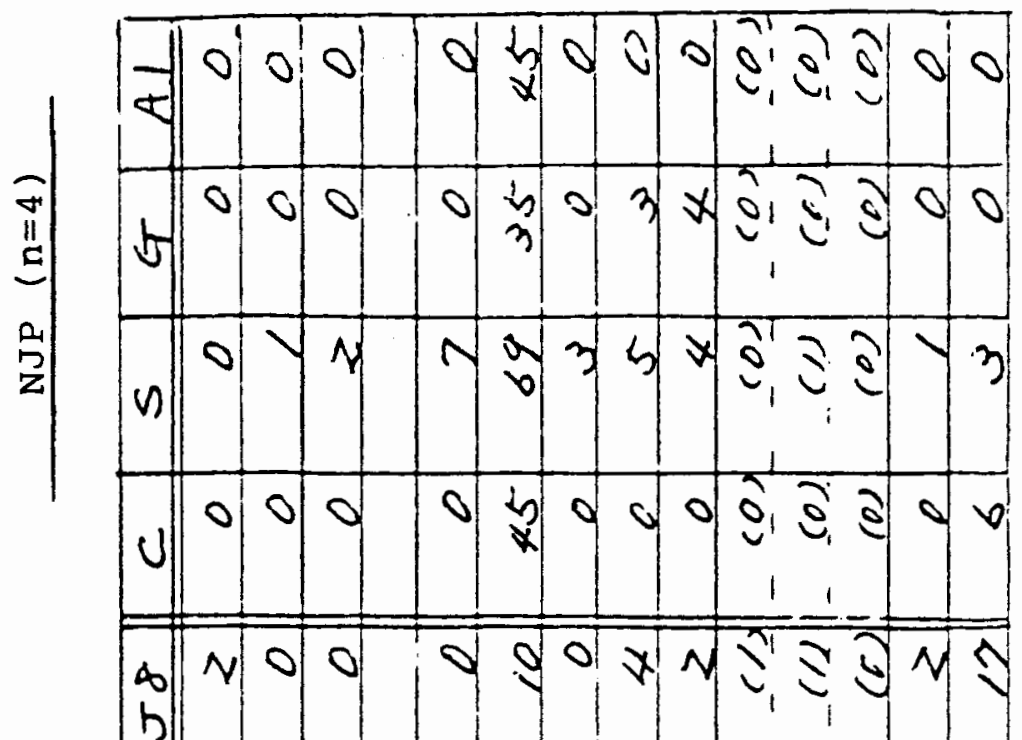

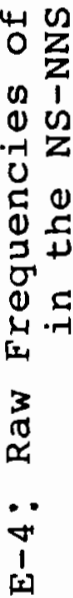
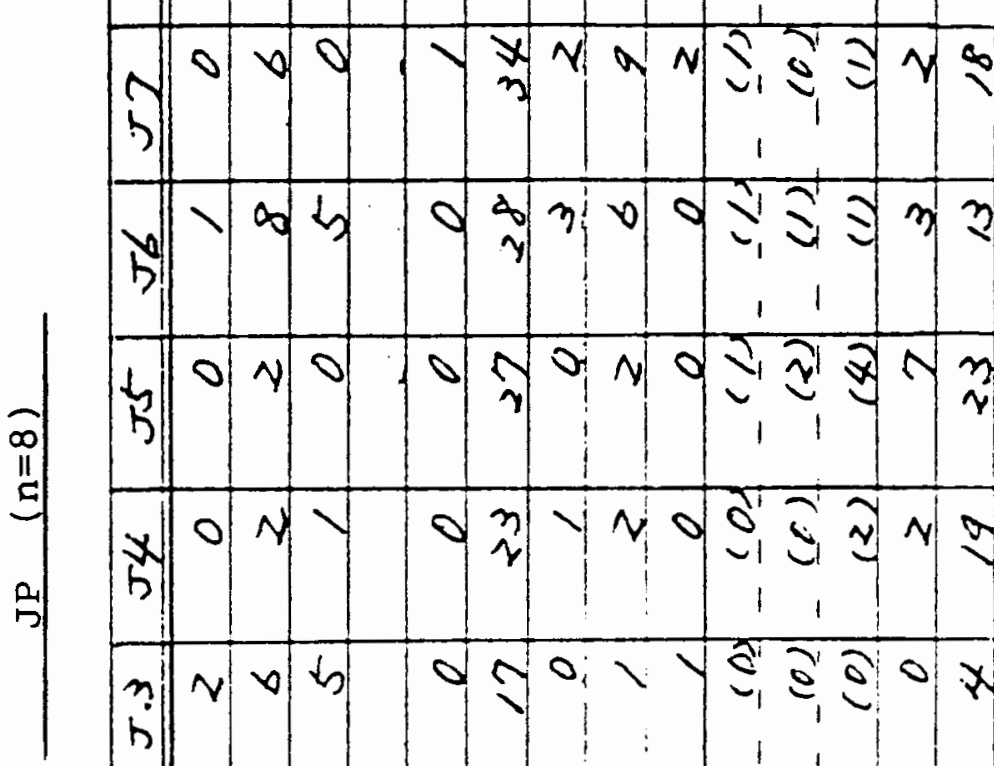

bु 0 O 0 ते n)

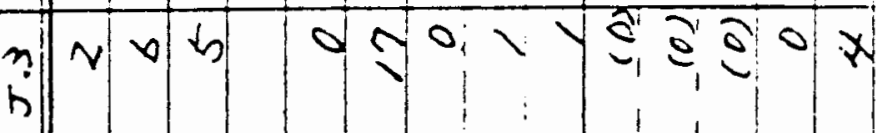

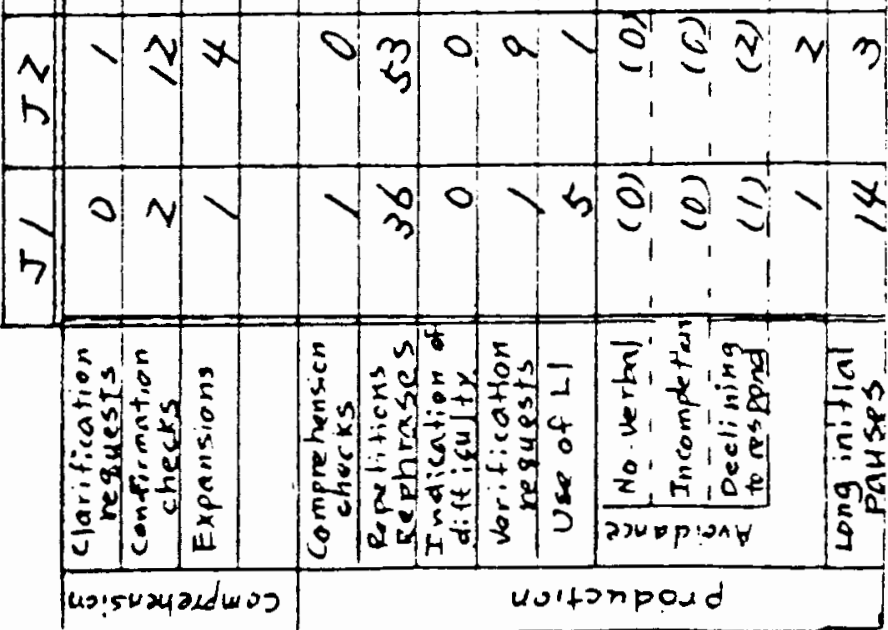

